\title{
THE SIPUNCULA OF JAPAN : THEIR SYSTEMATICS AND DISTRIBUTION
}

\section{$\operatorname{AUTHOR}(\mathrm{S}):$}

Cutler, Edward B.; Cutler, Norma J.; Nishikawa, Teruaki

\section{CITATION:}

Cutler, Edward B....[et al]. THE SIPUNCULA OF JAPAN : THEIR SYSTEMATICS AND DISTRIBUTION. PUBLICATIONS OF THE SETO MARINE BIOLOGICAL LABORATORY 1984 , 29(4-6): 249-322

\section{ISSUE DATE:}

1984-10-31

URL:

http://hdl.handle.net/2433/176092

RIGHT: 


\title{
THE SIPUNCULA OF JAPAN: THEIR SYSTEMATICS AND DISTRIBUTION
}

\author{
Edward B. CUTLER, Norma J. CUTLER \\ Utica College of Syracuse University, Utica, New York U.S.A. \\ and \\ TERUAKI NISHIKAWA \\ Biological Laboratory, College of General Education, \\ Nagoya University, Nagoya 464, Japan \\ With Text-figures $1-16$, Tables $1-2$ and Plates $I-I I$
}

\begin{abstract}
The 59 species of known Japanese Spiuncula (hoshi-mushi) representing 14 genera are described. A general section on the morphology of these worms and comments on their collection, preservation, and identification is presented. There is a key to the genera and a key to each species designed for the nonspecialist. A brief biogeographical analysis concludes this work. The approximately 3200 specimens examined for this study came from many recent as weli as historical collections, from depths ranging from intertidal to abyssal and from Hokkaido in the north to the Yaeyama Islands in the south.
\end{abstract}

\section{Contents}

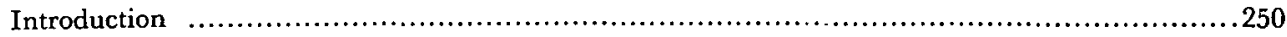

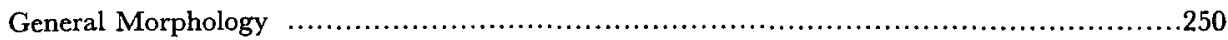

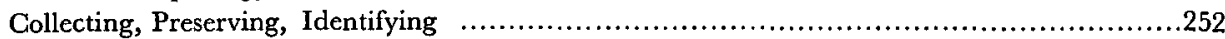

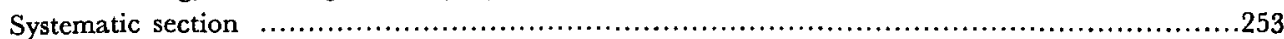

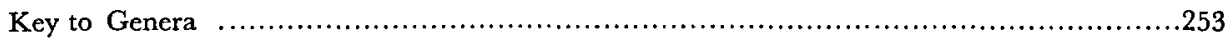

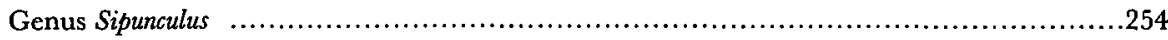

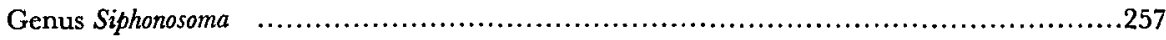

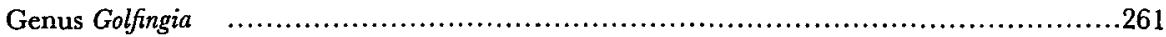

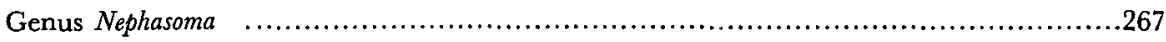

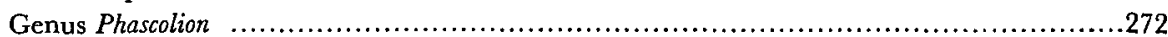

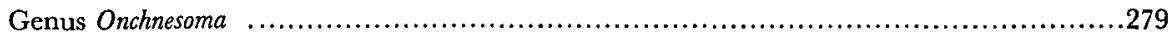

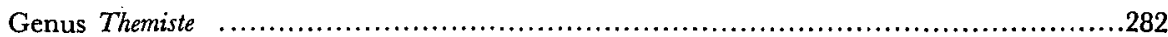

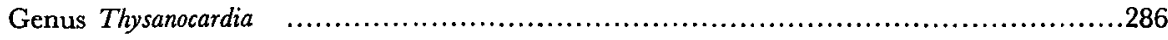

Genus Antillesoma ...............................................................289

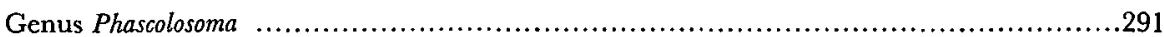

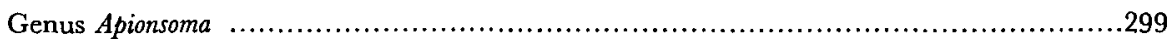

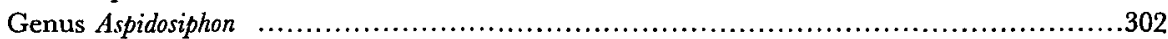

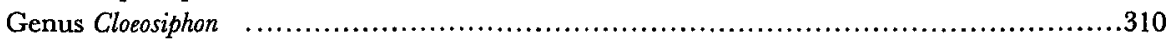

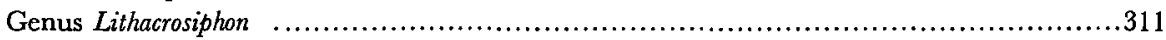

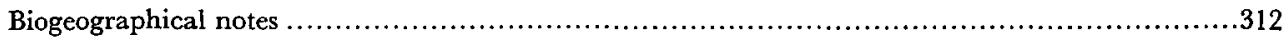

Publ. Seto Mar. Biol. Lab., XXIX (4/6), 249-322, $1984 . \quad$ (Article 7) 


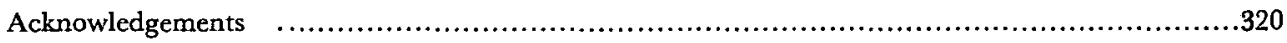

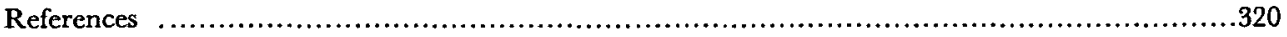

\section{Introduction}

The most recent comprehensive study of Japanese Sipuncula (hoshi-mushi) was that of H. Sato (1939). The first such work was that of I. Ikeda (1904). A recent review of the species named by these two men has been completed (Cutler and Cutler, 1981). This present report is an attempt to provide biologists with a useful catalog of the 52 currently known and valid species of Japanese sipunculans, plus seven taxa of uncertain identity, together with a discussion of their distribution.

By Japanese Sipuncula we mean those species recorded from the islands currently under Japanese political control thereby excluding some regions included by Ikeda and Sato.

Much of this information was gathered during 1979 while two of us (EC \& NC) were in Japan on a U.S. National Science Foundation Visiting Scientist grant. This enabled us to make new collections but also to examine the collections of Ikeda and Sato as well as recent collections made by M. Imajima (National Science Museum), M. Horikoshi (Ocean Research Institute), the Biological Laboratory of the Imperial Household, and several other marine biologists (see Cutler and Cutler, 1981, Table 1, for complete list). There are still large areas of Japanese waters which have not yet been adequately sampled so it is probable that additional species will be added to this fauna in the future.

The phylum Sipuncula is not a large group but is wide-spread throughout the world's oceans and in some areas, e.g., coral rock, may be a major component of the community. They are free living, non segmented, vermiform coelomates. They share many traits with the annelids but their complete lack of metamerism suggests that the ancestral stock deviated from the preannelidan stock prior to the appearance of segmentation. The taxon has had its status shifted several times in the early part of this century. The discredited concept Gephyrea had been used to include this group along with the Echiura and Priapulida. The spelling of the phylum has likewise undergone a tortured evolution. The current accepted spelling (Sipuncula) was introduced by Stephen (1964).

A series of recent revisionary papers have been published relating to the taxa Siphonosoma (Cutler and Cutler, 1982) Antillesoma, Ruepellisoma and Satonus (Cutler and Cutler, 1983), Thysanocardia (Gibbs, Cutler and Cutler, 1983). Cutler and Gibbs (in press) among other things, elevates some subgenera to generic rank and eliminates others. This present paper incorporates these anticipated changes.

General Morphology

The animals have two main regions: the larger trunk (body) and a more slender, protrusable introvert (proboscis) (Fig. 1). In this text trunk length is measured from the posterior end to the nephridiopores, which we use to mark the 
anterior end of the trunk. Introvert length is frequently reported but is difficult to measure if the introvert is not completely extended. It is an extremely elastic structure which, when fully extended, may stretch to several times its retracted length. The terminally located mouth is circled wholly or in part by peripheral tentacles or tentacular folds in some genera. In others, the tentacles surround the dorsal nuchal organ, peripheral tentacles being lost. The common Japanese name, starmouth worm, refers to the star-like arrangement of tentacles in the genus Themiste,
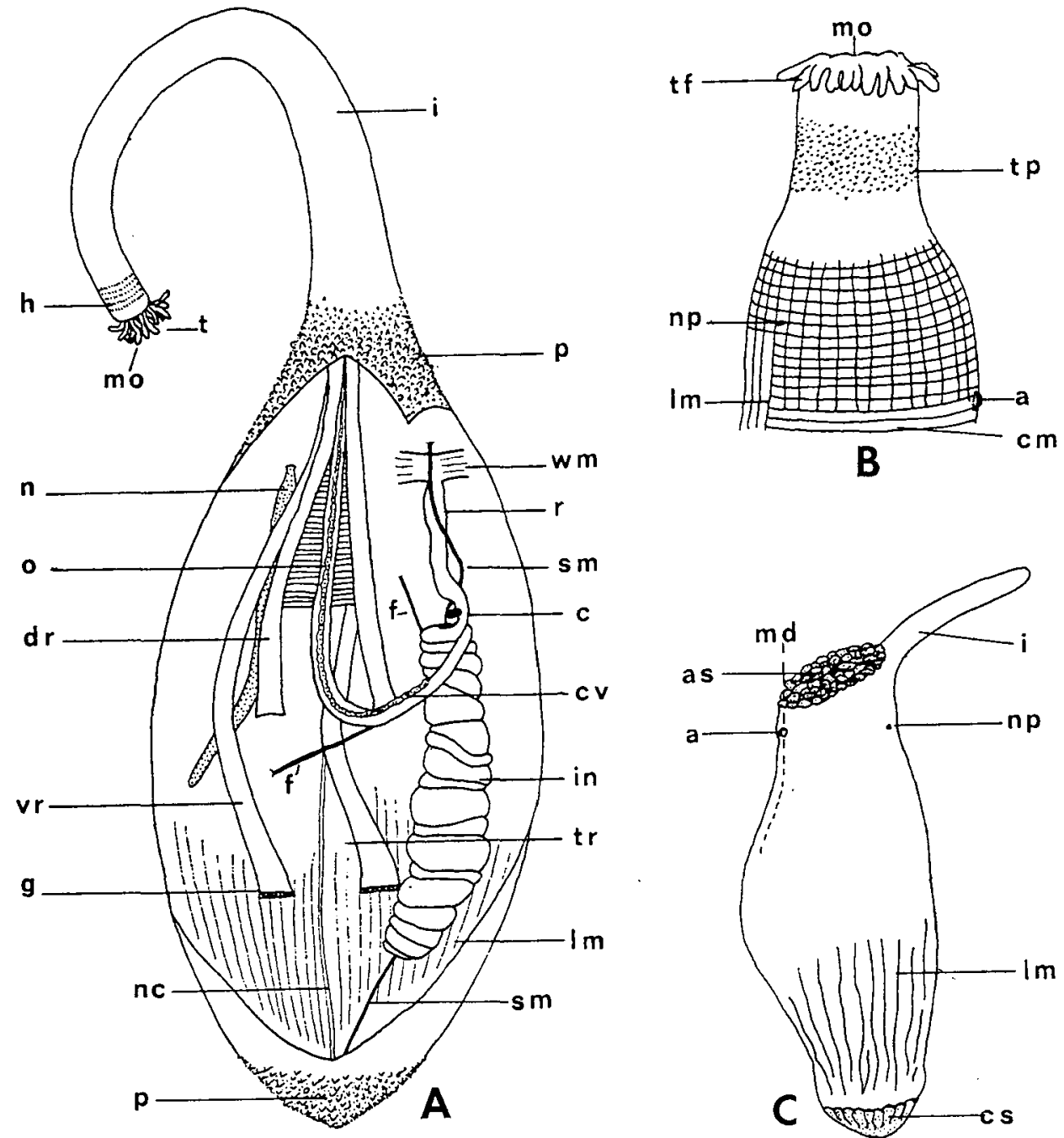

B

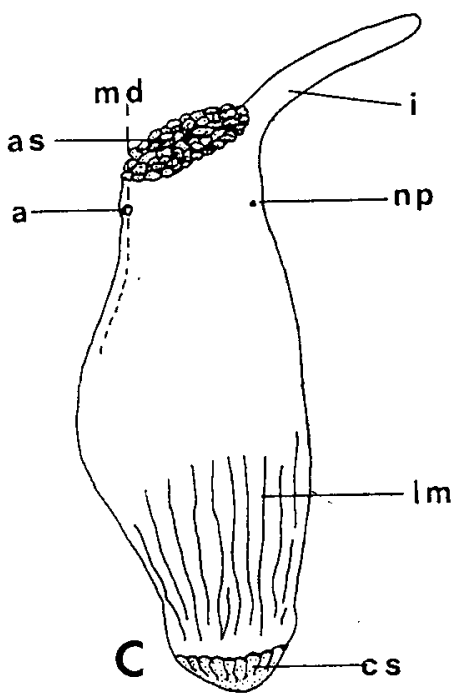

Fig. 1. Diagrams showing some of the external and internal characters of sipunculans. A: Dissected from the dorsal side. B: Sipunculus morph. C: Aspidosiphon morph. a, anus; as, anal shield; c, caecum; cm, circular muscle; cs, caudal shield; cv, contractile vessel; $\mathrm{dr}$, dorsal retractor; f, fixing muscle; $g$, gonad; $h$, hooks; $i$, introvert; in, intestine; $1 \mathrm{~m}$, longitudinal muscle; $m$, mesentery; md, mid-dorsal line; mo, mouth; n, nephridia; nc, nerve cord; np, nephridiopore; o, oesophagus; $p$, papillae; $r$, rectum; sm, spindle muscle; $t$, tentacles; tf, tentacular fold; tp, triangular papillae; tr, trunk; vr, ventral retractor; wm, wing muscle (from Edmonds, 1980). 
if viewed "head-on". Behind the tentacles, in many species, is a region carrying numerous chitinous uni- or bidentate hooks, sometimes in regular rings, sometimes randomly scattered. Epidermal papillae of various forms and density are found over much of the introvert and in some species these are tall, pointed, and somewhat curved which are then referred to as spines. Similar papillae often are spread over the trunk usually more dense towards both ends. The only other external features are the openings of the middorsal anus and the rarely visible ventrolateral nephridiopores found at the anterior end of the trunk.

The inside of the body wall has a layer of longitudinal muscles which is either a continuous sheet or divided into separate bundles. This is underlain by a circular muscle layer which is usually continuous. The dominant structure in the body cavity is the alimentary canal formed of a long oesophagus, a coiled intestine which doubles back on itself, and a short rectum. Sometimes a rectal caecum is present. Several types of muscles anchor this gut coil: a spindle muscle, slender and threadlike goes from just anterior to the anus and into the coil, sometimes extending beyond and attaching to the posterior end of the trunk; a broad wing muscle holds the distal rectum to the body wall; and fine threadlike fixing muscles (1-4) from the body wall to various points around the anterior of the coil. One or two pairs of retractor muscles originate on the body wall and insert in the oral region to withdraw the introvert completely into the trunk. A pair of tubular or saclike nephridia (segmental organs) is present (only one in Phascolion and Onchnesoma) and vary in length from $10-100 \%$ of the trunk. They are often attached to the body wall by connective tissue for some portion of their length.

The tentacular coeloms are connected to a tubular contractile vessel which runs along the oesophagus and in those species with large tentacular crowns, numerous villi are associated with this closed vessel (compensatory sac). An unsegmented ventral nerve cord goes the whole length of the animal connecting with cerebral ganglia. Transitory gonads develop across the base of the ventral retractor muscles. Fertilization is external, cleavage is spiral and a trochophore larva develops.

\section{Collecting, Preserving, Identifying}

Sipunculans live in a wide variety of habitats so collecting techniques vary. Many Japanese species (e.g. in genera Aspidosiphon, Phascolosoma, Cloeosiphon and Lithacrosiphon) live in coral and soft rocks in the inter- and shallow subtidal zone so they can be obtained by carefully breaking these rocks with a hammer. Others (Sipunculus, Siphonosoma, a few Golfingia, and Thysanocardia) can be found by digging in sand or muddy areas. Small sand-filled crevices between rocks are often inhabited by Themiste, Antillesoma, and a few Golfingia. Phascolion, Onchnesoma, and many Golfingia live in deeper waters and require dredging, preferably with a dredge or trawl which bites into the sediment at least two or three centimeters and has a fine mesh bag (less than $2 \mathrm{~mm}$ ) to retain the smaller forms. After collecting, they should be relaxed (narcotized) for about one hour with something like menthol crystals or a dilute (5-10\%) solution of alcohol so that the introvert is protruded. 
They should then be placed in a $4 \%$ formalin solution for a few days and eventually transferred to $70 \%$ ethyl alcohol for permanent storage.

Identification almost always requires opening the worms to examine the internal organs. This should be done by making a longitudinal incision along the dorsal side just to one side of the anus. It can then be pinned open without disrupting the organs. Often it is necessary to examine the introvert hooks under a compound microscope. This can be done by removing a small piece of epidermis from the introvert, placing it on a slide in a drop of dilute glycerine. Then using needles, tease the tissue apart to spread out the hooks, remove excess tissue such as underlying muscle layer, then cover and examine.

The monograph by Stephen and Edmonds (1972) is a complete statement of our knowledge prior to 1970 and is an important reference. These worms are very elastic, subject to changes induced by the microhabitat or as a result of age. Caution should be used when working with one or two specimens; a large sample from a population is desirable to avoid mistakes based on anomolous or atypical individuals.

Descriptions found in the following sections are not complete but designed to serve as elaboration on the keys so non-specialists can be reasonably sure of their identification. The size ranges given are for those specimens we examined and not always indicative of the potential size of juveniles or large adults.

\section{Systematic Section}

The higher taxa in this phylum are currently undergoing revision so we will make no reference to those categories here (Gutler and Gibbs, in press). The following key is designed to assist the worker in identifying the material to genus. Within each genus section there is a general description/diagnosis and a key to Japanese species. As with all keys these are generalizations and exceptions do exist.

Key to Sipuncula Genera (* =not known from Japan)

1a. Hardened anal shield present; inhabits hard substrata ..................... 2

1b. Hardened anal shield absent ........................................... 4

2a. Introvert protrudes from center of white, calcareous shield (cap) made up of many polygonal subunits ...........................Cloeosiphon p. 310

2b. Introvert shifed ventrally at angle to main trunk axis $\ldots \ldots \ldots \ldots \ldots \ldots \ldots \ldots$

3a. Shield made up of single, calcareous unit ................ Lithacrosiphon p. 311

3b. Shield made up of many, hardened subunits...............Aspidosiphon p. 302

4a. Longitudinal musculature in separate bands......................... 5

4b. Longitudinal musculature continuous layer............................11

5a. Complex peripheral tentacles around mouth present; adult body more than $5 \mathrm{~cm}$; inhabit sandy/muddy sediment...........................6 6

5b. Complex peripheral tentacles around mouth absent; adult body generally less than $5 \mathrm{~cm}$; inhabit firm substrata. 
6a. Introvert papillae scattered, flattened and subtriangular; longitudinal muscle bands with few anastomoses

6b. Introvert papillae in rings and conical or cylindrical; longitudinal muscle bands with many anastomoses..................................... 8

7a. Four introvert retractor muscles; no protractors .............Sipunculus p. 254

7b. Six introvert retractor muscles including protractors............... Xenosiphon

8a. Four introvert retractor muscles........................................ 9

8b. Two introvert retractor muscles .............................* Siphonomecus

9a. Spindle muscle attached posteriorly .....................Siphonosoma p. 257

9b. Spindle muscle not attached posteriorly........................* Phascolopsis

10a. Introvert hooks absent; contractile vessel villi present ......Antillesoma p. 289

10b. Introvert hooks present; contractile vessel villi absent ...Phascolosoma p. 291

11a. Two nephridia; inter- and sub-tidal depths........................... 12

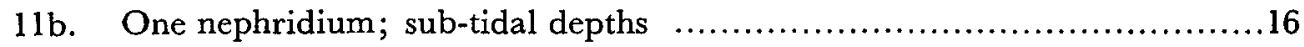

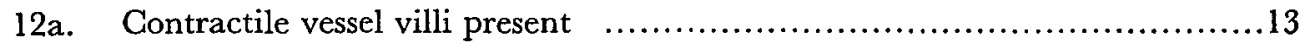

12b. Contractile vessel villi absent ....................................... 4

13a. Complex dendritically branched peripheral tentacles present; nuchal

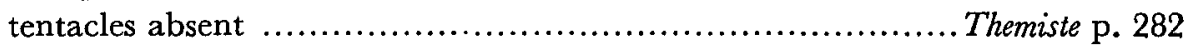

13b. Complex dendritically branched peripheral tentacles absent; nuchal tentacles present ........................................Thysanocardia p. 286

14a. Spindle muscle attached posteriorly .......................Apionsoma p. 299

14b. Spindle muscle not attached posteriorly ............................... 15

15a. Two pairs of introvert retractor muscles ..................... Golfingia p. 261

15b. One pair of introvert retractor muscles .................... Nephasoma p. 267

16a. Anus at anterior of trunk; chitinous epidermal attachment papillae usually present; lives in empty shells; two (sometimes one) pair of retractor muscles Phascolion p. 272

16b. Anus displaced out on to distal half of introvert; no chitinous attachment papillae; lives in sediment; one pair of retractor muscles, greatly fused often appearing as one

Onchnesoma p. 279

\section{Genus Sipunculus Linnaeus, 1766}

Usually large, stout animals (Fig. 2, A). Trunk cylindrical and surface often divided into squares or rectangles by intersection of longitudinal and circular muscles. Introvert short, and carrying numerous, flat, triangular papillae. Mouth surrounded by a tentacular fold, the margins forming more or less distinct tentacles. Introvert lacks hooks and spines. Four introvert retractor muscles; spindle muscle attached anteriorly in front of anus. Contractile vessel double. Post-oesophageal or 'sipunculus' loop present in alimentary canal anterior to intestinal spiral. Paraneural muscle well developed. Inhabits sandy sediments.

Key to Sipunculus species known from Japan

1A. 21-24 longitudinal muscle bands (usually from deep water)........S. norvegicus 
1B. More than 26 longitudinal muscle bands............................... 2

2A. 28-33 longitudinal muscle bands (usually 28-30; intertidal or shallow

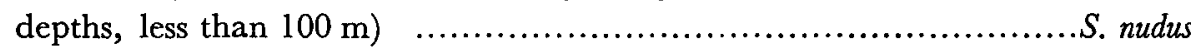

2B. 34-38 longitudinal muscle bands (usually deeper water, greater than

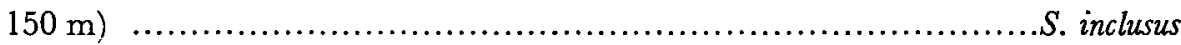

\section{Sipunculus inclusus Sluiter, 1902}

Description: These three worms have trunks measuring 28, 38, and $95 \mathrm{~mm}$ long and have 34-38 longitudinal muscle bands with rare anastomosing. There is a very short introvert bearing an elaborate tentacular crown with many tentacles. The retractor muscles originate at about the same anterior/posterior level, the stronger ventral pair from muscle bands $2-5$ and the more delicate dorsal pair from bands 11-14 in one and 14-16 in the others. The intestine is connected to the body wall by numerous mesenteric fibers/sheets and has a short rectum with a caecum and carrying small racemose glands near the anus. The nephridiopores are located on a level with the anus and the short nephridia are unattached to the body wall.

Remarks: This species was described from two specimens by Sluiter 80 years ago and has not been reported since then. Stephen and Edmonds (1972: 26) question the validity of this species pointing out its similarity to $S$. nudus and $S$. robustus. We are using this name with certain reservations. The habitat is rather deeper and colder than the type locality but the morphological variations are of uncertain significance. The larger number of longitudinal muscle bands and different habitat seem sufficient to distinguish this from $S$. nudus. These worms have some similarities to the deep-water S. lomonossovi (Murina, 1968) but because of the brevity of the description (based on a single worm) and the lack of any illustrations, we are reluctant to use that name.

Previous Japanese Records: None.

Material Examined: Nishikawa-KT 77-16, St. W2D, NW off Motobu Peninsula, Okinawa, 26 $49^{\prime} \mathrm{N}, 127^{\circ} 55^{\prime} \mathrm{E}, 365 \mathrm{~m}$; 12/7/77;2 spec.; col. T. Yamaguchi. Okutani-Soyo Maru Exp. 38A, Kusagaki Islet, $\mathrm{W}$ of Kyushu, $30^{\circ} 53^{\prime} \mathrm{N}, 129^{\circ} 31^{\prime} \mathrm{E}, 150-158 \mathrm{~m} ; 1 / 28 / 65 ; 1$ spec.

Japanese Distribution: In deep water from Okinawa ( $365 \mathrm{~m}$ ) and west of Kyushu $(150 \mathrm{~m})$.

Worldwide Distribution: Besides the new Japanese collections, this is known only from the type collected in Indonesia from coral sand.

\section{Sipunculus norvegicus Danielssen, 1868}

Description: These 17 stout, cylindrical specimens have trunks from $40-90 \mathrm{~mm}$ long and possess 21-24 longitudinal muscle bands. The introvert has triangular, flattened papillae towards the distal end and complex, lobular tentacles. A discussion of external variations in form can be found in Cutler (1973). The ventral 

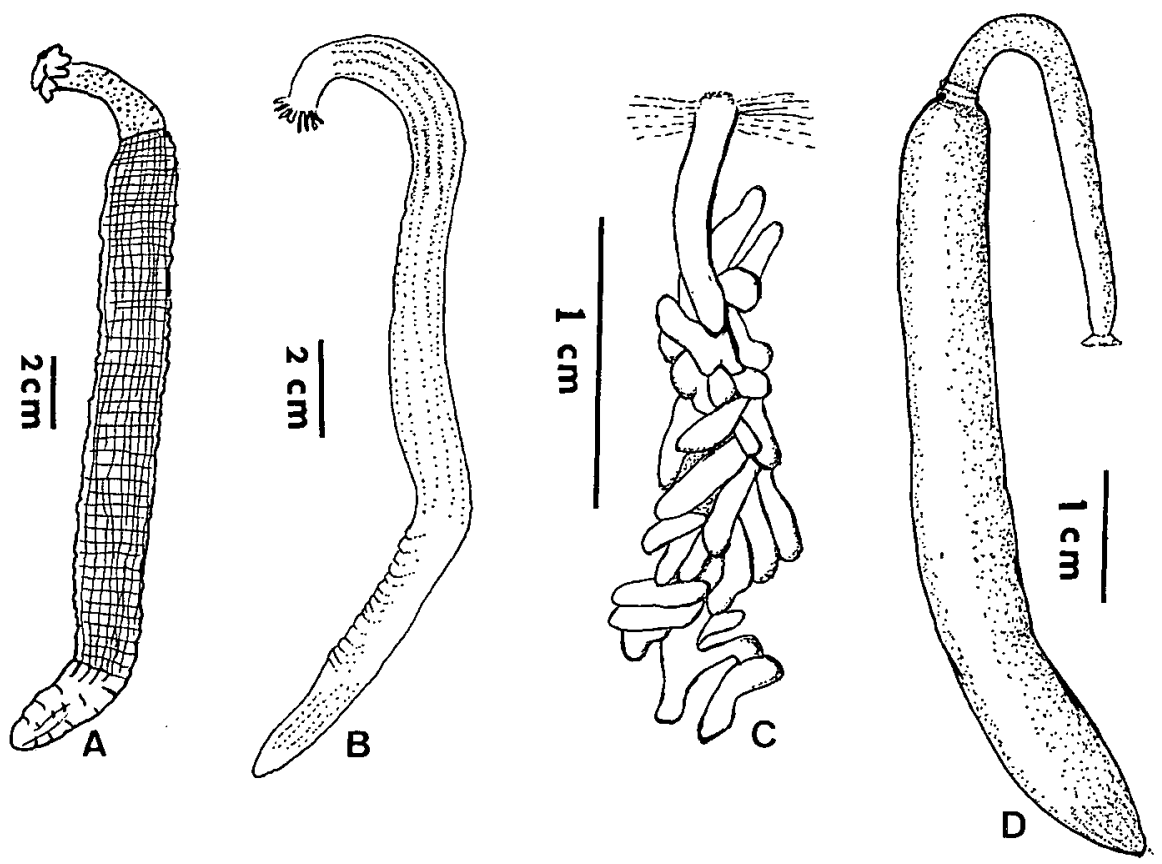

Fig. 2. A: General form of Sipunculus. B: General form of Siphonosoma. C: Rectum of Siphonosoma vastum showing multiple caeca (anus and wing muscles on left). D: General form of Golfingia.

retractor muscles originate from muscle bands $3-4$ and the dorsal pair at about the same level from bands 8-9. The free nephridia open anterior to the anus. The intestine is fastened to the body wall by numerous mesenteric strands and the rectum bears a caecum as well as racemose glands.

Previous Japanese Records: None.

Material Examined: Imajima-St. 159, Tosa Bay; 7/24/74; 1 spec. Okutani-Soyo Maru Expedition; $32^{\circ} 00^{\prime} \mathrm{N}, 140^{\circ} 29^{\prime} \mathrm{E} ; 2120-2140 \mathrm{~m} ; 6 / 3 / 62 ; 1$ spec. $32^{\circ} 00^{\prime} \mathrm{N}, 140^{\circ} 23^{\prime} \mathrm{E} ; 2020 \mathrm{~m} ; 12 / 4 / 64 ; 2$ spec. $32^{\circ} 58^{\prime} \mathrm{N}, 140^{\circ} 02^{\prime} \mathrm{E} ; 2230-2245 \mathrm{~m} ; 7 / 12 / 64 ; 7$ spec. $30^{\circ} 59^{\prime} \mathrm{N}, 140^{\circ} 43^{\prime} \mathrm{E} ; 2420-2470 \mathrm{~m} ; 3 / 2 / 70 ; 2$ spec. $30^{\circ} 51^{\prime} \mathrm{N}, 140^{\circ} 44^{\prime} \mathrm{E} ; 2450 \mathrm{~m} ; 7 / 12 / 64 ; 1$ spec. $30^{\circ} 39^{\prime} \mathrm{N}, 140^{\circ} 47^{\prime} \mathrm{E} ; 2270 \mathrm{~m} ; 3 / 5 / 59 ; 1$ spec. NishikawaSt. Y 4463, Wakasa Bay, Maizura, $3 \mathrm{~km}$ N of Ura River esturay; $20 \mathrm{~m} ; 1 / 74 ; 1$ spec.

Japanese Distribution: Found from deep water (over $2000 \mathrm{~m}$ ) far south off Izu Islands, in Tosa Bay, and in the Japan Sea from shallower water $(20 \mathrm{~m})$ in Wakasa Bay.

Worldwide Distribution: This is a deep-water species found commonly in the North Atlantic around Scandinavia, Iceland and Creenland; off the east coast of the U.S.A. and from the Azores, Cape Verde Islands and off West Africa. A few records are from the Indian Ocean and the Red Sea, and more recently from the Tasman Sea and South Pacific.

\section{Sipunculus nudus Linnaeus, 1766}

Description: This species is the common intertidal member of this genus in Japan 
and is represented by 35 specimens, some are damaged and others are juveniles (trunk length from 5-145 mm). These are whitish, translucent worms with 28-30 (rarely up to 33) longitudinal muscle bands. The short introvert has scale-like papillae behind the tentacles. Internally the four retractors originate at the same level, the intestine has numerous mesenteries attaching it to the body wall, and the short nephridia are attached for $1 / 4-1 / 2$ their length to the body wall and open just anterior to the anus.

Discussion: In Edmonds' recent work (1980: 10) he discusses $S$. nudus and S. robustus and establishes three criteria he uses to separate these very similar taxa concluding that the $S$. nudus previously reported from Australia are, by his criteria, probably $S$. robustus. The distinctions between these forms are not well defined and there is, in our minds, room for doubt; i.e., they may well be one and the same biological species. By Edmonds' standards these Japanese worms might be considered $S$. robuistus, but for the moment we shall retain the historically associated name, $S$. nudus. Previous Japanese Records: Ikeda, 1904-Misaki, Tateyama, and Seto Inland Sea. Sato, 1930- Mutsu Bay; 1934a-off Muroto-zaki, Shikoku and Sata-misaki, Kyushu; 1934b-Onomichi, Seto Inland Sea, Osaka Bay and Matsushima Bay; 1937a- Karakuwa, Miyagi Pref.

Material Examined: Imajima-St. 124, off Nii-jima, 65-80 m; 6/77; 1 spec. St. 127, Arita Bay, Kushimoto-cho, Wakayama Pref., 33 m; 7/15/?; 2 spec. St. 136, near Habu H., Izu-Oshima; 45-80 $\mathrm{m} ; 7 / 77 ; 1$ spec. St. 137, Kabira Bay, Ishigaki-jima, intertidal; 6/23/73; 3 spec. St. 138, Ishigaki-jima, dry beach; 7/27/73; 1 spec. Nishikawa-St. 11, Taketomijima, Okinawa, intertidal; 6/23/75; 4 spec. St. 26, Takasu, near Mukaijima M.B.L., intertidal; 5/28/75; 5 spec. Osaka Museum of Natural History -St. 165-166, Hiraiso, Tarumi, Kobe, Hyogo Pref. 2 spec. St. 176, Osaka Bay; 2/71; 1 spec. SawadaNakajima, intertidal; 1 spec. Cutler-St. 3, Sagami Bay, near Misaki M.B.L., 50 m; 3/13/79; 1 spec. St. 19, Okinawa, near Sesoko M.B.L., intertidal; 4/17/79; 3 spec. Tohoku Univ., Sato's collections10 bottles. NMNH, Washington- 17192 Okinawa, Ryukyu Isl., 11/7/45; 1 spec.

Japanese Distribution: This species is found in the intertidal sands from Ishigakijima in the south, on both sides of Honshu to Mutsu Bay in the north (only three specimen north of Sagami Sea). Three young individual were found in deeper water off Shikoku $(421 \mathrm{~m})$ and Kyusyu $(516 \mathrm{~m})$ (Sato, 1934b). These depths are not usual for this species.

Worldwide Distribution: This is a widespread and common species (over 50 reports in the literature) recorded from both sides of the Atlantic and Pacific Oceans, from the Indian Ocean as well as the Mediterranean and Red Seas in tropical to warm temperate shallow waters.

\section{Genus Siphonosoma Spengel, 1912}

Adults usually large, cylindrical, and slender (Fig. 2, B). Introvert often not well differentiated from trunk and lacking scale-like, triangular papillae but sometimes possessing hooks and spines. Tentacles numerous and finger-like surrounding mouth; no tentacular fold. Longitudinal muscle divided into bands (sometimes 
not readily noticed from outside). Four introvert retractor muscles. Spindle muscle arises anteriorly and attaches posteriorly to body wall. Contractile vessel single and dorsal with villi in some species. Two nephridia (usually with large crescentric nephrostomes). No post-oesophageal loop. Inhabits soft sediments in shallow water.

A recent revision of this genus reduced the number of species to ten and eliminated the subgenera (Cutler and Cutler, 1982).

Key to Siphonosoma species known from Japan

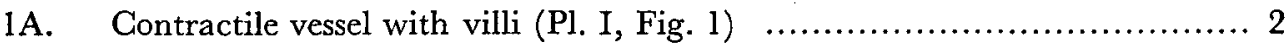

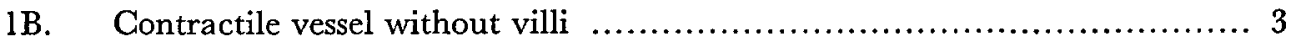

2A. Dorsal and ventral retractor muscles originate at same level .......S. cumanense

2B. Dorsal retractor muscles originate anterior to the ventral muscle....S. mourense

3A. Rectum with numerous elongate, club-shaped caecae, hooks present on introvert (Fig. 2, G) ............................................. vastum

3B. Rectum with one small caecum or none, no hooks on introvert...S. funafuti

\section{Siphonosoma cumanense (Keferstein, 1867)}

$$
\text { (P1. I, Fig. 1) }
$$

Description: This most common member of this genus is a cylindrical species usually $10-20 \mathrm{~cm}$ long, but may exceed $40 \mathrm{~cm}$. It varies in color depending on its microhabitat and the preservative used, being off white, grey, yellowish-tan, to grey brown. Generally it is smooth but may have dome-shaped skin bodies at the anterior end of the trunk. The body wall is opaque but often the 18-25 longituinal muscle bands can be seen through the skin. This is a very plastic form and has been discussed at length in Cutler and Cutler (1979). The introvert carries a complex array of tentacles arranged in 10-12 double rows each row containing up to 10 tentacles. It lacks hooks. The retractor muscles originate near the anterior end of the trunk. It is the only species in this genus in which both pairs arise at the same level. The rectum usually bears a single caecum. In most specimens one can locate small, fragile, crescentric transverse dissepiments distributed around the inner surface of the body wall. In addition there are 2-4 fixing muscles. The contractile vessel exhibits numerous villi. In a specimen from Tchoja-hama, the right nephridium is unusually short and has a short anterior extension. The nephridia are always anterior to the anus. Spherical eggs about $100-130 \mu$ in diameter are present.

Remarks: The species S. edule (Pallas) has been considered to be a separate, distinct species but its distinctiveness has been questioned by Stephen and Edmonds (1972: 44, 47-49, 53). The primary (sole?) difference is the introvert length $(1 / 8$ $1 / 14$ the trunk length vs $1 / 3-1 / 7$ in $S$. cumanense). When Cutler and Cutler (1979: 947-948) discussed $S$. cumanense, the issue of the introvert length was examined: 
"Extrapolating from the data shown in fig. 1, it is possible that large S. cumanense (over 250 mm trunks) would have an introvert small enough to approach the $7-11 \%$ range reported for $S$. edule. The unanswered question then becomes: are $S$. edule only very large $S$. cumanense or S. cumanense with unusually short introverts?"

The measurements made were based on smaller worms but in these recent Japanese collections, large worms were present and additional measurements were made. Cutler, Cutler and Nishikawa (1983) stated, "It is now clear to us that as these worms increase in size, the rate of growth of the introvert is slower than the trunk and that those few larger individuals, when seen in isolation from a population have erroneously been considered a distinct species." It was concluded that $S$. cumanense be reduced to a junior synonym. However, for several reasons, one of us (E. Cutler) is petitioning the International Commission of Zoological Nomenclature to conserve the more widely used and familiar name, $S$. cumanense, for this taxon (Gutler, 1984).

Previous Japanese Records: Ikeda, 1904; Okinawajima Isl.; Tokyo and Sagami Bays; Seto Inland Sea; Miyagi Pref; Kagoshima; Amami-Oshima. Sato, 1934b; Onomichi, Seto Inland Sea and Matsushima Bay; 1937a-Fukushima, Miyagi, Aomori, Akita and Yamagata Pref.; 1939-Miyako, Ryukyu Islands.

\begin{abstract}
Material Examined: Imajima-St. 101, Niyagawa, Ebime Pref., intertidal; 8/30/69; 3 spec. St. 102, 1968, St. 30; 1 spec. St. 103, Mukaishima, Hiroshima Pref., intertidal; 5/64; 3 spec. St. 104, Hiroshima, dry beach; 24 spec. St. 105, Sunozaki, Tanegashima; intertidal; 6/75; 3 spec. St. 106, Manazuru, Kanagawa Pref.; 2 m; 1/16/78. Niigata Univ.-Tassha, Kuroshima, Sado Isl; 1955 \& $1956 ; 2$ spec. Noto M.B.L.-collected in front of lab., 1958 \& 1975; 2 spec. Nishikawa-St. 15, N beach, Seto M.B.L.; 8 m; 9/1/75; 1 spec. St. 19, off Kagawa Pref.; 1 spec.; 3/75. 20, off Kagawa Pref., 7/75; 2 spec. St. 22, off Gobo, Wakayama; $5 \mathrm{~m} ; 5 / 78 ; 2$ spec. St. 28, Hoshidate Bay, Iriomotejima Isl; intertidal; $6 / 22 / 75 ; 1$ spec. St. 36, Hatakejima, Tanabe Bay, Wakayama; intertidal; $8 / 27 / 73$; 1 spec. St. 37, same as 28; 6/21/75; 2 spec. Kowa, Mikawa Bay, Chita Penn.; intertidal; 5/4/80; I spec. Higashihazu, Mikawa Bay; intertidal; 6/1/80; 1 spec. Tchoja-hama, Toshijima Isl., Ise Bay; intertidal; $7 / 11 / 80 ; 3$ spec. Senzyo-iso, Sugashima Isl., Ise Bay, subtidal; 7/29/80; 2 spec. Cutler-St. 6, Koajiro Bay, Miura Penn.; 3/30/79; intertidal; 3 spec. St. 9, Mukaishima M.B.L., Hiroshima Pref.; 4/7/79; 3 spec. St. 14, Katetsu, E. of Koniya, Amami-Oshima; 4/13/79; 4 spec. St. 17, Sakaurjima, Kagoshima Bay; intertidal; 4/10/79. St. 19, Sesoko M.B.L., Okinawa, intertidal; 4/17/79; 80 spec. St. 27, Moroiso Bay, Miura Penn.; 5/26/79; 5 spec. St. 30 ,Okinoshima Isl., near Tateyama M.B.L.; 6/13/79; 1 spec. St. 35, Koajiro Bay; 6/26/79; 6 spec. Osaka Mus.-St. 161-2, Tannowa, Misaki-cho, Osaka Pref.; 8/25/67; 2 spec. St. 163, same; 2/8/59; 1 spec. St. 277-8, Sagi-jima Isl., off Mihara, Hiroshima Pref.; 7/10/60; 2 spec. St. 180, Ategi-jima Isl., off Onomichi, Hiroshima Pref.; 7/19/55; 1 spec. St. 182-3, Kashima Isl., off Onomichi; 7/9/60; 2 spec. St. 186-8, Hishio, Mukaishima Isl., Onomichi; $8 / 24 / 61 ; 4$ spec. St. 196, same; 7/22/76; 1 spec. Tohoku Univ.-more than 20 bottles collected by H. Sato plus his other three species synonomized with this: $S$. formosa, Hattosi, Formosa; 3/23/36; 1 spec. S. hataiz, Marukyoku, Palau; 6/16/28; 3 spec. $S$. koreae, Gunzan, Korea; 9/2/37; 1 spec. Sawada-St. 1, Matsuyama; 2 spec.
\end{abstract}

Japanese Distribution: This eurytopic species is found in the intertidal sands along both sides of Japan from Okinawa in the South through Amami-Oshima, Kyushu, Shikoku to Mutsu Bay in northern Honshu. It is the most common species in this habitat.

Worldwide Distribution: Previous records are from widely distributed tropical and subtropical areas in the West Pacific, Indian Ocean, the Red Sea to South Africa, 
and in the western Atlantic and the Caribbean from Florida and Cuba to Venezuela. Its apparent absence in the Eastern Pacific and Atlantic Oceans is an interesting feature of an otherwise circumtropical and subtropical species.

\section{Siphonosoma funafuti (Shipley, 1898)}

Sipunculus amamiense: Ikeda, 1904: 36-38; 1924: 31.

Siphonosoma amamiense: Sato, 1939: 371.

Description: These worms are whitish to yellow-brown with trunks 18-120 mm long. The introverts lack hooks. The number of infrequently anastomosing longitudinal muscle bands is usually 15-16 but in the mid-region of some there are 19-20. The rectum sometimes bears a single, small caecum, and the dorsal retractor muscles are thinner, originating significantly anterior to the broader ventral pair. The contractile vessel has folds or bubbles along it, but lacks actual villi. The short nephridia are not attached to the body wall.

Remarks: In Cutler and Cutler (1982) S. amamiense and $S$. funafuti were shown to be conspecific. The description of $S$. amamiense and the specimens are superior in quality but $S$. funafuti is the senior name.

Previous Japanese Records: Ikeda, 1904 -Amami-Oshima and Okinawa-jima; 1924 -Tanegashima. Sato, 1939 -Miyakojima, Ryukyu Islands.

Material Examined: Univ. of Tokyo, Ikeda's coll.-I-37, Naze, Amami-Oshima; 4/5/01; 1 spec. I-45, Koniya, Amami-Oshima; 1901; 9 spec. I-46, Itoman, Okinawa; coral reef; 4/11/01; 1 spec. (may be type). Tohoku Univ., Sato's coll.—\#3-12, Miyakojima, Okinawa; shore; 4/5/36; 1 spec. Nishikawa-St. 6, Kabira Bay, Ishigakijima; intertidal; 10/78; 1 spec.

Japanese Distribution: This species seems restricted to the warm waters of the Ryukyu and Amami-Oshima Islands.

Worldwide Distribution: Outside of Japan this has been reported from Funafuti and Ellice Islands in the south Pacific.

\section{Siphonosoma mourense Sato, 1930}

Description: These elongate (up to $350 \mathrm{~mm}$ long), pale worms without introvert hooks superficially resemble the common $S$. cumanense but can easily be distinguished by their internal anatomy. The dorsal retractor muscles originate several millimeters anterior to the ventral pair and the longitudinal musculature is separated into 20-25 bundles. The rectum is without a caecum and transverse dissepiments are absent.

Remarks: This species is very similar to $S$. ingens from Southern California but the latter has peculiar elongate fusiform bodies in the posterior end of the trunk. These might represent two subspecies of a northern Pacific Siphonosoma.

Previous Japanese Records: Sato, 1930, 1937a -Mutsu Bay and Miyagi Prefecture. 
Material Examined: Tohoku Univ., Sato's coll.-\# 183-G 38, type, Moura, Mutsu Bay; 8/24/26; 1 spec. Also catalogue numbers 1-2, 1-3, 4-10, 4-13, 4-21, 5-4.

Japanese Distribution: The only records are those of Sato's from Moura and Asamushi in Mutsu Bay and from Karakuwa and Miyato-jima in Miyagi Prefecture. They are all from northern Honshu dredged at unknown depths.

Worldwide Distribution: Other than Sato's records, Leroy (1936) lists this species in collections in the Paris Museum as coming from Amboine (Mer des Moluques) but the specimens cannot be located to verify this record.

\section{Siphonosoma vastum (Selenka, DeMan \& Bulow, 1883)}

(Fig. 2, G)

Description: These nine white to pale orange worms range in trunk length from $15-92 \mathrm{~mm}$ with introverts $50-90 \%$ of this length. The papillae on the anterior end of the trunk and base of the introvert are large in many. The introvert carries dark, large, claw-shaped hooks arranged in rings.

Internally the prime character is the cluster of large spherical or digitiform caecae on the rectum. The four retractor muscles originate at the same level and the nephridia extend back to the base of the retractor muscles, being about 50 $75 \%$ attached to the body wall. The contractile vessel is without villi.

Previous Japanese Records: None.

Material Examined: Nishikawa-St. 27, Kushimoto, S Kii Pen., intertidal; 12/4/75; 1 spec. Cutler-St. 19, near Sesoko M.B.L., Okinawa; intertidal; 4/17/79; 7 spec. St. 31, Hisashi tidal pool, Miyake-jima; 6/15/79; 1 spec.

Japanese Distribution: Only from the three separate locations mentioned above. The specimen from Kushimoto is the most northerly record ever found.

Worldwide Distribution: There are a number of records of this species from the tropical Indian and West Pacific Oceans and Australia. Guam is the closest previous record and the most northern until now.

\section{Genus Golfingia Lankester, 1885}

Usually small to moderate size, slender sipunculans with continuous longitudinal muscle layer (Fig. 2, D). Introvert equal to or shorter than trunk. Tentacles (finger-shaped, leaf-shaped or filiform) surround mouth. Hooks present or absent on introvert; four introvert retractor muscles; contractile vessel simple without villi. Intestine of double-spiraled coil around axial spindle muscle which is not attached at the posterior end. Two nephridia.

Remarks: As noted in the Introduction the nature of this taxon has changed in that the previously contained subgenera have been removed, leaving only Golfingia sensu stricto. 
Key to the Golfingia species known from Japan

1A. Posterior end of trunk extended into tail-like appendage (PI. I, Fig. 3) .... 2

1B. Posterior end of trunk rounded and not extended into tail-like appendage

2A. Hooks absent; thick coarse body wall.

G. appendiculata

2B. Hooks present; thin body wall often with an irridescent sheen.

G. muricaudata

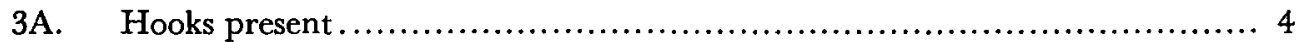

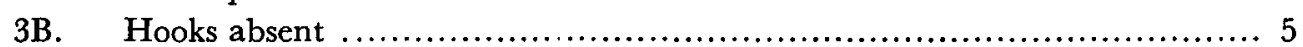

4A. Trunk smooth and pale; no papillae, only flattened skin bodies; hooks in

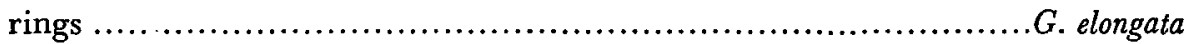

4B. Trunk smooth in mid-section only; anterior and posterior $10-15 \%$ dark color and with papillae; hooks scattered............................... vulgaris

5A. Trunk cylindrical with same color overall; no large papillae posteriorly G. margaritacea

5B. Trunk with only posterior quarter pigmented, of smaller diameter with wavy ripple marks and obvious cylindrical papillae (Pl. I, Fig. 2)...G. singa

\section{Golfingia appendiculata (Sato, 1934)}

(PI. I, Fig. $3 \mathrm{~A}$ )

Description: These seven worms range in trunk length from 10-25 mm, (Sato's was $120 \mathrm{~mm}$ ), have tails about $10 \%$ of the trunk length (Pl. I, Fig. 3A), and lack hooks. As pointed out in Cutler and Cutler (1981) these worms are placed in this taxon with reservations as they vary somewhat from Sato's description. They are in many ways similar to $G$. muricaudata but do lack hooks at all stages of their life. Other differences are less clear but lie in the thicker, coarser nature of the body wall. Cutler (1977) points to the similarity of this species to G. margaritacea (if one expands the concept of the latter to include a tailed variety).

Internally all three have retractor muscles which originate in the anterior half of the trunk, the dorsals just behind the anus. The nephridia open just anterior to the anus and are otherwise unattached to the body wall.

Previous Japanese Records: Sato, $1934 \mathrm{a}-\mathrm{Tosa}$ Bay $\left(33^{\circ} \mathrm{N}, 134^{\circ} \mathrm{E}\right), 288-527 \mathrm{~m}$.

Material Examined: Imajima-St. 132, near Tsushima; 205 m; dredge; 7/68; 7 spec.

Japanese Distribution: From south of Shikoku and north of Kyushu, from water deeper than $200 \mathrm{~m}$.

Worldwide Distribution: This species has been recorded in the South Pacific and Tasman Sea, and once from the Bering Sea.

\section{Golfingia elongata (Keferstein, 1863)}

Description: These 12 slender worms are from $8-115 \mathrm{~mm}$ long (elsewhere up to 
$200 \mathrm{~mm}$ ) and have smooth lustrous pale skin. The short introverts are about 20$40 \%$ of the trunk length and exhibit a single disc of 20-36 tentacles in mature worms, fewer in small individuals. The hooks are tall, slender, and arranged in distinct rings. Gibbs (1977) reports 20 rings in smaller worms which decline to 3 or 4 in older worms presumably due to wear or abrasion.

The two pairs of retractor muscles originate in the anterior half of the trunk (ventral pair at $30-40 \%$ of trunk length) with the dorsal pair near the anus (about $10 \%$ of trunk length). In a population off England Gibbs (1977) reported that one or sometimes two muscles are missing. There is a caecum on the short rectum and the unattached, short (15-25\%) nephridia open at or just anterior to the anus. Gametes were present in the worms from St. 153 and TA 29-46.

Previous Japanese Records: None

Material Examined: Imperial Household- $\$ 533$, Minami-amadaiba, Sagami Bay; $150 \mathrm{~m} ; 1 / 19$ / $60 ; 1$ spec. Yamashita- $-31^{\circ} 30^{\prime} \mathrm{N}, 125^{\circ} 59^{\prime} \mathrm{E} ; 69 \mathrm{~m} ; 6 / 23 / 63 ; 1$ spec. $33^{\circ} 03^{\prime} \mathrm{N}, 125^{\circ} 04^{\prime} \mathrm{E} ; 76 \mathrm{~m} ; 1 / 31$ / 66; 23 spec. Hayashi-St. TA29-46; Tango-kai, Wakasa Bay; $75 \mathrm{~m} ; 7 / 26 / 76 ; 1$ spec. Imajima-St. $145 ; 35^{\circ} 05^{\prime} \mathrm{N}, 138^{\circ} 48^{\prime} \mathrm{E}$, Suruga Bay; $300 \mathrm{~m} ; 6 / 77 ; 1 \mathrm{spec}$. St. 153; Suruga Bay, slope of Senoumi; 435-590 m; 2/78; 4 spec. St. 160; off Chikura, Boso Peninsula, 130 m; 9/76; 1 spec.

Japanese Distribution: Found on both sides of central Honshu, then out in the East China Sea south of Korea from 70-590 m.

Worldwide Distribution: A cold-water species found on both sides of the North Atlantic and the Gulf of Guinea. Scattered records are from the Mediterranean, Antarctic, and the South China Sea.

\section{Golfingia margaritacea (Sars, 1851)}

Golfingia glossipapillosa (see Cutler \& Cutler, 1981: 61-62)

Golfingia okinoseana (see Cutler \& Cutler, 1981:64).

Description: This widespread and variable species has many described subspecies (Stephen and Edmonds, 1972) and in Cutler and Cutler (1981) two more taxa were reduced to subspecific status. The following description is of the nonminate form. The variations from this pattern will then be articulated for the three subspecies reported from Japanese waters.

This is a smooth-skinned, cylindrical species which may reach $300 \mathrm{~mm}$ long (shallower forms commonly around $20 \mathrm{~mm}$ ). The introvert is $30-50 \%$ of the trunk length, is without hooks, and has a complex tentacular crown with from 8-100 tentacles, depending on age.

The ventral retractor muscles originate in the second quarter of the trunk and the dorsal pair originate just behind the anus (5-15\%). A well-developed rectal caecum is usually present and the intestine forms a tight coil. The unattached nephridia are $20-40 \%$ of the trunk length and open just anterior to the anus. There are usually 3-4 fixing muscles anchoring the intestinal coil to the body wall.

Worldwide Distribution: This is a well-known, cold-water species common on both sides of the Northern Atlantic; in the south Atlantic down into Antarctic, into the 
far south Pacific and a few records from the North Pacific.

\section{Golfingia margaritacea ikedai sensu Cutler and Cutler, 1981}

This most common Japanese representative of this subgenus was originally. described by Ikeda (1904) as Phascolosoma japonicum but later it was changed to Golfingia ikedai by Fisher (1950). Its status is discussed in Cutler and Cutler (1981).

The population ranges in trunk length from 6-65 $\mathrm{mm}$. It differs from the nominate form in that the contractile vessel is thick and large and usually has a vesicular appearance with small bubbles or swelling along it (not villi) which are most pronounced in contracted individuals. Two other distinctions are the occasional absence of a rectal caecum and the presence in some of darkly pigmented eyespots. A single specimen (St. 274) with a $30 \mathrm{~mm}$ trunk lacks a left dorsal retractor muscle. The spherical eggs measure up to $150 \mu$.

Of particular interest is the population from St. 34 (Cutler) from a sandy pocket at Kurosaki near Misaki Marine Biological Laboratory. Twenty of these 38 worms have small $(25-35 \mu)$, pale hooks which are scattered but sometimes appear in irregular rings. The largest hook-bearing worm has a $20 \mathrm{~mm}$ trunk. There are clear indications that these are deciduous hooks as their density decreases with age, becoming more scattered. However, there is not always a direct correlation with size but sometimes it is a reflection of microhabitat, some worms losing their original set more quickly than others.

When we first observed this we were puzzled as they were clearly not any other described species and coexisted in the same pockets of sand along this rocky coast. Peter Gibbs (Plymouth) has examined some specimens and concurs in our decision to place them here as juvenile members of this species. Deciduous hooks are not unique within this phylum but this is the first record for this species (Gerould, 1907 -P. gouldi; Wesenberg-Lund, 1963 -G. capense; Southern, 1913 -G. muricaudata; Akesson, $1958-G$. minuta; Murina, $1964-G$. muricaudata). We suspect it is not unique to this subspecies but probably true for other populations also.

Previous Japanese Records: Ikeda, 1904 -Tokyo and Sagami Bays.

Material Examined: Nishikawa-St. 33; Kushimoto, S end of Kii Peninsula; intertidal; 12/4/75; 1 spec. Hayashi-St. 29-2; Tango-kai, Wakasa Bay; $307 \mathrm{~m} ; 5 / 23 / 78 ; 1$ spec. St. W-474; off Wakasa; 110 m; 9/25/75; 1 spec. Imajima-St. 106; Manazuru, Kanagawa Pref; 2 m; 1/16/78; 6 spec. St. 114; Aburatsubo Bay; intertidal; 6/71; 1 spec. St. 116; Hayama, Kanagawa Pref; intertidal; 4/66; 1 spec. St. 135; Tsushima Strait; $96 \mathrm{~m}$; dredge; 8/68; 1 spec. Univ. of Tokyo, Ikeda's coll.-Koajiro, 1890; 3 spec. Moroisa, Miura Peninsula; 1902; many spec. Enoura, Shizuoka Pref.; 6/1885; 13 spec. Awa Kominato, Chiba Pref.; 4/1886; 8 spec. Cutler-St. 22; Misaki M.B.L., sandy pockets between rocks; 4/28/79; 13 spec. St. 28; Kurosaki, Miura Peninsula; sandy pockets; 5/25/79; 26 spec. St. 30; Okinoshima Island, Tateyama; intertidal; 6/13/79; 1 spec. St. 34; same as St. 28; 6/25/79; 38 spec. Imperial Household- 7 (part), Tozaki, Kushimoto; 6/3/29; 3 spec. \#46, Koajiro, Misaki, Sagami Bay; 4/4/28; 4 spec. $\neq 274$. Nashima, Hayama, Sagami Bay; shallow; 3/19/57; 3 spec. $\neq 887$, Ishimo, Kasa-jima, Sagami Bay; 7/11/64; 1 spec. \# 1024, Nishino-saki, Sagami Bay; shallow; 3/28/67; 5 spec. ₹1 059, Arashidome, Susaki, Izu; shallow; 6/14/72; 1 spec. USNM-USS Albatross; Misaki; 6 spec. 
Japanese Distribution: Found from the intertidal zone to $307 \mathrm{~m}$ off both sides of central Honshu and one record from north of Kyushu.

Worldwide Distribution: This subspecies not recorded outside of Japan.

\section{Golfingia margaritacea soyo sensu Cutler and Cutler, 1981}

This form is based on 12 individuals, 3 recently collected ones with $20-35 \mathrm{~mm}$ trunks, and nine of Sato's original specimens with $35-150 \mathrm{~mm}$ trunks. This was discussed in Cutler and Cutler (1981) wherein Golfingia noto is considered as conspecific. The large cone or pear-shaped papillae around the base of the introvert is all that distinguishes this from the nominate form.

Previous Japanese Records: Sato, 1934a -Japan Sea and Tsugaru Strait, 110-552 m. Also $G$. noto off the Noto Peninsula.

Material Examined: Tohoku Univ.-Sato's coll; type 9 spec. Yasuda-St. 9; $36^{\circ} 20^{\prime} \mathrm{N}, 135^{\circ} 40^{\prime} \mathbf{E}$; Japan Sea; 535 m; 3 spec.

Japanese Distribution: In the Japan Sea off central and northern Honshu.

Worldwide Distribution: Only as above.

Golfingia margaritacea antarctica (Michaelsen, 1889)

According to Stephen and Edmonds (1972) this form differs from the nominate one by having dark papillae covering the trunk. However, Sato's comments did not mention that fact, rather that it had tall papillae on the posterior end with pigmented reticulations.

Previous Japanese Records: Sato, 1934a -off Noto Peninsula, $172 \mathrm{~m}$.

Material Examined: None.

Japanese Distribution: Only from the Japan Sea off Noto Peninsula.

Worldwide Distribution: One record of three specimens in the Antarctic.

Considering these three taxa as one species, the distribution in Japanese waters is intertidal $-555 \mathrm{~m}$ in the Japan Sea, off Honshu, and on the Pacific side around Suruga and Sagami Bays.

\section{Golfingia muricaudata (Southern, 1913)}

$$
\text { (Pl. I, Fig. 3B) }
$$

Description: This single worm has a 13-mm trunk with a 1-mm tail (Pl. I, Fig. 3B) and a $7-\mathrm{mm}$ introvert which are typical proportions for this species. The posterior $20 \%$ of the trunk has tall, cylindrical papillae but the rest of the animal is rather smooth. The surface of this worm has an irridescent sheen which is not present in the Atlantic Ocean population. The short tail is a distinct appendage and not just a contracted section of the trunk. Introvert hooks and tentacles are present in this worm but hooks may be absent in larger specimens (up to $48 \mathrm{~mm}$ in Southern, 1913). 
Four short retractor muscles originate in the anterior half of the trunk and the two free hanging nephridia open a little anterior to the anus. The nerve cord ends before the beginning of the tail.

Previous Japanese Records: Murina, 1964-Japanese Trench $\left(38-41^{\circ} \mathrm{N}, 144^{\circ} \mathrm{E}\right)$.

Material Examined: Imajima-St. 142, off Tsushima; $85 \mathrm{~m}$; dredge; 8/68; 1 spec.

Japanese Distribution: In the Japan Sea north of Kyushu and in the Japanese Trench (over $5000 \mathrm{~m}$ ).

Worldwide Distribution: In the Atlantic Ocean it is found from Hudson Bay and east coast of U.S. in the west, and in the east from Ireland, South West Africa, and then far south at $54^{\circ} \mathrm{S}$. It is off southeast Africa in the Indian Ocean; then from New Zealand and the Northwest Pacific.

\section{Golfingia signa (Sato, 1934)}

(Pl. I, Fig. 2)

Description: This species is known from only five specimens ranging in length from $10-45 \mathrm{~mm}$. The two recently collected worms differ from Sato's description in ways discussed in Cutler and Cutler (1981) and as suggested therein, this species is very similar to $G$. margaritacea and perhaps should be properly considered a subspecies. It is included in this report with reservations about its biological significance. Additional specimens of this taxon would be extremely helpful in resolving this problem.

In general, the description of $G$. margaritacea found herein would suffice for this species. The primary difference is that the posterior quarter of the trunk in this form is pigmented, of a smaller diameter than the rest, has more obvious cylindrical papillac, and wavy ripple marks on the surface (Pl. I, Fig. 2).

Previous Japanese Records: Sato, 1934a-Wakasa Bay, $658 \mathrm{~m}$.

Material Examined: Hayashi-St. W-242, off Wakasa; $330 \mathrm{~m} ; 8 / 27 / 75 ; 1$ spec. St. 29-2, Tango-kai, Wakasa Bay; 307 m; 5/23/78; I spec.

Japanese Distribution: Found only in the area of Wakasa Bay, Japan, Sea at depths of $307-658 \mathrm{~m}$.

Worldwide Distribution: Not found outside of Japan.

\section{Golfingia vulgaris (de Blainville, 1827)}

Golfingia owstoni (See Cutler \& Cutler, 1981: 64-65)

Description: The Japanese material ranges in trunk size from $3.5-65 \mathrm{~mm}$ (up to $200 \mathrm{~mm}$ elsewhere) with introvert shorter than the trunk. The most distinctive external character of this species is the nature of the body surface: the posterior $10-15 \%$ and the region anterior to the anus out a short distance onto the introvert is generally papillated and medium to dark brown while the remainder is smooth, 
sometimes irridescent and white. The posterior end is often rounded but may form a conical pointed tip. The introvert carried scattered, tall, large hooks and up to 150 tentacles (see Gibbs, 1977).

The two pairs of retractor muscles originate in the anterior half of the trunk, the dorsal pair only a short distance behind the anus. The pair of short nephridia open a little anterior to the anus and are otherwise unattached. A rectal caecum and several fixing muscle are present.

Note: The single $39 \mathrm{~mm}$ specimen from the Imperial Household, Sta. 172, is anomalous in that the pair of dorsal retractor muscles is missing. At first we considered this a Nephasoma species but with additional study and consultation with P. Gibbs, it was decided to include it here. Gibbs (1977) described similar anomalies in this retractor system.

Previous Japanese Records: Ikeda, 1904-P. owstoni, Uraga Channel, $300 \mathrm{~m}$. Sato, 1934a -var. tropicum off Funai, Iwate Pref., $170 \mathrm{~m}$. Sato, 1937a-Mutsu Bay.

Material Examined: Imperial Household-St. 172, Kado-ne, off Nagai, Sagami Bay; 100-200 m; 12/12/53; 1 spec. Nishikawa-St. 17, 18, 20, from off Kagawa Pref., Seto Inland Sea; 7 spec. Imajima-St. 121, Otsuchi Bay; $50 \mathrm{~m}$; dredge; 10/78; 1 spec. Horikoshi-St. 78-11, K-2, 34 ${ }^{\circ} 55^{\prime} \mathrm{N}, 1^{\circ} 8^{\circ}$ 30’E, Suruga Bay; 128 m; 7/18/78; 2 spec. Osanai-St. 1, Asamushi M.B.L., Mutsu Bay; 1 spec.

Japanese Distribution: From Mutsu Bay down the Pacific side of Honshu and into the Inland Sea.

Worldwide Distribution: From the North Atlantic from Greenland to West Africa, the eastern Mediterranean into the Red Sea and into the Antarctic. Also from the sublittoral zone in the Indo-West Pacific.

\section{Genus Nephasoma Pergament, 1940}

Species usually small to medium (trunk less than $5 \mathrm{~cm}$ ). Introvert about equal to or shorter than trunk (Fig. 3, A). Body wall with continuous muscle layers. Oral disc carries tentacles around the mouth, but tentacles may be reduced in both size and number and restricted to dorsal region. One pair of retractor muscles, spindle muscle unattached posteriorly, simple contractile vessel. Two nephridia. Simple hooks may be present.

Key to Nephasoma species known from Japan

1A. Introvert hooks scattered; skin not white or irridescent ................... 2

1B. Introvert hooks in spiraled rings; smooth, white, irridescent skin (Fig. 3, B) N. abyssorum

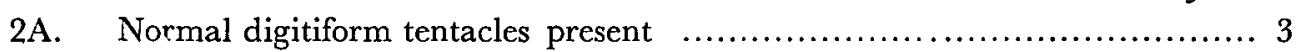

2B. Tentacles reduced to a few lobes (Fig. 3, C) $\ldots \ldots \ldots \ldots \ldots \ldots \ldots \ldots . . \ldots$ diaphanes

3A. Large hemispherical papillae evenly distributed over trunk (Fig. 3, D); introvert shorter than trunk. N. pellucida

3B. Papillae small or absent from mid-region of trunk; introvert equal to or longer than trunk. 

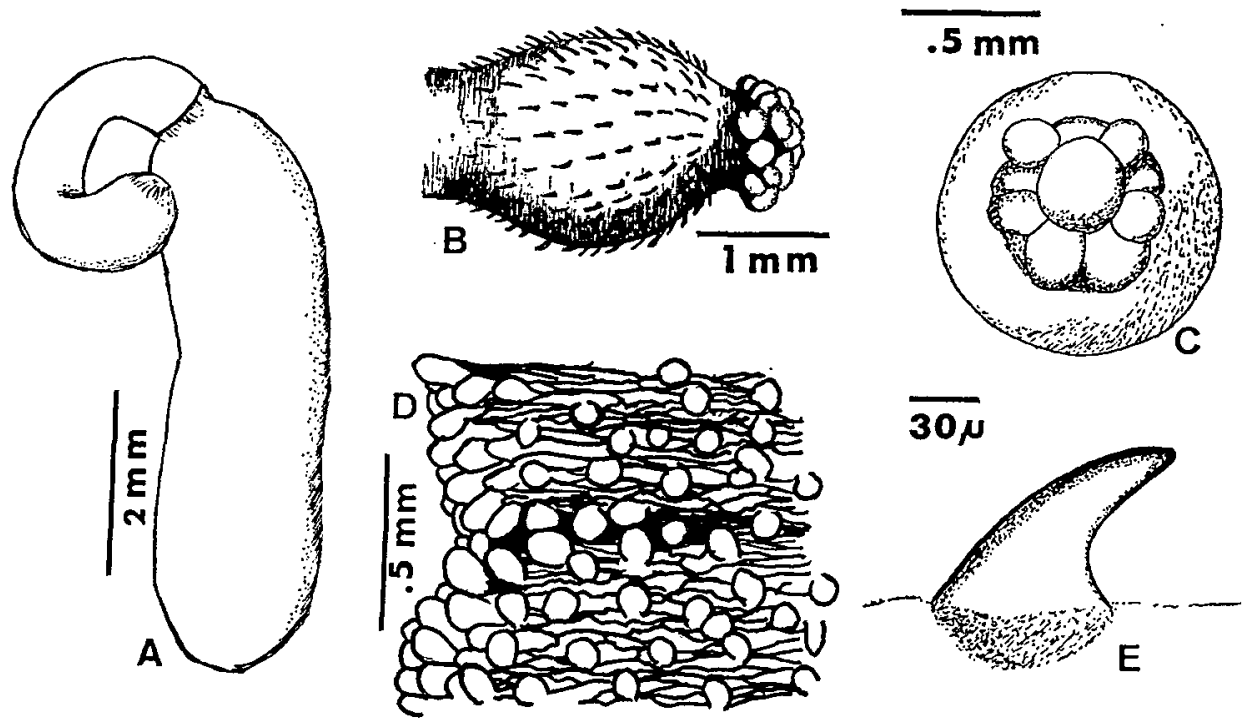

Fig. 3. Genus Nephasome. A: General from. B: Distal end of introvert of N. abyssorum showing tentacles and hooks in spiral rings. C: Reduced tentacles in $N$. diaphanes. D: Portion of body wall of $N$. cf. pellucida with papillae. E: Hook of $N$. confusa.

4A. Small, pale hooks $(25-45 \mu)$; large mammiform papillae on both ends of trunk. . N. subhamata

4B. Large, dark hooks $(70-80 \mu)$ (Fig. 3, E); papillae small and cylindrical... N. confusa

\section{Nephasoma abyssorum (Koren and Danielssen, 1875)}

(Fig. 3, B)

Description: This species is represented by ten worms and two of these are very small and doubtful (Sta. T-2 and 78-14 B3). The trunks are white, smooth, often irridescent, cylindrical, and range in length from $3-30 \mathrm{~mm}$. There are elliptical skin bodies plus dome-shaped papillae at the posterior end. The introvert is shorter than the trunk, bears tentacles and distinctive large hooks arranged in spiraled rings (Fig. 3, B).

The one pair of retractor muscles originate in the second quarter of the trunk. The short, free nephridia open at the level of the anus. One specimen from Sta. 75-15 B was coiled in a manner suggesting that it had been removed from a gastropod shell, not typical for this species.

Previous Japanese Records: None.

Material Examined: Hayashi-St. T-2; Tango-kai, Wakasa Bay; $116 \mathrm{~m} ; 6 / 20 / 78$; 1 spec. ImajimaSt. 155; Senoumi, Suruga Bay; $970 \mathrm{~m} ; 2 / 9 / 78 ; 1$ spec. Horikoshi-St. 74-14 B3; $34^{\circ} 45^{\prime} \mathrm{N}, 138^{\circ} 44^{\prime} \mathrm{E}$; $140 \mathrm{~m} ; 9 / 21 / 47 ; 1$ spec. St. $75-15 \mathrm{~B} ; 34^{\circ} 04^{\prime} \mathrm{N}, 138^{\circ} 47^{\prime} \mathrm{E} ; 279 \mathrm{~m} ; 11 / 24 / 75 ; 1$ spec. St. $76-16 \mathrm{~T} 1 ; 34^{\circ} 55^{\prime}$ N, $138^{\circ} 46^{\prime} \mathrm{E} ; 127 \mathrm{~m} ; 9 / 20 / 76 ; 1$ spec. St. $78-11 \mathrm{~K} 2 ; 34^{\circ} 55^{\prime} \mathrm{N}, 138^{\circ} 30^{\prime} \mathrm{E} ; 128 \mathrm{~m} ; 7 / 18 / 78 ; 5 \mathrm{spec}$. 
Japanese Distribution: This is found between $120-970 \mathrm{~m}$ on both sides of central Honshu in Suruga and Wakasa Bays.

Worldwide Distribution: Found in the Barent's Sea, North Atlantic, Mediterranean and one questionable record from Cuba (Murina, 1967).

\section{Nephasoma confusa (Sluiter, 1902)}

(Fig. 3, E)

Description: These two specimens have trunks 15 and $19 \mathrm{~mm}$ long without obvious large papillae. Both ends of the trunk are opaque with intersecting grooves probably caused by irregular contraction of the circular muscle layer. The mid region also exhibits circular grooves but is thin-walled and semi-transparent. The introvert is about equal to the trunk length and carries the unique large (about 70-80 $\mu$ tall) scattered hooks (Fig. 3, E).

Internally the pair of retractor muscles originate in the middle of the trunk and the pair of short, free nephridia open at the level of the anus. A caecum is present on the rectum.

Previous Japanese Records: None.

Material Examined: Horikoshi-St. 78-11 OT $-8 ; 34^{\circ} 40^{\prime} \mathrm{N}, 138^{\circ} 40^{\prime} \mathrm{E} ; 1020 \mathrm{~m} ; 7 / 15 / 78 ; 2$ spec.

Japanese Distribution: Found over $1000 \mathrm{~m}$ in Suruga Bay.

Worldwide Distribution: Found in 4-4600 $\mathrm{m}$ water in the Atlantic from Brazil down to Antarctic, southern Australia, Indonesia and the northwest Pacific.

\section{Nephasoma diaphanes (Gerould, 1913)}

(Fig. 3, C)

Description: This is probably one of the most common cold water species in the world's oceans but better known as N. minuta. Gibbs (1975) and Cutler and Cutler (1980) discuss the differences and restrict the concept of $N$. minuta to the shallow water, hermaphroditic population from the northeast Atlantic Ocean. One additional problem mentioned was the real possibility of misidentifying a juvenile member of some other Nephasoma species as $N$. disphanes simply because the species-specific characters have not developed yet.

This population ranges in trunk length from 3-9 mm, most five or less and frequently were taken from arenaceous foraminiferan tests or small scaphapod shells. They are usually cylindrical with pale or translucent body walls and very few, small papillae. The introvert is not longer than the trunk, carries scattered, spine-like hooks $35-50 \mu$ tall and a few short tentacular lobes.

The pair of ventral retractor muscles usually originate from $50-80 \%$ of the distance to the posterior end of the trunk but may exceed this range (see Cutler, 1973). The short, free nephridia open at the level of the anus and gametes are 
present in the specimens from St. 74-14 B10.

Previous Japanese Records: None

Material Examined: Imajima-St. 144; off Heda, Suruga Bay; 240-320 m; 8/73; 17 spec. St. 145; $35^{\circ} 05^{\prime} \mathrm{N}, 138^{\circ} 48^{\prime} \mathrm{E} ; 300 \mathrm{~m} ; 6 / 77 ; 10$ spec. Hayashi-St. W-405; off Wakasa; $315 \mathrm{~m} ; 9 / 25 / 75 ; 2$ spec. St. TA-15-75; Tango-kai, Wakasa Bay; 75 m; 7/26/76; 1 spec. St. 29-2; Tango-kai, Wakasa Bay; 307

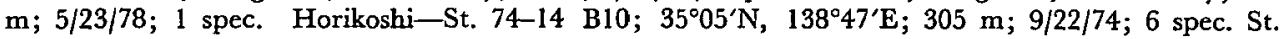
$76-16 \mathrm{~T}-2 ; 34^{\circ} 55^{\prime} \mathrm{N}, 138^{\circ} 44^{\prime} \mathrm{E} ; 297 \mathrm{~m} ; 9 / 23 / 76 ; 7$ spec.

Japanese Distribution: Found off both sides of Honshu in Suruga and Wakasa Bays at depths between 75 and $320 \mathrm{~m}$.

Worldwide Distribution: A cosmopolitan, deep-water species from the North Atlantic and Antarctic with scattered reports from western South America, both sides of Central America, northwest Pacific, Australia, south and west Africa, the Azores, and the Mediterranean Sea. Most records use the name $N$. minuta.

Nephasoma cf. pellucida (Keferstein, 1865)

(Fig. 3, D)

Description: This single 6-mm worm is assigned to this taxon with some reservation. In most ways it is similar to the large North Carolina population (Cutler, 1973) but there are minor differences, especially the hooks which are larger and more numerous in this worm. Before a positive affirmation is made, it would be well to examine more individuals.

This species is distinctive because of the large number of well-developed hemispherical papillae evenly distributed all over the body surface (Fig. 3, D). The introvert is not longer than the trunk and has papillae extending out along much of its length. Distally there is a region which usually carries small, scattered hooks (sometimes absent in larger worms; see Cutler, 1973: 161) and then the tentacular crown with 12-30 tentacles, depending on the size of the worm.

The two broad retractor muscles originate from $50-70 \%$ of the distance to the posterior end of the trunk. The two nephridia open at the level of the anus, are otherwise unattached, and are about one-third the trunk length. A small caecum is usually present on the rectum and the coiled intestine is held in place by up to five fixing muscles.

Previous Japanese Records: None.

Material Examined: Horikoshi-Kabira Bay, Ishigakijima; coral reef; 1 spec.

Japanese Distribution: Only from the Yaeyama Islands.

Worldwide Distribution: Found from the Western Atlantic Ocean and Caribbean Sea to Brazil, the South Pacific, mainly in the Indonesian/Australian region.

\section{Nephasoma subhamata (Sluiter, 1902)}

Description: These 20 worms have pear-shaped to cylindrical trunks ranging in 
length from 4-20 mm, most or 10 less. The posterior end often exhibits transverse, concentric grooves and has a rounded tip. They are dark and rough on the anterior and posterior ends but often pale and translucent in the center section. There are numerous papillae at both ends of the trunk, generally dome-shaped or mammiform, sometimes becoming cylindrical on the base of the introvert. The number and form of these varies considerably from worm to worm. The introvert is variable in length but is usually longer than the trunk. There are 12-16 normal tentacles behind which is a zone of scattered, pointed hooks from $25-45 \mu$ in height.

Internally the single pair of retractor muscles originate in the mid-region of the trunk and the spindle muscle is not always apparent. The short rectum does not carry a caecum. The nephridia open at the level of the anus (occasionally a little anterior to it), are less than one-third the trunk length, and are otherwise unattached to the body wall.

Remarks: These specimens seem to fit Sluiter's description in most ways so we are assigning them to this taxon after some initial hesitation. An examination of the type material was not helpful as the worms available varied considerably and were not in very good condition. This is the first time since 1902 this name has been used. The depth of the two collections is comparable.

Previous Japanese Records: None.

Material Examined: Imajima-St. 153, slope of Senoumi, Suruga Bay; 435-590 m; 2/78; 2 spec. Horikoshi-St. $78-5$ BS14; $34^{\circ} 52^{\prime} \mathrm{N}, 139^{\circ} 28^{\prime} \mathrm{E} ; 1690 \mathrm{~m} ; 12 / 12 / 78 ; 2$ spec. St. $78-11$ OT8, 34 $4^{\circ} 55^{\prime} \mathrm{N}, 138^{\circ}$ $40^{\prime} \mathrm{E} ; 1020 \mathrm{~m} ; 7 / 15 / 78 ; 14$ spec. St. $78-11$ OT9, $34^{\circ} 55^{\prime} \mathrm{N}, 138^{\circ} 39^{\prime} \mathrm{E} ; 1585 \mathrm{~m} ; 7 / 15 / 78 ; 1$ spec. St. 79 $11 \mathrm{OT}_{4}, 34^{\circ} 56^{\prime} \mathrm{N}, 138^{\circ} 43^{\prime} \mathrm{E}$; $495 \mathrm{~m}$; 7/19/79; 2 spec.

Japanese Distribution: From deep water (435-1690 m) in Suruga Bay.

Worldwide Distribution: Only one other record from Malaya, from 1301 and $2053 \mathrm{~m}$.

\section{Nephasoma species}

Description: These five worms do not fit any existing description very well. The closest seems to be Golfingia mucida (Sluiter, 1902) which is known only from three specimens described almost 80 years ago from $1788 \mathrm{~m}$ off Malaya. However, it lacks the "felt-like covering" which may be an important feature; it may also be only a matrix of adhering sediment and not part of the animal itself. Hopefully, additional specimens will be found in future collections which will clarify the status of these worms. For the moment we will describe, but not name them.

These specimens have trunks 6-15 mm long which are thin-skinned and translucent in the mid-region but with thicker, light brown, rougher skin at each end. The papillae are large and dense at the two ends with shapes varying from cylindrical to dome-shaped, becoming smaller and scattered centrally. These papillae do extend out onto the introvert which is about equal to the trunk length. Hooks are absent but digitiform tentacles are present.

Internally the pair of retractor muscles originate about $60-70 \%$ of the distance 
to the posterior end of the trunk. The nephridia are $25-35 \%$ of the trunk length, open at the level of the anus but are otherwise unattached. No rectal caecum was found and the intestine is in the normal coiled configuration unattached posteriorly.

Material Examined: Imperial Household- \# 710, off Jogashima, Sagami Bay; 80-85 m; 2/1/62;1 spec. Imajima-St. 157, Sagami Bay; $34^{\circ} 44^{\prime} \mathrm{N}, 139^{\circ} 13^{\prime} \mathrm{E} ; 580 \mathrm{~m} ; 4$ spec.

\section{Genus Phascolion Theel, 1875}

Members of this genus commonly inhabit empty mollusc shells or similar structures and rarely exceed $30 \mathrm{~mm}$ in length (Fig. 4, A). Most species have complex trunk papillae (holdfasts or attachment papillae) with hardened chitinous borders of varying shapes (V, $U$ or circular). The anterior end of the trunk usually bears large, dark papillae and often epizoic hydrozoans, entoprocts or bryozoans. The introvert is tipped with a single row of tentacles around the mouth. Behind these is usually a bulbous area with hooks. The longitudinal muscle layer is continuous, a single nephridium is present, and the intestine usually forms a number of loose loops rather than a tight coil. The dorsal retractor muscle is usually a single, broad muscle and the ventral muscle, which is frequently bifurcated, is more variable: either equal in thickness to the dorsal, much thinner, or fused for most of its length to the dorsal so that it appears as a single retractor column. Contractile vessel is simple.
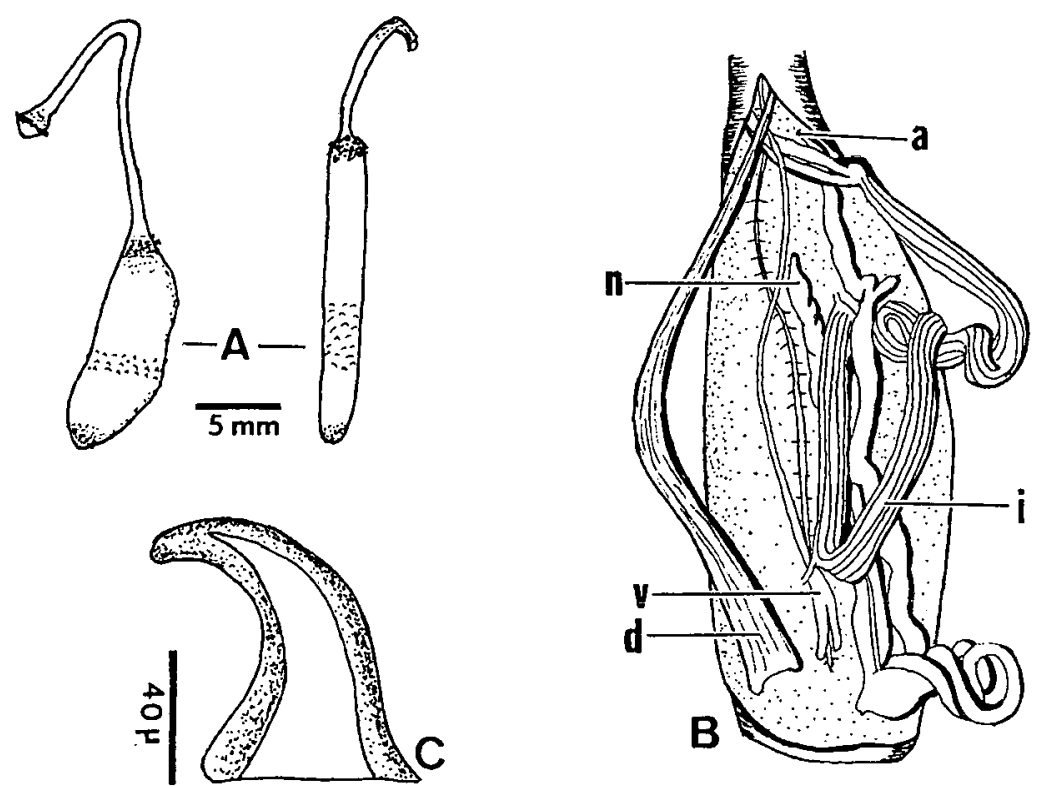

Fig. 4. Genus Phascolion. A: General form. B: Internal organs of $P$. strombi (a, anus; d, dorsal retractor muscle; $i$, intestine; $n$, nephridia; $v$, ventral retractor muscle straddling ventral nerve cord). C: Hook of $P$. cf. tuberculosum. 
Note: There are two species of Phascolion which have been reported from Japanese waters but not included in this paper $-P$. lucifugax and $P$. hedraeum. The first was reported by Selenka, DeMan and Bulow (1883) from Hokkaido; the second by Fischer (1895) from South Japan. Neither of these species has subsequently been reported from anywhere in the Pacific Ocean and due to the paucity of records and lack of any precise location data, we have arbitrarily omitted them. Not all of the Phascolion specimens placed at our disposal have been included due to their size, condition or uncertainty of affinity. The genus Phascolion is in need of a more exhaustive examination and review.

Key to the Phascolion species known from Japan

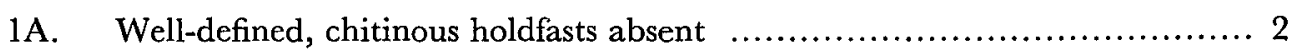

1B. Well-defined, chitinous holdfasts present ................................ 4

2A. Broad, large hooks present; two retractor muscles present ......P. tuberculosum

2B. Hooks absent; fused retractor column ................................ 3

3A. Anus at anterior end of trunk..................................... rectum

3B. Rectum extends out introvert and anus about 3/4 of distance towards the mouth (Pl. I, Fig. 4) ............................................. indicus

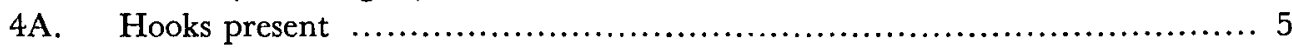

4B. Hooks absent .............................................. artificiosum

5A. Single retractor column only (sometimes with $2-3$ short roots) $\ldots \ldots \ldots \ldots \ldots 6$

5B. Dorsal and ventral retractor muscles separate........................... 7

6A. Holdfasts dark, V-shaped; 25-35 tentacles; from depths less than $100 \mathrm{~m}$... . P. ikedai

6B. Holdfasts pale, usually U-shaped; 10-16 tentacles; from depths greater

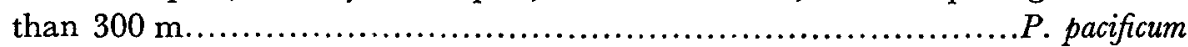

7A. Dorsal and ventral retractor muscles of equal dimensions; hooks straight and spine-like. P. dentalicolum

7B. Dorsal retractor muscle considerably larger than ventral (Fig. 4, B); hooks small and claw-like P. strombi

\section{Phascolion artificiosum Ikeda, 1904}

Description: This species, which inhabits empty gastropod and scaphopod shells is up to $40 \mathrm{~mm}$ long with introvert usually 1.5-2 times the trunk length. The trunk is pinkish tan to grey except at the anterior end where it is darker and carries papillae and occasionally epizoic hydrozoans. Chitinous U- or V-shaped holdfasts are distributed in the central third of the trunk. Hooks are absent, but 12-20 tentacles are present in mature worms. In a $5 \mathrm{~mm}$ worm there were 8-10 tentacles.

The undivided dorsal retractor muscle originates from the posterior end of the trunk while the two roots of the ventral muscle usually straddle the mid-ventral line posterior to the end of the ventral nerve cord. The short nephridium opens posterior to the anus (not anterior as mistakenly stated in Cutler and Cutler, 1981) and a rectal caecum is present. 
As pointed out in Cutler and Cutler (1981) this species differs only slightly from $P$. strombi (lacks hooks) and one must look carefully to discern the difference, especially in retracted specimens. This absence of hooks might be the result of predation and subsequent regeneration without hooks or a genetically programmed deciduous phenomena (Gerould, 1913). These individuals could represent only a variation within the common and plastic species $P$. strombi.

Previous Japanese Records: Ikeda, 1904 -Sagami Bay.

Material Examined: Imperial Household- 7949 , Mito-no-hana, Sagami Bay; 13 m; 7/27/64; 1 spec. Yasuda-St. $1,35^{\circ} 50^{\circ} \mathrm{N}, 135^{\circ} 40^{\prime} \mathrm{E} ; 210 \mathrm{~m} ; 6 / 12 / 79 ; 8$ spec. St. $9,36^{\circ} 20^{\prime} \mathrm{N}, 135^{\circ} 40^{\prime} \mathrm{E} ; 535$ $\mathrm{m} ; 6 / 14 / 79 ; 6$ spec. Imajima-St. 132, near Tsushima Island; $205 \mathrm{~m} ; 7 / 68 ; 1$ spec.

Japanese Distribution: In deep water in the Japan Sea off central Honshu and in the Pacific only from Sagami Bay.

Worldwide Distribution: Not found outside of Japan.

\section{Phascolion dentalicolum Sato, 1937}

Description: This species inhabits both gastropod and scaphopod shells despite its name (first found in scaphapod shells of the genus Dentalium). Most trunks measure less than $20 \mathrm{~mm}$ (one is $35 \mathrm{~mm}$ long), and usually have dark, barrel shaped papillae at the anterior end. The introvert is $50-75 \%$ of the trunk length carrying dark, bluntly-pointed, thorn-like hooks (see Cutler and Cutler, 1981), and from 12-20 digitiform tentacles. The chitinous holdfasts are either U-shaped or occasionally O-shaped and lack apical points. A noteworthy internal feature is that the two retractor muscles which originate near the posterior end of the trunk are of nearly equal size. The ventral muscle originates just past the end of the ventral nerve cord and may be offset to the left. The intestine is loosely coiled with several fixing muscles attaching it to the body wall.

Previous Japanese Records: Sato, 1937a -Onagawa Bay, Miyagi Pref.

Material Examined: Imperial Household— 530, Minami-Amadaiba, Sagami Bay; $150 \mathrm{~m} ; 1 / 19 / 60$; 1 spec. $\div 610$, off Jogashima, Sagami Bay; $150-250 \mathrm{~m} ; 6 / 3 / 60 ; 1 \mathrm{spec}$. $\# 990$, off Jogashima, 120-260 $\mathrm{m}, 2 / 15 / 66 ; 3$ spec. Horikoshi-St. $74-14 \mathrm{B9}, 35^{\circ} 02^{\prime} \mathrm{N}, 138^{\circ} 51^{\prime} \mathrm{E} ; 96 \mathrm{~m} ; 9 / 22 / 74 ; 1$ spec. Asamushi M.B.L. -3 stations $2 \mathrm{~km}$ offshore; $30 \mathrm{~m}$; in shells; 7/20/79; 7 spec.

Japanese Distribution: Found in northern Honshu from Mutsu Bay down the Pacific side to Sagami and Suruga Bays.

Worldwide Distribution: Recorded from the South Pacific and Tasman Sea plus one record from the west coast of South Africa.

\section{Phascolion ikedai Sato, 1930}

Description: This small species (less than $10 \mathrm{~mm}$ ) has been found in empty gastropod shells or in the base of solitary corals. It has a narrow band of dark, chitinous, $\mathrm{V}$-shaped holdfasts usually with a tooth-like projection. The introvert carries 
numerous small hooks and up to 35 slender tentacles. The two retractor muscles are fused for almost their entire length originating near the posterior end of the trunk. The nephridium opens anterior to the anus.

As discussed in Cutler and Cutler (1981) this species is not based on a firm foundation. In many ways it is similar to $P$. pacificum and may represent a few small, shallow-water individuals of this more common deep-water species. Additional material is needed to affirm the credibility of this species.

Previous Japanese Records: Sato, 1930 -Mutsu Bay, $30 \mathrm{fms.;} \mathrm{1937a-Onagawa,}$ Miyagi Pref., $34 \mathrm{~m}$.

Material Examined: Tohoku Univ., Sato's coll. 一年 8-32, east of Yushima, Mutsu Bay, in solitary co$\mathrm{ral} ; 7 / 19 / 30 ; 4$ spec.

Japanese Distribution: Known only from northern Honshu.

Worldwide Distribution: Recorded only from Japan.

\section{Phascolion indicus Murina, 1974}

(P1. I, Fig. 4)

Description: This species has neither introvert hooks nor holdfasts. The trunk length of these 17 specimens taken from gastropod and scaphopod shells ranges from $5-17 \mathrm{~mm}$. The introvert is $1.5-4$ times the trunk length giving it an Onchnesoma-like appearance. This is reinforced by the location of the anus: about 65$75 \%$ of the distance along the introvert towards the tentacles (Pl. I, Fig. 4). There are 6-8 short tentacles present around the mouth. The trunk papillae at the posterior end are usually digitiform, clavate, or cylindrical and at the anterior end they are dome-shaped and crowded together with a rough, dark appearance in some, typical of many other Phascolion. The overall color varies from very pale to dark grey.

Internally the retractor muscles are almost completely fused giving the appearance of a single muscle sometimes with two short roots at the posterior end of the trunk. The intestine is an irregular array of loops and loose coils. The single nephridium is short and attached only at the anterior end. The contractile vessel is reduced or absent.

Remarks: This species is very similar to, and sympatric with, $P$. rectum. The anus location is the only distinctive feature. It also is similar to some of the Japanese Onchnesoma but its molluscan habitat and differences in papillae can be used to differentiate these. Phascolion indicus was described from a single specimen which Murina (1974) compared to $P$. manceps and $P$. hupferi, all lacking hooks and holdfasts, having a single retractor muscle and with the anus displaced out on the introvert. Neither of these two species has been reported in this century. The existence of these forms does make the distinction between the genera Phascolion and Onchnesoma rather hard to define. Our attempts to locate the museum specimens of $P$. manceps 
were futile. A reexamination of $P$. hupferi revealed that the single retractor muscle actually extends well beyond the middle of the trunk (as originally stated) to near the posterior end. This makes the distinction between $P$. indicus and $P$. hupferi very difficult to express in words. They do look different: $P$. hupferi has a smooth, white, translucent, sometimes irridescent body wall with obvious dome-shaped papillae (skin bodies) present only at the anterior end. Often each papilla is situated within a rectangular area. Many of Fischer's (1895) worms had not been removed from their shells and at least two Aspidosiphon are present in the type bottle. Work in progress on this genus may lead to the transfer of this species to the genus Onchnesoma.

Previous Japanese Records: None.

Material Examined: Imperial Household- $\#$ 596, west of Kamekisyo, Sagami Bay; $250 \mathrm{~m} ; 6 / 2 / 60$; 1 spec. 7667 , off Kamekisyo; $200 \mathrm{~m}$; 3/15/61; 4 spec. 995 , off Jogashima, Sagami Bay; 82-83 m; 6/22/66; 1 spec. Cutler-St. 34, off Misaki, Sagami Bay; $90 \mathrm{~m} ; 5 / 25 / 79 ; 7$ sepc. St. 25, off Misaki, Sagami Bay; $80 \mathrm{~m} ; 5 / 25 / 79 ; 4$ spec.

Japanese Distribution: These have been found only in Sagami Bay at depths from 80 to $250 \mathrm{~m}$.

Worldwide Distribution: The only other record of this species is from the holotype $12^{\circ} 58^{\prime} \mathrm{S}, 122^{\circ} 27^{\prime} \mathrm{E}, 1010 \mathrm{~m}$ near Indonesia in the eastern Indian Ocean.

\section{Phascolion pacificum Murina, 1957}

Description: These 487 worms have trunk lengths ranging from 3-19 mm, most being around $10 \mathrm{~mm}$. They had been living in scaphopod or gastropod shells. Many of those from scaphopod shells have epizoic commensals (probably entoprocts and/or bryozoans) at the posterior end of the trunk. The skin is pale and smooth without large papillae except at the anterior end where they show the enlarged form typical of this genus. In most specimens these anterior papillae are mammiform to conical and dark, reddish brown, but in smaller worms they are pale tan or grey. Often the spaces between the individual papillae are filled with grey mud from the environment. This anterior end of the trunk sometimes is flattened rather than rounded when the introvert is withdrawn giving this area an unusual appearance, somewhat like an anal shield in Aspidosiphon.

Holdfasts (attachment papillae) are present but are very pale and indistinct on most worms. They usually occupy the middle $20-30 \%$ of the trunk but may shift posteriad to the fourth quintile $(60-80 \%)$ of the trunk. The density and pigmentation of these structures are quite variable. The chitinized rim of the holdfast is generally U-shaped or crescentric but tends towards a V-shape in some and a few exhibit a small tooth or apical spine-like point, but this is rare.

The introvert, which is about the same length as the trunk in the extended state, bears relatively few tentacles for this genus. Simple, claw-like hooks are present but they are small $(20-30 \mathrm{~mm})$, almost transparent, and few in number. In animals 
with retracted introverts they are very difficult to find as they get embedded in the folds of skin.

Internally the retractor muscles are fused into a single column for most of their length. They originate from very near the posterior end of the trunk and exhibit one, two or three separate origins, the remnants of the separate dorsal and ventral muscles. The intestine has a few irregular coils and several loops typical of this genus. One or sometimes two fixing muscles are present. A small, digitiform rectal caecum is present and the anus opens just a little anterior to the nephridiopore. The single nephridium is about one-third as long as the trunk. It appears at first to be unattached along its length to the body wall but on closer inspection one finds a connective tissue sheet along most of its length which forms a continuous but loose and fragile connection.

Previous Japanese Records: Murina, 1957 -Japanese trench, $38^{\circ} \mathrm{N}, 144^{\circ} \mathrm{E}$.

Material Examined: Collected by Horikoshi from Suruga Bay: St. $76-0300334^{\circ} 56^{\prime} \mathrm{N}, 138^{\circ} 44^{\prime} \mathrm{E}$; $373 \mathrm{~m} ; 2 / 27 / 76 ; 185$ spec. St. $76-16 \mathrm{~T}-23^{\circ} 55^{\prime} \mathrm{N}, 138^{\circ} 44^{\prime} \mathrm{E} ; 297 \mathrm{~m} ; 9 / 23 / 76 ; 85$ spec. St. $78-02 \mathrm{~B}$ $35^{\circ} 04^{\prime} \mathrm{N}, 138^{\circ} 47^{\prime} \mathrm{E} ; 335 \mathrm{~m} ; 2 / 10 / 78 ; 2$ spec. St. $78-11$ B $35^{\circ} 04^{\prime} \mathrm{N}, 128^{\circ} 47^{\prime} \mathrm{E} ; 450 \mathrm{~m} ; 7 / 14 / 78 ; 2$ spec. St. $78-11$ SW $34^{\circ} 41^{\prime} \mathrm{N}, 138^{\circ} 23^{\prime} \mathrm{E} ; 530 \mathrm{~m} ; 7 / 17 / 78 ; 1$ spec. St. $78-11$ OT2 $34^{\circ} 56^{\prime} \mathrm{N}, 138^{\circ} 44^{\prime} \mathrm{E} ; 315$ $\mathrm{m} ; 7 / 13 / 78 ; 1$ spec. St. $78-11$ OT3 $34^{\circ} 56^{\prime} \mathrm{N}, 138^{\circ} 43^{\prime} \mathrm{E} ; 392 \mathrm{~m} ; 7 / 13 / 78 ; 11$ spec. St. $78-11$ OT 4 $34^{\circ} 56^{\prime} \mathrm{N}, 138^{\circ} 43^{\prime} \mathrm{E} ; 495 \mathrm{~m}$; $7 / 13 / 78 ; 4$ spec. St. $78-18$ OT10 $34^{\circ} 54^{\prime} \mathrm{N}, 138^{\circ} 43^{\prime} \mathrm{E} ; 404 \mathrm{~m} ; 11 / 20 / 78$; 190 spec. St. $78-18$ OT $1134^{\circ} 55^{\prime} \mathrm{N}, 138^{\circ} 43^{\prime} \mathrm{E}$; $532 \mathrm{~m} ; 11 / 23 / 78 ; 3$ spec. St. $78-5$ BS14 $34^{\circ} 52^{\prime} \mathrm{N}$, $139^{\circ} 28^{\prime} \mathrm{E}$; $1690 \mathrm{~m}$; $12 / 12 / 78 ; 2$ spec. St. $73-15 \mathrm{~V} 34^{\circ} 51^{\prime} \mathrm{N}, 139^{\circ} 27^{\prime} \mathrm{E} ; 1680 \mathrm{~m} ; 10 / 31 / 73 ; 1$ spec.

Japanese Distribution: This species has been found in Suruga Bay at depths between $300-1700 \mathrm{~m}$ and in the Japanese Trench at 5100-6100 $\mathrm{m}$.

Worldwide Distribution: A deep water species from several sub-Antarctic localities of all three Oceans, the northwest Pacific and one record in the Caribbean at $5800 \mathrm{~m}$.

\section{Phascolion rectum Ikeda, 1904}

Description: Most of these 11 specimens are 2-10 $\mathrm{mm}$ long with one having a 20 $\mathrm{mm}$ trunk. They lack both holdfasts and introvert hooks. The introvert is 1-1.5 times the trunk length and the trunk is often rough, with dense papillae at the anterior end, generally pale grey in color, and a few have epizoans around the anterior end of the trunk.

The dorsal and ventral retractors are almost completely fused together except for a slight separation in some at the posterior end of the trunk giving the appearance of a single muscle column. The anus opens at the anterior end of the trunk with the single nephridium opening just posterior to it, being otherwise unattached to the body wall. The intestine has both irregular loops and coils.

Remarks: This species is very similar to $P$. indicus and the only obvious difference is that the anus is located on the introvert in $P$. indicus. Finding the anus is not an easy task, especially in small worms from gastropod shells which have a retracted introvert. Those worms designated by Cutler \& Cutler (1981) as neotype and paraneotype are really $P$. indicus, not $P$. rectum. 
Previous Japanese Records: Ikeda, 1904 -Sagami Bay.

Material Examined: Imperial Householdspec. $\# 997$, off Jogashima, Sagami Bay; $130-230 \mathrm{~m} ; 6 / 24 / 66 ; 1 \mathrm{spec}$. Horikoshi-St. 78-11 OT11 (II), Suruga Bay $34^{\circ} 58^{\prime} \mathrm{N}, 138^{\circ} 45^{\prime} \mathrm{E} ; 185 \mathrm{~m} ; 7 / 13 / 78 ; 1$ spec. Hayashi-St. W-172, off Wakasa; 120 $\mathrm{m} ; 8 / 27 / 78 ; 1$ spec. Cutler-St. 2, off Misaki, Sagami Bay; $30 \mathrm{~m} ; 3 / 13 / 79 ; 1$ spec. St. 4, off Misaki, Sagami Bay; $40 \mathrm{~m} ; 3 / 13 / 79 ; 6$ spec.

Japanese Distribution: Most found in Sagami and Suruga Bays at depths from 30$230 \mathrm{~m}$. There is only one record elsewhere in Japan and that is Wakasa Bay.

Worldwide Distribution: Not reported outside of Japan.

\section{Phascolion strombi (Montague, 1804)}

(Fig. 4, B)

Description: This species has been reported over 60 times in the literature but not from Japanese waters. It is a very plastic form and the morphological variations have been discussed in Cutler (1973). The recent appearance of almost 200 specimens is undoubtedly due to the more intensive deep water dredging done by several Japanese biologists and their close examination of gastropod and scaphapod shells which house these worms.

This population ranges in trunk length from $3-30 \mathrm{~mm}$ with introverts longer than the trunk. At the anterior end of the trunk are coarse papillae and sometimes epizoic entoprocts or hydrozoans. The chitinous holdfasts are U- or V-shaped and usually located in the posterior third of the body, commonly in a narrow belt but sometimes broadly dispersed. Towards the anterior end of the trunk circular, partially chitinized papillae are sometimes found. The introvert bears numerous claw-like hooks on a swollen bulbous region (if expanded) near the tentacular crown.

The broad dorsal retractor muscle is usually undivided and the very thin ventral retractor muscle usually has two roots which most often straddle the ventral nerve cord (Fig. 4, B). The nephridium opens at or very near the level of the anus and the intestine is arranged in a series of irregular loops. Several worms from St. 78$18 \mathrm{~B}$ lacked introverts and some with introverts seemed to lack introvert hooks. The introvert is especially accessible to predators and we are assuming that during regeneration, hook production may be delayed.

Previous Japanese Records: None.

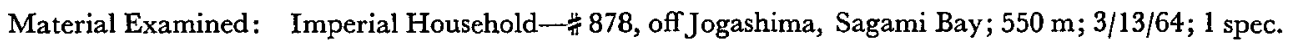
Hayashi-St. TA-9-26, Tango-kai, Wakasa Bay; $68 \mathrm{~m}$; 7/26/76; 1 spec. Imajima-St. 141, Suruga Bay, $34^{\circ} 46^{\prime} \mathrm{N}, 138^{\circ} 42^{\prime} \mathrm{E} ; 320 \mathrm{~m} ; 1$ spec. St. 145 , Suruga Bay, $35^{\circ} 05^{\prime} \mathrm{N}, 138^{\circ} 48^{\prime} \mathrm{E} ; 300 \mathrm{~m} ; 6 / 77 ; 26$ spec. St. 161, Tosa Bay; dredged at $500 \mathrm{~m} ; 7 / 74 ; 1$ spec. St. 163, off Abashiri, Hokkaido; $100 \mathrm{~m}$; 10/77; 1 spec. Cutler-St. 24, 25, 26, off Misaki, Sagami Bay at 90, 80, \& $10 \mathrm{~m} ; 5 / 25 / 79 ; 3$ spec. Horikoshi-collected in Suruga Bay: St. 73-15-D $34^{\circ} 46^{\prime} \mathrm{N}, 138^{\circ} 43^{\prime} \mathrm{E} ; 314 \mathrm{~m} ; 10 / 19 / 73 ; 1$ spec. St. 74-14-B10 $35^{\circ} 05^{\prime} \mathrm{N}, 138^{\circ} 47^{\prime} \mathrm{E} ; 305 \mathrm{~m} ; 9 / 22 / 74 ; 1 \mathrm{spec}$. St. 75-15 B $35^{\circ} 04^{\prime} \mathrm{N}, 1^{\prime} 8^{\circ} 47^{\prime} \mathrm{E} ; 279 \mathrm{~m}$; $11 / 24 / 75 ; 1$ spec. St. 76-03 $00334^{\circ} 56^{\prime} \mathrm{N}, 138^{\circ} 44^{\prime} \mathrm{E} ; 373 \mathrm{~m} ; 2 / 27 / 76 ; 13$ spec. St. $76-0300634^{\circ} 46^{\prime}$ $\mathrm{N}, 138^{\circ} 42^{\prime} \mathrm{E} ; 276 \mathrm{~m} ; 2 / 28 / 76 ; 2$ spec. St. $76-16 \mathrm{~T}-234^{\circ} 55^{\prime} \mathrm{N}, 138^{\circ} 44^{\prime} \mathrm{E} ; 297 \mathrm{~m} ; 9 / 23 / 76 ; 46$ spec. 
St. $76-16 \mathrm{~T}-334^{\circ} 55^{\prime} \mathrm{N}, 138^{\circ} 42^{\prime} \mathrm{E} ; 647 \mathrm{~m} ; 9 / 23 / 76 ; 1$ spec. St. $78-11$ B $35^{\circ} 04^{\prime} \mathrm{N}, 138^{\circ} 47^{\prime} \mathrm{E} ; 450 \mathrm{~m}$; $7 / 14 / 78$; 3 spec. St. $78-11$ OT $134^{\circ} 56^{\prime} \mathrm{N}, 138^{\circ} 44^{\prime} \mathrm{E} ; 200 \mathrm{~m}$; 7/13/78; 1 spec. St. $78-11 \mathrm{OT}^{3} 34^{\circ} 56^{\prime}$ $\mathrm{N}, 138^{\circ} 43^{\prime} \mathrm{E} ; 392 \mathrm{~m}$; 7/13/78; 8 spec. St. 78-18 OT7 $34^{\circ} 55^{\prime} \mathrm{N}, 138^{\circ} 45^{\prime} \mathrm{E} ; 153 \mathrm{~m} ; 11 / 20 / 78 ; 8$ spec. St. $78-18$ OT $1034^{\circ} 54^{\prime} \mathrm{N}, 138^{\circ} 43^{\prime} \mathrm{E}$; $404 \mathrm{~m} ; 11 / 20 / 78 ; 10 \mathrm{spec}$. St. $78-18$ OT11 $34^{\circ} 55^{\prime} \mathrm{N}, 138^{\circ} 43^{\prime} \mathrm{E}$; $532 \mathrm{~m} ; 11 / 23 / 78 ; 1$ spec. St. $78-18$ B $35^{\circ} 03^{\prime} \mathrm{N}, 138^{\circ} 47^{\prime} \mathrm{E} ; 272 \mathrm{~m} ; 11 / 19 / 78 ; 37$ spec. St. $78-18$ OT8 $34^{\circ} 55^{\prime} \mathrm{N}, 138^{\circ} 44^{\prime} \mathrm{E} ; 200 \mathrm{~m} ; 11 / 20 / 78 ; 15$ spec. St. $79-11$ OT $434^{\circ} 47^{\prime} \mathrm{N}, 138^{\circ} 42^{\prime} \mathrm{E} ; 450 \mathrm{~m}$; $7 / 19 / 79 ; 9$ spec.

Japanese Distribution: Most records are from Suruga and Sagami Bays from 80$650 \mathrm{~m}$, plus one record each from south of Shikoku, Wakasa Bay, and off Hokkaido. Worldwide Distribution: This is a very common and eurytopic North Atlantic and Arctic species also found in deep water in the Caribbean. There are scattered reports from the Mediterranean, Red Sea, and the Gulf of Aden. There are two Antarctic records and off Argentina and Chile. This latter one is the only other Pacific Ocean record.

\section{Phascolion sp. (cf. tuberculosum Theel, 1875)}

(Fig. 4, C)

Description: These four worms (10-15 mm long, large one from a gastropod shell) fit in a general way the characteristics of this species but we hesitate to use the name. If more individuals can be found which compare well then the uncertainty could be removed.

These lack chitinous holdfasts, possess a pair of retractor muscles which are of approximately equal size, and a rectal caecum. The introvert is about one half the trunk length with 12-16 short tentacles. The large, dark, broad curved hooks are the most distinctive feature of this species (Fig. 4, C).

Previous Japanese Records: None.

Material Examined: Imperial Household-7 1012, off Jogashima, Sagami Bay; 93-97 m; 1/21/67; 1 spec. Horikoshi-St. $78-11$ OT6 (II), $35^{\circ} 03^{\prime} \mathrm{N}, 138^{\circ} 50^{\prime} \mathrm{E} ; 112 \mathrm{~m} ; 7 / 14 / 78 ; 3 \mathrm{spec}$.

Japanese Distribution: Suruga and Sagami Bays.

Worldwide Distribution: P. tuberculosum is found between 1100 and $2700 \mathrm{~m}$ only in the Northeast Atlantic with one record off Argentina.

\section{Genus Onchnesoma Koren \& Danielssen, 1875}

Adults usually less than $8 \mathrm{~mm}$ long with introverts thin and several times longer than the trunk (Fig. 5, A). Tentacles few and small or reduced to an oral lobe. Anus located well out on introvert, often just behind the head region. One retractor muscle and a single nephridium.

Key to the Onchnesoma species known from Japan

1A. Posterior of trunk with papillae randomly arranged (Fig. 5, B); tentacles present; retractor muscle with two short roots................... O. squamatum 

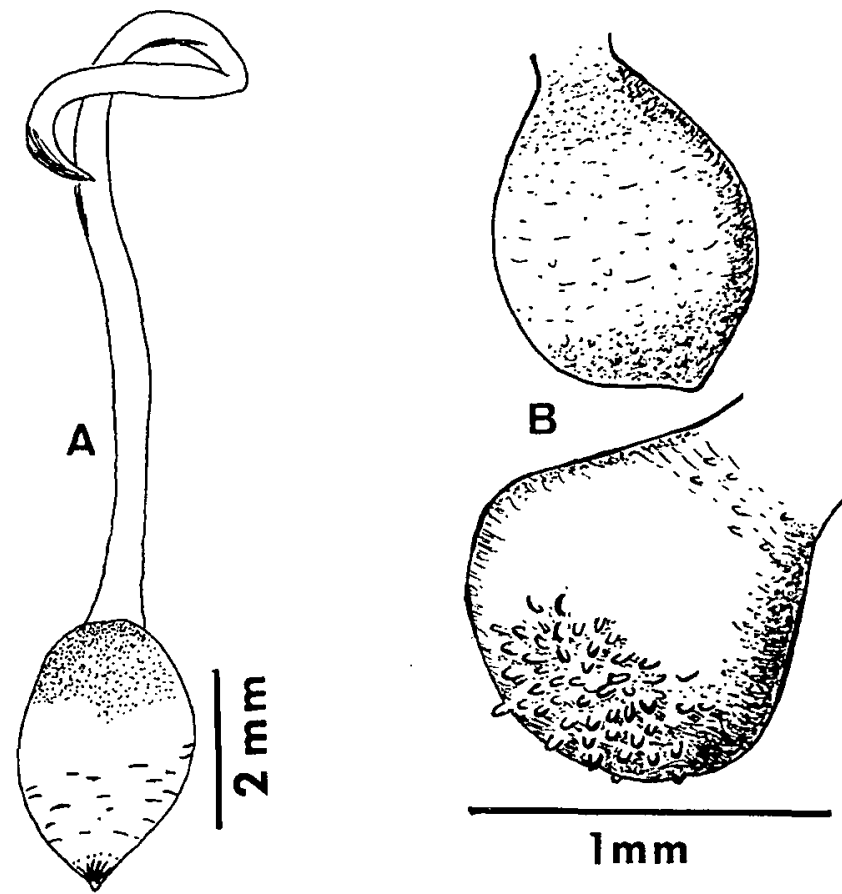

Fig. 5. Genus Onchnesoma. A: General form. B: Posterior trunk of O. suqamatum oligopapillosum subsp. nov.

1B. Posterior of trunk with papillae in radiating rows (keels); tentacles absent; retractor muscle with one root....

O. steenstrupii

\section{Onchnesoma steenstrupii Koren \& Danielssen, 1875}

Description: These six worms have spheroidal or pear-shaped trunks about $2 \mathrm{~mm}$ long (elsewhere up to $4 \mathrm{~mm}$ ) with the very thin introverts partially retracted (may be 5-10 times the trunk length when everted). The tentacular apparatus is reduced to an oral lobe or disc. The posterior third to half of the trunk has 20-30 radiating ridges or keels made up of tiny flattened papillae merging at the apex, which is sometimes pointed. This population differs from the Atlantic Ocean ones in that these scale-like papillae are smaller.

Internally what appears to be a single retractor muscle originates from one root at the posterior end of the trunk. The intestine is irregularly looped and coiled and the single nephridium is fixed to the body wall only at its anterior end. The long rectum leads to the anus which is located on the introvert, only a short distance behind the mouth.

Previous Japanese Records: None.

Material Examined: Imajima-St. 160, off Chikura, Boso Pen.; $130 \mathrm{~m} ; 9 / 76 ; 6$ spec.

Japanese Distribution: Only one record off the Boso Peninsula. 
Worldwide Distribution: Common at depths between $100-1000 \mathrm{~m}$ in the East Atlantic especially around the British Isles and Scandinavia, down to Angola and South Africa. In the western Atlantic found from Cape Cod to Georgia. There are scattered records also from the Mediterranean and Tasman Seas and South Pacific Ocean. This is the first record from the North Pacific. Its small size probably accounts for its having been overlooked in the past.

\section{Onchnesoma squamatum oligopapillosum subsp. nov.}

(Fig. 5, B)

Description: Two individuals are designated as type-series, deposited with Dr. Imajima at the National Science Museum, Tokyo. The holotype (NST-Si-1172) has a $4 \mathrm{~mm}$ long trunk while the paratype (NSMT-Si-1173) is $3 \mathrm{~mm}$. The introverts of both are 3 times the trunk length. There are 6 flat, pointed tentacles. The anterior $1 / 5$ of the trunk is densely covered with slender papillae (can be up to $70 \mu$ tall, but most shorter and stouter). The posterior end of the trunk has small, scattered, flat scale-like papillae. The middle $2 / 5$ of the trunk is smooth. The anus is located about $75 \%$ of the distance out towards the tip of the introvert. The proximal end of the introvert has concentric furrows, probably due to strong circular muscle contraction. Internally the retractor muscle has two short origins at the posterior end of the trunk. The single nephridium is slender, about $1 / 2$ the trunk length, and attached only at the anterior end. The long intestine is irregularly coiled and looped.

The other ten specimens have $1.5-3 \mathrm{~mm}$ trunks with introverts $2.5-4$ times the trunk length. Tentacle-number range is $4-6$. The anus location ranges from $70-80 \%$ of the distance to the introvert tip. The posterior ends of the trunks are flattened in most and in a few the scale-like papillae are arranged in an indistinct radial pattern (Fig. 5, B). Otherwise, these ten share the common characters of the type.

Remarks: At first glance these worms seem similar to $O$. steenstrupii in general form. However, the papillae are not arranged in keels and other differences are significant. Its kinship with $O$. squamatum is shown by the presence of tentacles, the anus location, two retractor roots, and the introvert length. The sole difference lies in the size and number of papillae. In the nominate form these are large and densely packed, while in this population they are small and sparsely distributed. A critical review of O. intermedium (Murina, 1976) from the East China Sea, may show it to be more closely related to $O$. squamatum than originally proposed.

Previous Japanese Records: None.

Material Examined: Imperial Household60; 1 spec. Imajima-Kushimoto, Wakayama Pref.; $35 \mathrm{~m} ; 2$ spec. (type-series). Kosaka-St. 37, Suruga Bay off Yui-Yaizu; $23 \mathrm{~m} ; 6 / 25 / 71 ; 1$ spec. St. 40, Suruga Bay off Yui-Yaizu; $14 \mathrm{~m} ; 6 / 26 / 71$; 1 spec. St. 50, off Uchiura Wan/Yui; $88 \mathrm{~m} ; 9 / 29 / 71 ; 6$ spec. 
Japanese Distribution: Found off Honshu in Sagami and Suruga Bays and one location off Wakayama, from 14-250 m.

Worldwide Distribution: This seems to be a North Atlantic species found on both sides of the ocean - on the east from the North Sea to Spain, on the west from the Carolinas to Florida. There are also a few records from the Mediterranean Sea. This present work is the only record of this species from the Pacific Ocean.

\section{Genus Themiste Grey, 1828}

Trunk relatively smooth and usually pear-shaped but varies from cylindrical to globose (Fig. 6, A). Many tentacles arising from 4-8 primary stems and branching in a pinnate or palmate fashion (therefore, the one-time name of Dendrostomum). Large hooks may be present on the introvert which is usually less than half the trunk length. Longitudinal musculature is continuous and two retractor muscles are present. Spindle muscle does not attach to the posterior of the trunk and there are two free nephridia. The contractile vessel has villi of variable number and
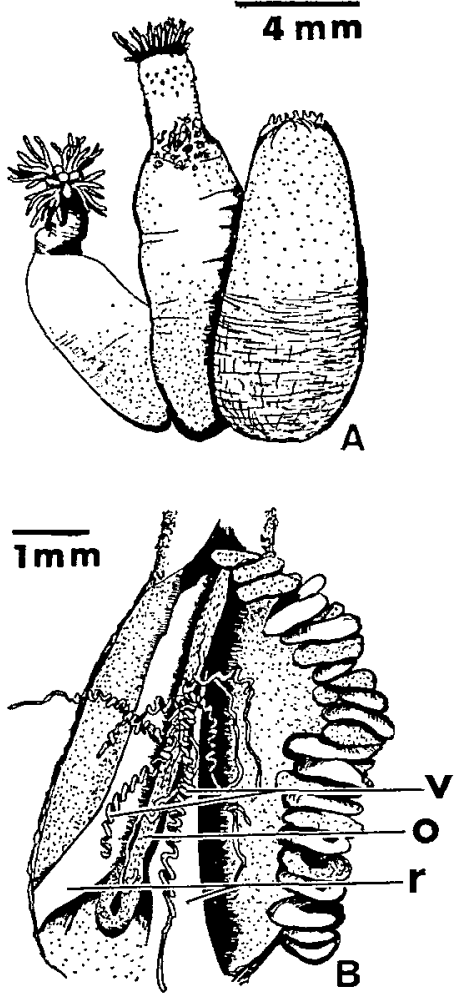
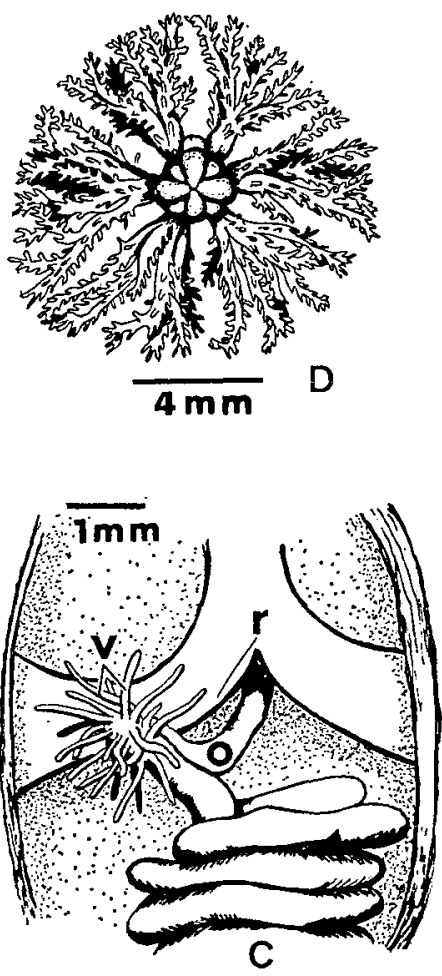

Fig. 6. Genus Themiste. A: General form with introvert in various stages of retraction. B: Internal view of Themiste sp. with long contractile vessel villi (v). C: Themiste sp. with short villi (v). D: Tentacular crown of T. hexadactyla from which phylum derived its common Japanese name (hoshimushi). (o, oesophagus; $r$, retractor) 
length but usually well developed.

Note: This genus was recently subdivided into three subgenera by Edmonds (1980). Members of this genus can be mistaken for Golfingia if the tentacles are not examined.

Key to the Themiste species known from Japan

1A. Tubular extensions of contractile vessel long (more than $2 \mathrm{~mm}$ ) (Fig. 6, B) and thread-like-subgenus Themiste s.s. ................................ 2

1B. Tubular extensions of contractile vessel short (less than $2 \mathrm{~mm}$ ) (Fig. 6, C) and finger-like-subgenus Lagenopsis ................................ 3

2A. Tentacular crown with six primary stems; adults often well over $25 \mathrm{~mm}$ up to $180 \mathrm{~mm}$.............................................. . hexadactyla

2B. Tentacular crown with four primary stems; adults usually less than 25

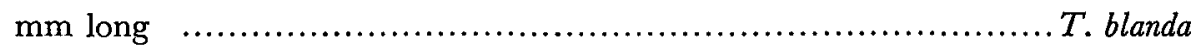

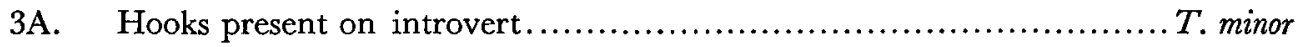

3B. Hooks absent from introvert ......................................... 4

4A. Subtidal, central Honshu; trunk slender (up to $80 \mathrm{~mm}$ )........... elliptica

4B. Intertidal, Ryukyu Islands; trunk stout (up to $30 \mathrm{~mm}$ ).......T. lageniformis

\section{Themiste (Lagenopsis) elliptica (Sato, 1934)}

Description: This species has a slender, cylindrical trunk, $80 \mathrm{~mm}$ long with no hooks present on the introvert which is one-fifth the trunk length. The contractile vessel has short, digitiform villi on it. The nephridia open posterior to the anus and there are four main tentacular stems. Elliptical trunk papillae are present and are all that seem to distinguish this from $T$. dehamata.

As noted in Cutler and Cutler (1981) this species is still known from only Sato's single specimen which cannot be located and is, in most ways, very similar to $T$. dehamata from Australia and T. fisheri from Argentina (see Edmonds, 1980: 35).

Previous Japanese Records: Sato, 1934a-51 m in Suruga Bay.

Material Examined: None.

Japanese Distribution: Only one specimen Sato collected at $51 \mathrm{~m}, 34^{\circ} 44^{\prime} \mathrm{N}, 138^{\circ}$ 30' E, Suruga Bay.

Worldwide Distribution: Known only from the holotype.

\section{Themiste (Lagenopsis) lageniformis Baird, 1868}

Description: This widespread species (formerly $T$. signifer) usually has a subspherical trunk less than $30 \mathrm{~mm}$ long. The introvert is about one-third the trunk length and somewhat darker. The tentacular crown arises from four stems which branch into many fine, slender, white tentacles. The internal organs are typical for this genus with numerous short contractile vessel villi.

Sato (1939) described several specimens of Golfingia pyriformis which we were 
able to examine in Sendai. These worms were all strongly retracted but they are clearly Themiste and most probably this species. The anus and nephridiopore are not on the introvert as Sato stated. The tentacles, when dissected out, are dendritically branched which points to the difficulty in separating these two genera when the tentacles are not showing. We did not see Sato's specimens from the Ryukyus but presume they are the same as those from Formosa.

Stephen and Edmonds (1972: 205) and Edmonds (1980: 33, 42) discuss the systematic problems related to this species and several very similar species. More clarification is needed.

Previous Japanese Records: Ikeda, 1904 -Ryukyu Islands (identified as Dendrostoma signifer); Sato, 1939 -Miyako and Naha, Ryukyu Islands (identified as Phascolosoma pyriformis).

Material Examined: Tohoku Univ., Sato's coll.- 3-13, Kirun, Formosa, 3/28/36; identified as $P$. pyriformis. NMNH, Washington- 121354, Japan; 1 spec.

Japanese Distribution: This is found only in the Ryukyu Islands.

Worldwide Distribution: This is widely distributed in the Indo-West Pacific region (one record from Hawaii) with additional records from the Gulf of Guinea and southwest Africa. One record from Tristan de Cunha in the south Atlantic seems unlikely and the description is too incomplete to evaluate (Wesenberg-Lund, 1963).

\section{Themiste (Lagenopsis) minor (Ikeda, 1904)}

Description: This most common intertidal, central Honshu Themiste is easily identified by the presence of introvert hooks and the short, digitiform contractile vessel villi. As the name implies, they are small, usually $5-10 \mathrm{~mm}$ but up to $15 \mathrm{~mm}$ trunks have been reported. The introvert is about one-third the trunk length. The tentacles arise from four stems and may be white or with varying amounts of violet pigment. The two retractor muscles originate in the middle of the trunk and the rectum bears a caecum.

This species, together with $T$. huttoni and $T$. fusca form a complex of very similar forms (see Edmonds, 1980: 40; Cutler and Cutler, 1981). Themiste minor may simply be the northern hemisphere and the others the southern hemisphere representatives of a single species.

Previous Japanese Records: Ikeda, 1904 -Oga, Akita Pref.; Izu-Oshima; Misaki; Tanegashima Island.

Material Examined: Univ. of Tokyo, Ikeda's coll.--type, Aug. 1901 (dried up) ; 5 spec. Nishino-omote, Tanegashima; 1/1/03; 3 spec. Nishikawa-St. 35, near Seto M.B.L.; Wakayama Pref. 5/15/74; 2 spec. Cutler-St. 8 Matsugahana, Mukaishima M.B.S., Hiroshima Pref.; crevices in granite; 4/7/79; 33 spec. St 21, Misaki M.B.S; intertidal; 4/28/79; 3 spec. St. 29, Tateyama, Boso Pen., $1 \mathrm{~km} \mathrm{~W}$ of Ochanomizu M.B.L.; 6/12/79; 1 spec. St. 34, Kurosaki, Miura Pen.; 6/25/79; 1 spec.

Japanese Distribution: Found in several locations around Sagami Bay, off Wakayama Prefecture, in the Inland Sea near Onomichi and then Ikeda's record from Tanegashima Island. 
Worldwide Distribution: This Japanese species has also been reported from Fukien, China; several locations off South Africa and in the Mozambique Channel; from the Tasman Sea, New Zealand, and off Southern Argentina.

\section{Themiste (Themiste) blanda (Selenka, DeMan \& Bulow, 1883)}

Description: These small worms are usually less than $25 \mathrm{~mm}$ long with introverts about 1/3-1/2 the trunk length and bearing large, dark hooks. The complex tentacular crown has four main branches. A small caecum is present on the rectum of Sato's specimen \#7-26 which he overlooked. The long, thin, branched contractile vessel tubules and other internal organs are like those in $T$. hexadactyla. These two species are very similar (as is $T$. alutacea) and what has been called $T$. blanda may be simply small $T$. hexadactyla. The differences in number of tentacular stems is not easy to discern but for the moment we shall retain both names. This issue is also discussed in Stephen and Edmonds (1972: 203) and in Cutler and Cutler (1981).

Previous Japanese Records: Selenka et al., 1883 -Enoshima. Ikeda, 1904 -Aomori and Wakkanai, Hokkaido; 1924 -Hokkaido. Sato, 1930 -Mutsu Bay; 1937a -Onahama, Fukushima Pref.

Material Examined: Shigei-Chosi, Chiba Pref.; intertidal; 4/29/79; 1 spec. Nishikawa-St. 23, off Gobo, Wakayama Pref.; 5 m; 5/78; 32 spec. Tohoku Univ., Sato's coll.-- 7-26, Cape Amitori, Onahama, Fukushima Pref.; 1 spec.

Japanese Distribution: This species is found on both sides of Honshu as well as Hokkaido.

Worldwide Distribution: Outside of Japan there is one record in the Pacific from California. A single specimen reported from off Cuba (Murina, 1968) seems unlikely given its absence from other very extensive collections made in that area. However, there have been numerous reports of $T$. alutacea which, as noted above, is very similar and these two species may be the same.

\section{Themiste (Themiste) hexadactyla (Sato, 1930)}

(Fig. 6, D)

Description: These large worms (commonly $40-60 \mathrm{~mm}$ but up to $180 \mathrm{~mm}$ trunks) have large and elaborate tentacular crowns (Fig. 6, D) and scattered dark hooks around the introvert. The tentacles come from six main stems but this is not always easy to discern, especially in contracted specimens. The introvert is about $1 / 3-1 / 2$ the trunk length.

The pair of large retractor muscles originate about $2 / 3$ of the distance to the posterior end of the trunk and the nephridia open at the level of the anus. The numerous long, thin tubules from the contractile vessel are sometimes spirally coiled and tangled in the gut coils. 
Previous Japanese Records: Sato, 1930 -Mutsu Bay; 1937a -Mutsu Bay; Oya and Karakuwa, Miyagi Pref.; Takada, Iwate Pref. Okuda, 1946 -Akkeshi, Hokkaido.

Material Examined: Tohoku Univ., Sato's coll.-一G26, type plus six vials of many spec. Akkeshi M.B.L., Hokkaido; 7/11/68; 2 spec.

Japanese Distribution: This is found in northeast Honshu, especially numerous in Mutsu Bay and from Akkeshi Bay, Hokkaido.

Worldwide Distribution: The only report outside of Japan is Fisher (1952) from southern California.

\section{Genus Thysanocardia (Fisher, 1950)}

Trunk cylindrical with long, tapering introvert generally twice as long as trunk. Oral disc complex with numerous tentacles: dorsally enclosing nuchal organ and a peripheral set surrounding mouth (Fig. 8). The peripheral tentacles are grouped in paired rows and additional tentacles are developed posteriorly to form 'festoons' extending down anterior-most part of introvert. No hooks on introvert. Skin wrinkled and often folded into longitudinal zig-zag lines. Nephridiopores ventrolateral, anterior to anus. Two retractor muscles originating in posterior half of trunk. Contractile vessel bears numerous villi. Spindle muscle unattached posteriorly.
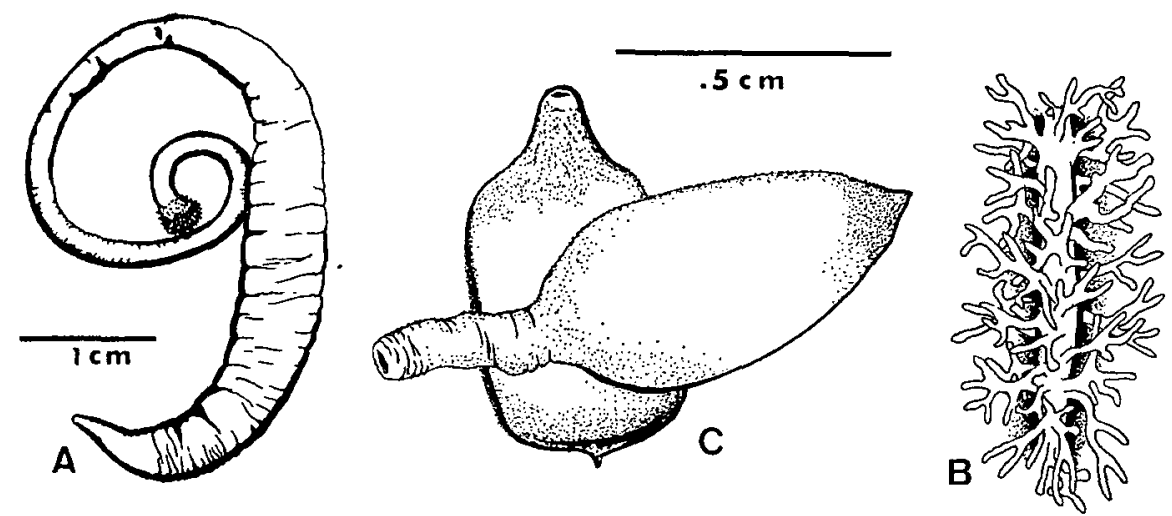

Fig. 7. Genus Thysanocardia. A: General form of T. nigra. B: Enlargement of contractile villi of T. nigra. G: General from of Thysanocardia species.

Remarks: This taxon was originally proposed as a Golfingia subgenus by Fisher (1950) but a recent study by Gibbs, Cutler and Cutler (1983) has elevated it to generic rank. This same work redefines the species in this group such that only one described species is represented in the Japanese fauna. T. zenibakense and T. hyugensis are now considered to be junior synonyms of T. nigra. A small population of a yet unnamed species is also reported. 


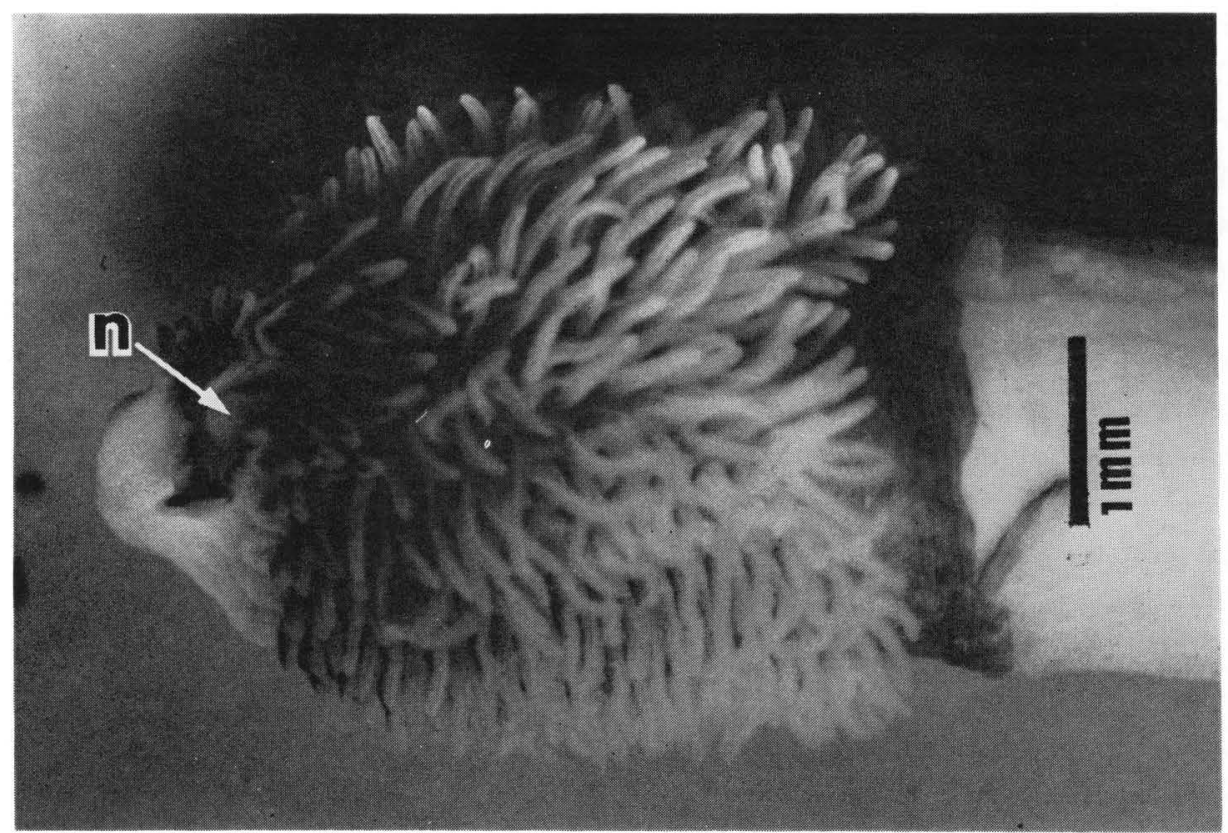

Fig. 8. Thysanocardia nigra. Tentacle crown showing nuchal organ (n).

Key to Thysanocardia species known from Japan

1A. Tentacles with pigment spots; retractor muscles originate in third quarter $(50-75 \%)$ of trunk and cylindrical shape; intertidal and shallow water $(0-30 \mathrm{~m})$ T. nigra

1B. Tentacles without pigment spots; retractor muscles originate in posterior quarter $(75-95 \%)$ of the trunk; spheroid shape; deeper waters (over

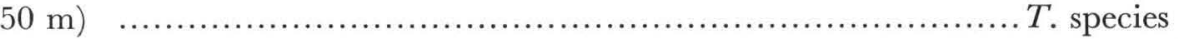

\section{Thysanocardia nigra (Ikeda, 1904)}

(Fig. 7, A-B; Fig. 8; Pl. II, Fig. 1)

Phascolosoma pavlenkoi (Ostroumov, 1909)

Phascolosoma zenibakense (Ikeda, 1924)

Phascolosoma hyugensis (Sato, 1934)

Phascolosoma hozawai (Sato, 1937)

Phascolosoma onagawa (Sato, 1937)

Golfingia macginitiei (Fisher, 1952)

Golfingia puggettensis (Fisher, 1952)

Description: This species may have trunks up to $100 \mathrm{~mm}$ long but most in this collection are between 20 and $60 \mathrm{~mm}$. The specimen from St. 133 is only $5 \mathrm{~mm}$ long and its identification is uncertain. They have rough skin often with small wavy ripple lines and are commonly grey, only rarely black. The posterior end of the 
elongate cylindrical trunk may be contracted so that it resembles a pencil point. The introvert is 1-2.5 times the trunk length and bears a complex crown of 12-20 double rows of peripheral tentacles. Each row appears like a cycad frond with up to 40 tentacles per row (Fig. 8). The tentacular crown exhibits violet to brown pigmentation with individual tentacles varying in amount and placement of pigment. Nuchal tentacles are also present.

Internally the pair of retractor muscles originate between $55-75 \%$ of the distance to the posterior end of the trunk. The unattached nephridia, which open anterior to the anus, are $25-70 \%$ of the trunk length. A single fixing muscle arises from the middle of the trunk. A rectal caecum is usually present. The contractile vessel villi are present along most of the length of the oesophagus and increase in size and complexity becoming longer and branched posteriorly (Fig. 7, B). Many yellowish, spherical eggs up to $100 \mu$ are present in a few specimens.

Thysanocardia zenibakense has been regarded as valid (Cutler and Cutler, 1981) but here as a junior synonym of $T$. nigra because the alleged differences are neither consistent nor significant. Phascolosoma catharinae described by Sato (1937a) is here also synonymized with this species.

While Gibbs, Cutler and Cutler (1983) consider $T$. hyugensis to be a junior synonym, we are not including it here in the distribution data due to the real uncertainty of its status. The one and only specimen is lost now but was collected from 472 m off Miyazaki, Kyushu.

Previous Japanese Records: Ikeda, 1904 -Misaki, Tokyo Bay and Inland Sea. Sato, 1939 -Omuta Bay. Ostroumov, 1909 -P. pavlenkoi from north Japan Sea. $P$. zenibakense: Ikeda, 1924 -Zenibako, near Otaru, Hokkaido. Sato, 1930 -Mutsu Bay. 1937a -Mutsu Bay; Takada, Iwate Pref.; Karakuwa, Miyagi Pref. Okuda, 1946 -Akkeshi Bay. Sato, 1937a - P. hozawai from Miyagi Pref., P. onagawa from Onagawa Bay, and $P$. catharinae from Onagawa Bay, Miyagi Pref.

Material Examined: Imperial Householdspec.; $\neq$, Hayama, Sagami Bay; 2/30/30; 1 spec. Tohoku Univ., Sato's coll.—\# 3-29, 4-4; 2 spec. identified as G. zenibakense; $7-31$, Sato's type specimen of G. hozawai. Univ. of KTokyo, Ikeda's coll. Koajiro and Misaki, Miura Pen.; 1898-1902; 55 spec. Cutler-St. 7, Fukaura Bay, Inland Sea near Mukaishima M.B.L.; 3 m; 4/7/79; 2 spec. St. 30, Okinoshima Isl., Tateyama, Boso Pen.; 6/13/79; 2 spec. Imajima-St. 106, Manazuru, Kanagawa Pref.; $2 \mathrm{~m} ; 1 / 16 / 78 ; 4$ spec. St. 118, off Kashima, Fukushima Pref.; $9 \mathrm{~m} ; 10 / 68 ; 6$ spec. St. 131, Yamada Bay, Iwate Pref.; $30 \mathrm{~m}$; dredge; 8/67; 2 spec. St. 133, near Kanida River, Mutsu Bay; $5 \mathrm{~m} ; 1 / 20 / 73 ; 1$ spec. Nishikawa-St. 16, off Kagawa Pref.; Seto Inland Sea; 3/75; 29 spec. St. 20, off Kagawa Pref., Seto Inland Sea; 7/75; 30 spec. Tchojahama, Toshijima Isl. off Toba; intertidal; $5 / 31 / 80 ; 3$ spec. Ibid. $7 / 11 / 80 ; 5$ spec. Higashihazu, Mikawa Bay; intertidal sandy beach; $6 / 11 / 80 ; 2$ spec. Yamada-Akkeshi Bay, identified as G. zenibakense; $8 / 19 / 43 ; 2$ spec. and $8 / 22 / 63 ; 3$ spec.

Japanese Distribution: Found in the Inland Sea, along the Pacific side of central and northern Honshu, and off Hokkaido from 0-120 m.

Worldwide Distribution: Outside of Japan this species has been reported from Singapore and the west coast of the U.S. 


\section{Thysanocardia species}

(Fig. 7, C)

Description: These ten specimens have plump trunks ranging in length from 2.5-7 $\mathrm{mm}$ and from $2-5 \mathrm{~mm}$ in width i.e., the length being less than twice the width (Fig. $7, \mathrm{C})$. The introverts in retracted individuals are about equal to the trunk length. The posterior end of the animal is bluntly conical with a small nipple-like appendage. The body wall is relatively thin, grey, bears small uniform papillae over most of the surface which become cylindrical at the posterior and some exhibit zig-zag lines on much of the surface. Introvert hooks are absent but a crown of digitiform, unpigmented peripheral tentacles arranged in 8-10 rows with about 10 tentacles per row plus 8 tentacles enclosing nuchal organ are present. No worm has been preserved with the introvert extended so this is difficult to determine with certainty.

Internally the one pair of retractor muscles originates $80-95 \%$ of the distance to the posterior end of the trunk. The contractile vessel bears villi along most of its length. The size, degree of branching and density of these villi varies but they are numerous and bifurcated to some extent in all of these. A small caecum is usually present on the rectum and a single fixing muscle is usually present. The pair of nephridia open at the level of the anus or slightly anterior to it. They are short (less than one fourth the trunk length) and unattached to the body wall.

At first we thought these might be a few young individuals of Thysanocardia catharinae, but concluded that they probably represent a new species. Until additional specimens are collected, preferably with extended introverts, we reserve judgement.

Previous Japanese Records: None.

Material Examined: Horikoshi-St. 76-16 T-1; 34 ${ }^{\circ} 5^{\prime} \mathrm{N}, 138^{\circ} 46^{\prime} \mathrm{E} ; 127 \mathrm{~m} ; 9 / 20 / 76 ; 1$ spec. St. $77-7 \mathrm{~K} ; 34^{\circ} 54^{\prime} \mathrm{N}, 138^{\circ} 28^{\prime} \mathrm{E} ; 102 \mathrm{~m} ; 6 / 12 / 77 ; 1$ spec. St. $78-11 \mathrm{~K} 1-6 ; 34^{\circ} 56^{\prime} \mathrm{N}, 138^{\circ} 30^{\prime} \mathrm{E} ; 76 \mathrm{~m} ; 7 /$ 17/78; 5 spec. Hayashi-St. TA 7-6; Tango-Kai, Wakasa Bay; $78 \mathrm{~m} ; 7 / 27 / 76 ; 1$ spec. St. N-2; Tango-Kai, Wakasa Bay; $102 \mathrm{~m} ; 6 / 20 / 78 ; 2$ spec.

Japanese Distribution: Found in two restricted areas: Suruga Bay on the Pacific side of Honshu and in Wakasa Bay in the Japan Sea.

\section{Genus Antillesoma (Stephen \& Edmonds, 1972)}

Trunk with conspicuous papillae. Longitudinal musculature divided into separate bands which anastomose and are not always visible through the epidermis. Introvert hooks absent and tentacles which are arranged around the nuchal organ dorsal to the mouth numerous (more than 30 in adults). Four retractor muscles present but there may be extensive fusion between the two muscles on either side giving the appearance of a single pair with a notch or split in the broad origin. The spindle muscle is attached posteriorly and contractile vessel carries many digitiform villi. 
Remarks: The taxa Antillesoma and Rueppellisoma were reviewed in Cutler and Cutler (1983). They concluded that the taxon Rueppellisoma is null and void and among other things, that Phascolosoma onomichianum (as in Cutler and Cutler, 1981) is a junior synonym of $P$. antillarum. They did not elevate Antillesoma to generic rank but in a revision of sipunculan higher taxa Cutler and Gibbs (in press) do so.

\title{
Antillesoma antillarum (Grube \& Oersted, 1858)
}

(Fig. 9)

\author{
Phascolosoma asser (Selenka, DeMan \& Bulow, 1883) \\ Phascolosoma pelmum (Selenka, DeMan \& Bulow, 1883) \\ Phascolosoma weldonii (Shipley, 1892) \\ Phascolosoma onomichiantm (Ikeda, 1904) \\ Phascolosoma gaudens (Lanchester, 1905) \\ Phascolosoma simile (Chen \& Yeh, 1958) \\ Phascolosoma schmidti (Murina, 1975)
}

Description: This distinctive species has a trunk which may reach $30 \mathrm{~mm}$ long and large dark papillae at the anterior end (Fig. 9, A). It has a large crown of nuchal tentacles (up to 200) and lacks hooks (Fig. 9, B). Internally the presence of numerous contractile vessel villi distinguishes it from Japanese Phascolosoma species.

Previous Japanese Records: Ikeda, 1904 -Onomiti Bay, Inland Sea; Amami Oshima; Okinawajima Isl., Ryukyu Islands. Sato, 1934b-Ariake Bay, Kyushu.

Material Examined: Tohoku Univ., Sato's coll.-Korea and Formosa; $P$. pelmum from Hawaii. Univ. of Tokyo, Ikeda's coll.-Itoman, Okinawajima Isl, and Koniya, Amami-Oshima. Nishikawa-St. 31, Hikigawa-cho, Wakayama; 12/11/73; 1 spec. Culter-St. 8, Matsugahana, Mikaishima M.B.L.; intertidal, muddy crevices between rocks; $4 / 7 / 79 ; 8$ spec. St. 18, Sesoko M.B.L., Okinawa; intertidal; NMNH, Washington- 121354 , said to be from Japan; 1 spec.

Japanese Distribution: From the type locality of $P$. onomichianum near Onomichi in the Inland Sea, Wakayama, Amami Oshima, and Okinawa.

Worldwide Distsibution: In the western Atlantic this has been reported from Jamaica,
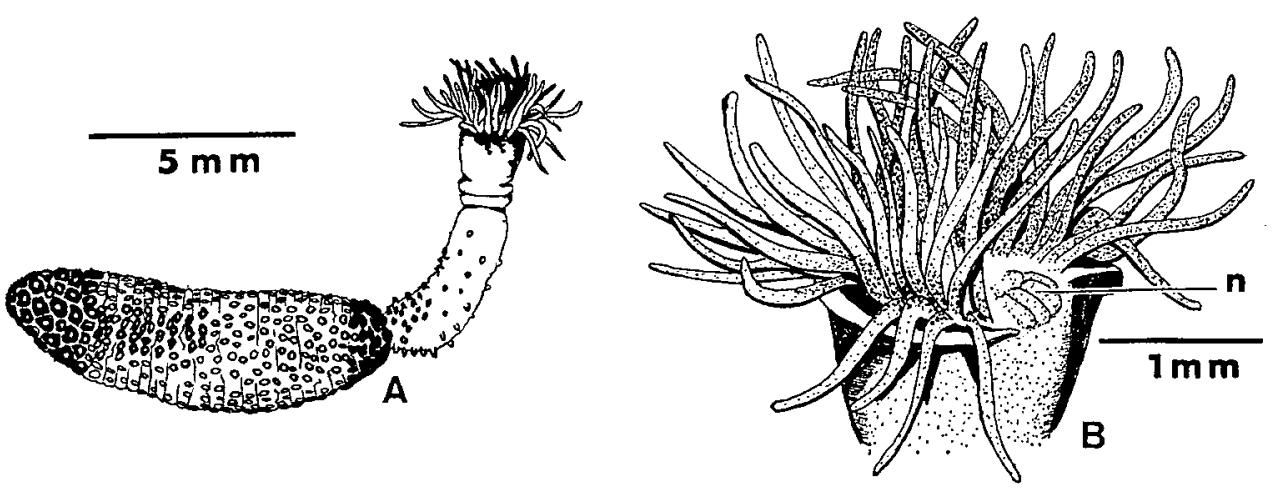

Fig. 9. Antillesoma antillarum. A: General form. B: Tentacular crown (n, nuchal organ). 
the Bahamas, Key West, Florida, Cuba, several West Indies Islands, Brazil, Venezuela and Panama. In the eastern Atlantic it has been found at Sierra Leone and the Gold Coast, then into the Indian Ocean at Durban, South Africa, Mozambique, Madagascar, Mauritius, Maldive and Laccadive Islands and Ceylon. In the IndoWest Pacific it is reported from Indonesia, Malaysia, Philippines, Korea, Formosa, China and southern Japan, then out to New Caledonia, the West Caroline Islands and Hawaii. In the eastern Pacific it has been recorded from Panama, Costa Rica (not Chile) and Baja, California. In summary, this is a cosmopolitan species found in tropical and subtropical, shallow water.

\section{Genus Phascolosoma Leuckart, 1828}

Trunk sub-cylindrical or flask-shaped (Fig. 10, A). Longitudinal muscles in bands which may anastomose. Tentacles lie in a semi-circle around nuchal organ dorsal to mouth (Pl. II, Fig. 2). Introvert and trunk usually covered with prominent, conical to hemispherical papillae, often brown to dark red-brown in color. Trunk papillae usually largest and most densely distributed at anterior and posterior ends
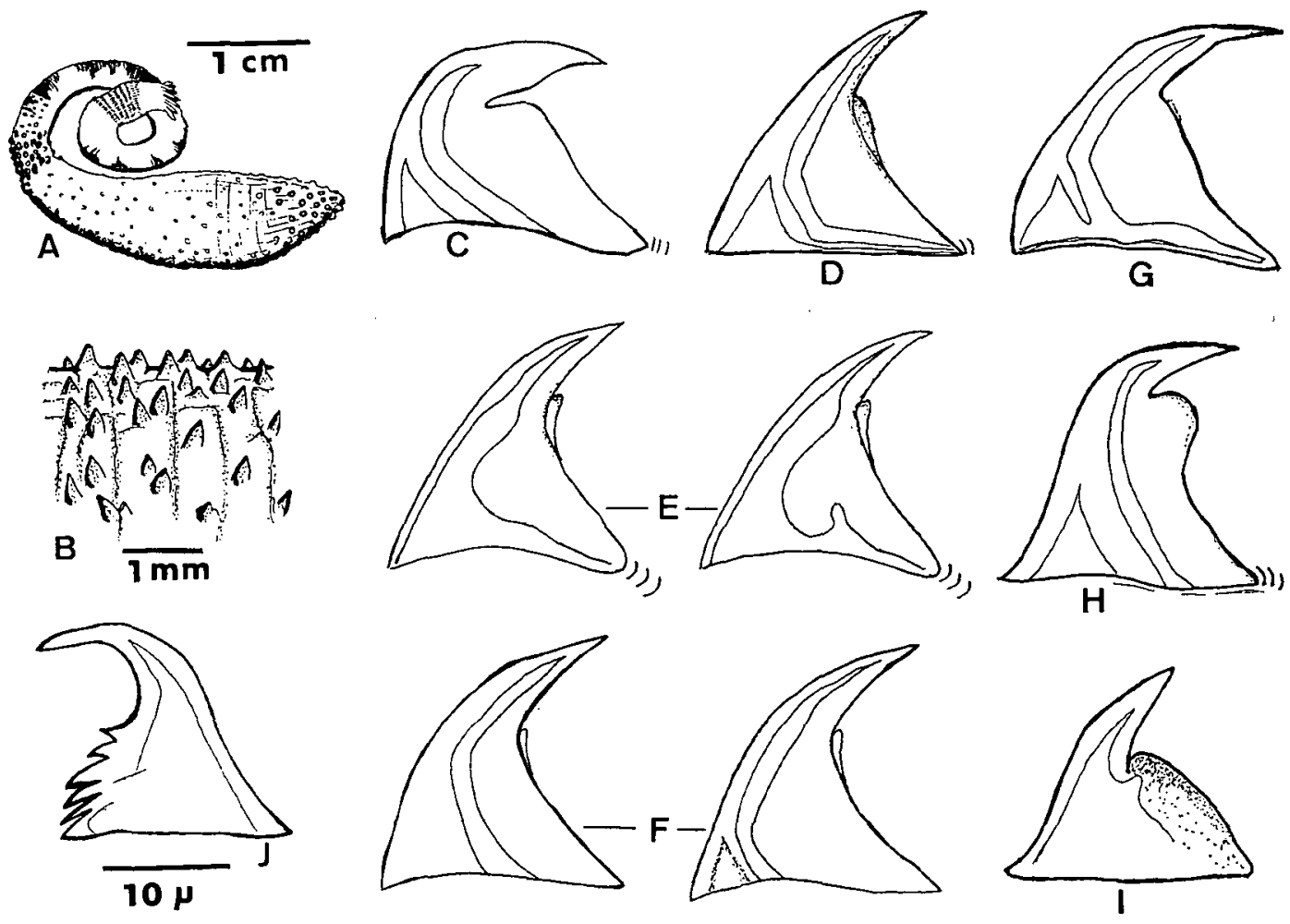

Fig. 10. Genera Phascolosoma (A-I) and Apionsoma (J). A: General form of Phascolosoma. B: Trunk papillae of $P$. pacificum. C: Hook of $P$. albolineatum. D: Hook of $P$. scolops. E: Two hooks of $P$. nigrescens. F: Two hooks of $P$. japonicum. G: Hook of $P$. pacificum. H: Hook of $P$. perlucens. I: Hook of Phascolosoma species. J: Hook of $A$. misakiana. 
(especially on dorsal side). Four introvert retractor muscles. Contractile vessel single and simple. Two nephridia and spindle muscles which is attached to body wall posteriorly. Generally inhabits firm substrata such as coral or soft rock in the intertidal or shallow subtidal regions.

Key to the Phascolosoma species known from Japan

1A. Trunk surface rough, bristling with tall, conical papillae (Fig. 10, B); nephridia nearly as long as trunk .................................P. pacificum

1B. Trunk papillae not tall and conical; nephridia less than one-half trunk length.................................................................. 2

2A. Papillae on dorsal surface on base of introvert dark, tall, and cone-shaped with apex directed posteriorly.....................................P. perlucens

2B. Papillae on base of introvert neither tall nor directed posteriorly..............

3A. At anterior basal corner of hook a separate triangular clear area is usually

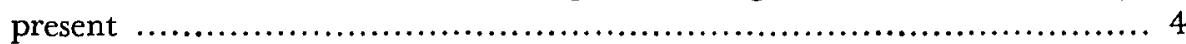

3B. At anterior basal corner of hook separate triangular clear area is absent but usually fused with adjacent clear streak............................. 5

4A. Tip of hook is bent at right $\left(90^{\circ}\right)$ angle to main axis (Fig. 10, G) ......... P. albolineatum

4B. Tip of hook bent at obtuse angle (Fig. 10, D) ....................... scolops

5A. The introvert hooks exhibit a small bump or swelling at center of base and vertical clear streak (Fig. 10, E) ................................. nigrescens

5B. Vertical clear streak in hook is smooth; bump or swelling absent (Fig. $10, \mathrm{~F})$ $P$. japonicum

\section{Phascolosoma albolineatum Baird, 1868}

(Fig. 10, C)

Description: In many ways this species is indistinguishable from many $P$. scolops. They both have pale skin with irregular reddish brown blotches, range in size from $5-35 \mathrm{~mm}$ (commonly $10-20 \mathrm{~mm}$ ), have introverts $50-75 \%$ of the trunk length with dark patches on the dorsal surface and rings of hooks; four retractor muscles, two nephridia about half as long as the trunk, and a posteriorly attached spindle muscle. The only way these species can be separated is by the form of the hook (Fig. 10, C). The apex is sharply bent so that it is almost parallel to the base of the hook. The internal clear streak and basal triangle are comparable to $P$. scolops except that the clear streak is sometimes shorter, not extending as far into the tip.

In the population of 41 specimens from Okinawa, a reexamination showed an interesting condition vis-a-vis their retractor muscles. A few worms exhibit very thin, weakly developed dorsal muscles and one worm possessed only the ventral pair. This condition which we believe to be anomalous was discussed in Cutler and Cutler (1981) for $P$. nahaense which we synonomized with $P$. scolops. This nondevelopment of a normal complement of retractor muscles has now been documented 
in several populations and further underscores the need for basing species descriptions on more than just a few individuals or, if chosing to do otherwise, be open to the possibility that one may not be dealing with a biological species.

Previous Japanese Records: Sato, 1939 -Miyako and Naha, Ryukyu Islands.

Material Examined: Univ. of Tokyo, Ikeda's coll.-Naha, Okinawa; 4/8/02; 4 spec. HorikoshiKabira Bay, Ishigakijima; 1 spec. Cutler-St. 16, Sokaru, $6 \mathrm{~km}$ E of Koniya, Amami-Oshima; 4/14/79; 2 spec. St. 18, Sesoko M.B.L., Okinawa; 4/17/79; 41 spec. St. 38, Laura, Majuro, Marshall Islands; lagoon; 8/2/79; 75 spec. St. 39, Laura, Majuro, Marshall Isl.; ocean side; 8/2/79; 1 spec.

Japanese Distribution: Found intertidally in Amami-Oshima and Ryukyu Islands. Worldwide Distribution: This species has been collected from several localities in the Western Pacific/Indonesian area with Indian Ocean records from Port Natal and Diego Garcia Island.

\section{Phascolosoma japonicum Grube, 1877}

(Fig. 10, F; Fig. 11)

Description: This most common Japanese Phascolosoma is also rather variable in form. Generally it is a medium, light-yellowish brown but may vary from off white to brown and sometimes has small scattered flecks of dark brown on the trunk. The trunk length ranges from $5-53 \mathrm{~mm}$ but most are between 15 and $35 \mathrm{~mm}$ long. The papillae are often sparsely distributed and, unlike the reddish structures in $P$. scolops, are usually pale or the same shade as the trunk, but may be more conspicuous on the anterior and posterior ends where they are up to $250 \mu$.

The introvert is usually $75-125 \%$ of the trunk length (ranges from 43-250\%) and often exhibits dark, dorsal patches. The number of rings of hooks exhibits some variation but in most is around 15-25, a few have up to 120 rings. In some there are also additional incomplete rings and some randomly scattered hooks. The classical nature of the internal clear streak of these hooks is a simple curved region of uniform width. However, this may show considerable variation with a distinct bend or angle in it or an expanded basal region blending into a triangular zone like an indistinct $P$. scolops hook (Fig. 10, F, right). In those worms less than $8 \mathrm{~mm}$ long, the internal structure of the hook is very indistinct. The nuchal tentacles are digitiform and number 8-30 which roughly correlates with the size of the worm.

The ventral retractor muscles originate about $50-75 \%$ of the distance to the posterior end of the trunk while the dorsal pair is usually $10-20 \%$ anteriad. The nephridia range in length from $25-135 \%$ of the trunk length. However, in the intertidal population, this organ is $25-60 \%$. The longer nephridia occur in small worms (less than $20 \mathrm{~mm}$ ) from subtidal collections. There is also asymmetry in the small worms with the left nephridium somewhat longer than the right. This organ clearly exhibits allometric growth becoming proportionately shorter in larger worms (Fig. 11). Their degree of attachment to the body wall also varies from 


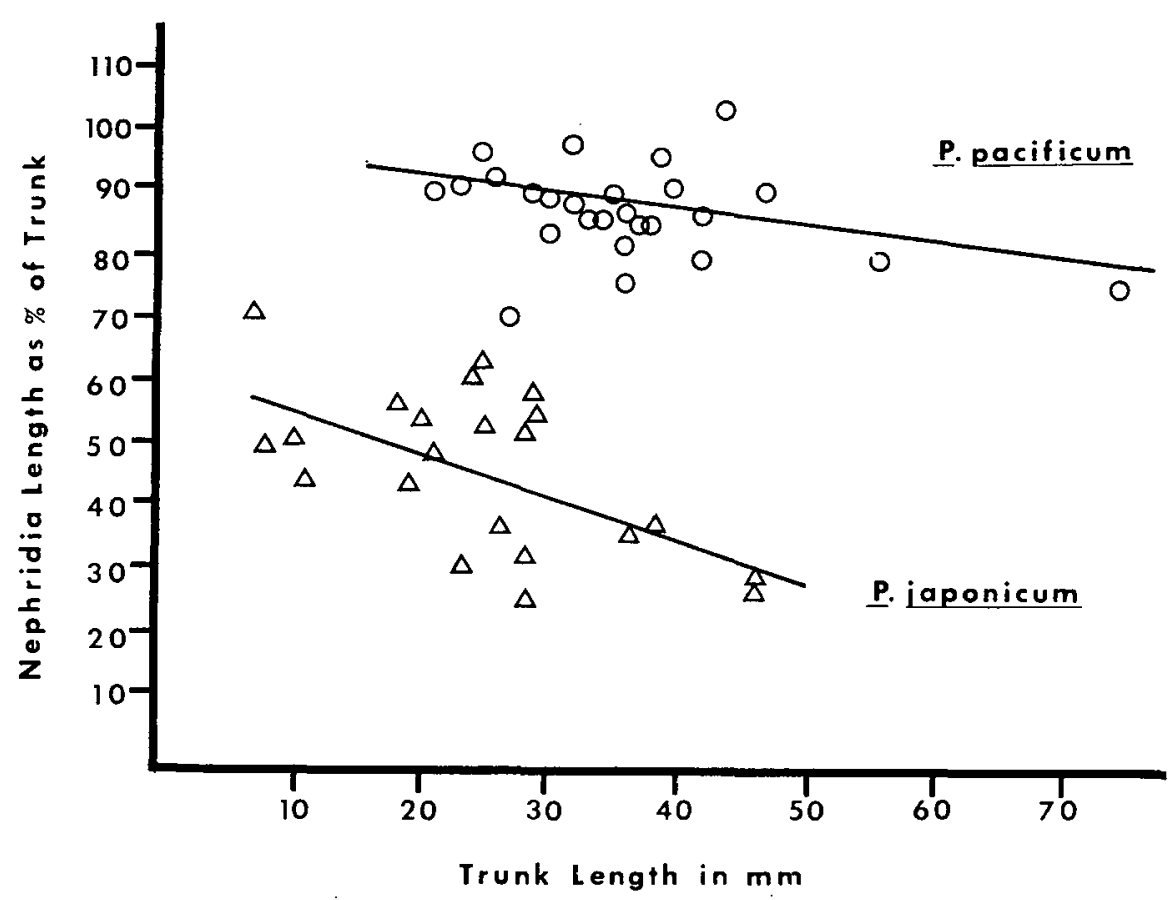

Fig. 11. Relative nephridial length of two intertidal Phascolosoma populations showing allometric growth. Plotted lines are linear regressions, $\mathrm{Y}=\mathrm{a}+\mathrm{bx}$. For $P$. japonicum, $\mathrm{a}=61.8, \mathrm{~b}=-0.68$; $P$. pacifictu, $\mathrm{a}=96.6, \mathrm{~b}=-0.28$.

$25-80 \%$, commonly around $50 \%$. A rectal caecum is usually discernable. A single fixing muscle is present. Eggs are flattened, $40 \mu$ thick, and up to $170 \mu$ in diameter.

Remarks: This species is part of a complex of Phascolosoma species which are not clearly differentiated. In Cutler and Cutler (1981) we reduced $P$. glaucum and $P$. yezoense to the status of junior synonyms and $P$. kurilense to a subspecies. In $\mathrm{Mu}$ rina (1977: 125) in an important section entitled "Taxonomic value of certain morphological characteristics", she made a series of measurements on a population of 30 worms she called $P$. japonicum collected from the Sea of Okhotsk. Among these data are the following with respect to the nephridia: 4-13 $\mathrm{mm}$ worms have pearshaped nephridia without secondary outgrowths; 14-30 mm worms have a weakly developed secondary lobe, and 31-55 $\mathrm{mm}$ animals have a well-formed second lobe. Sato (1937b: 119, fig. 4) shows the internal structure of his species with the small secondary lobe and of his three worms the largest was $65 \mathrm{~mm}$. This information confirms our earlier suggestion that $P$. kurilense is a northern subspecies of $P$. japonicum and we suggest that Murina's 1977 data are based on this subspecies. In the subtidal population from the Imperial Household, there are a few individuals which exhibit a small secondary lobe on the nephridia.

$P$. noduliferum is very similar but Edmonds (1980) maintains its separate status. $P$. granulatum is also very close in its morphology. Whether these represent bio- 
logically distinct species or artifacts of our incomplete knowledge is an open question. They all seem to be subtropical to temperate forms and the most eurytopic group in the genus, being very rare in the latitudes between $20^{\circ}$ north and south.

Previous Japanese Records: Fischer, 1914 -Sutsura and Nokabuta, probably southern Kyushu. Ikeda, 1904 -Enoura, Shizuoka Pref. and Misaki. 1924 -P. yezoense from Oshoro, Hokkaido. Sato, 1930 -Mutsu Bay and P. glaucum from Mutsu Bay. 1937a -Mutsu Bay, Iwate, Miyagi and Fukushima Pref. 1937b -P. kurilense from Shumshir Island. Selenka, DeMan \& Bulow, 1883 -Enoura, Shizuoka Pref. and Hakodate, Hokkaido.

\begin{abstract}
Material Examined: Imperial Household-From Sagami Bay: 777 , Kan-nontsuka-dasi, Amadaiba, $80 \mathrm{~m} ; 3 / 20 / 51 ; 1$ spec. \# 141, Sabane to Maruyama-dasi, off Hayama; 30-32 m; $7 / 18 / 52 ; 1$ spec. \#171, Kado-ne, of Nagai; 100-250 m; 12/12/53; 3 spec. $\# 255$, Mosaki, Kameki-syo; 10-12 m; 7/ $23 / 56 ; 1$ spec. $268,1.3$ miles SW off Jyogashima Lighthouse; $80-85 \mathrm{~m} ; 1 / 21 / 57 ; 2$ spec. \#319, Miyosenotakane, Kameki-syo; 10-12 m; 7/20/57; 1 spec. \#326, Mosaki, Kameki-syo; 15 m; 7/23/ 57; 5 spec. 328 , Kan-nontsuka-dasi to Maruyama-dasi, Amadaiba; $65-70 \mathrm{~m} ; 7 / 24 / 57 ; 3$ spec. \#329, Syuraga-ne; 30-35 m; 7/24/57; 2 spec. \#341, S off Jyogashima; 80-90 m; 7/25/57; 4 spec. \# 438, Nashima, Hayama; $10 \mathrm{~m} ; 7 / 16 / 59 ; 1$ spec. \#480, 9 miles off Sunosaki; $90 \mathrm{~m} ; 7 / 24 / 59 ; 6$ spec. \#811, near Sashima; 14-16 m; 7/14/63; 1 spec. \#853, Wareshima; 14-16 m; 7/27/63; 5 spec. 788, Kan-nontsuka-dasi, Amadaiba; 70-90 m; 7/14/64; 1 spec. From Susaki, Izu: 71069 , Nishijima, Shimoda Bay; 14 m; 12/9/72; 1 spec. \#1070, Saku-ne, Shimoda Bay; 24-28 m; 7/18/73; 2 spec. \#1087, Shore of Masakino-hana; shallow; $3 / 11 / 77 ; 1$ spec. 1090 , Saba-ne, south of Susaki Harbour; $10 \mathrm{~m} ; 6 / 17 / 77 ; 1$ spec. Univ. of Tokyo, Ikeda's coll.-Yenoura, Sagami Bay; 1884; 25 spec. Shibata, Osaka Mus.-N side Tomogashima Isl., Kada, Wakayama Pref.; 6/9/59; 5 spec. Inaba-Mitsukue, Ehime Pref., Shikoku; 11/29/72; 2 spec. Osanai-Asamushi M.B.L.; intertidal; 1977-1979; 9 spec. Noto Mar. Lab.-intertidal; 1958, 1975; 2 spec. Cutler-St. 1, Sagami Bay near Misaki; $10 \mathrm{~m} ; 3 / 13 / 79 ; 10$ spec. St. 10, 1/2 mile off Kataura, Kagoshima Pref.; 4/10/79; 2 spec. St. 12, 2 km E of Koniya, Amami-Oshima; 4/12/79; 5 spec. St. 16, Sokaru, 6 km E of Koniya; 4/24/79; 2 spec. St. 20, Kunri-banam, NNW Sesoko Isl., Okinawa; 4/17/79; 6 spec. St. 21, in front of Misaki M.B.L.; rock; 4/28/79; 15 spec. St. 23, Misaki M.B.L.; sandstone; 4/28/79; 3 spec. St. 27, Moroiso Bay; black sand; 5/26/79; 1 spec. St. 28, Kurosaki, Miura Pen.; 5/25/79; 16 spec. St. 29,1 km from Tateyama M.B.L., Boso Pen.; 6/12/79; 42 spec. St. 30, Okinoshima Isl., Tateyama, Boso Pen.; $6 / 13 / 79 ; 12$ spec. St. 31, Isashi tidal pool, Miyake-jima; 6/15/79; 7 spec. St. 32, Igaya Bay, Miyakejima; 6/15/79; 3 spec. St. 34, Kurosaki, Miura Pen.; 6/25/79; 12 spec. St. 35, Koajiro Bay, Miura Pen.; 6/26/79; 5 spec. Imajima-St. 111, Hahajima, Ogasawara Isl.; intertidal; 6/69; 65 spec. St. 113, Chichijima, Ogasawara Isl.; 6/69; 9 spec. St. 119, Yamada Bay, Iwate Pref.; intertidal; 8/67; 38 spec. St. 120. Shimoda; intertidal; 9/78; 5 spec. St. 158, Habu Harbour, Izu-Oshima; intertidal; 7/77; 35 spec. Nishikawa-St. 2, estuary, Sendai River, Tottori Pref.; 12/78; 10 spec. St. 3, same; 8/78; 32 spec. St. 12, Gogojima Isl., off Matuyama; interdital; 6/12/76; 3 spec. St. 24, off Gobo, Wakayama Pref.; $5 \mathrm{~m}$; 5/78; 4 spec. St. 27, Kushimoto, S end of Kii Pen.; intertidal; 5/28/75; 2 spec. St. 41 , off Noto-ogi, Noto Pen.; $15-40 \mathrm{~m} ; 6 / 9 / 75 ; 1$ spec. N.M.N.H., Washington-\# 52210 , Otaru, Japan; 4 spec. $\# 3720$, off Honshu; $113 \mathrm{~m} ; 5 / 11 / 00 ; 1$ spec. $\# 3733$, off Honshu; $90 \mathrm{~m}$; 5/16/00; 1 spec. $¥ 48923$, Ayukawa, Miyagi Pref.; 1906; 13 spec. USS Albatross, Misaki, Sagami Bay; 1 spec.
\end{abstract}

Japanese Distribution: A widely-spread species in Japan found in the intertidal zone in coral or stone, from Hokkaido and northeast Honshu down to Okinawa. Records on islands north and south of Honshu as well as in the Inland Sea.

Worldwide Distribution: In the Pacific from Sea of Okhotsk and Japan, then skips to Tasmania, New Zealand, Southern Australia. There is one report in the east 
Pacific from Vancouver, B.C. In the Indian Ocean it is reported from Mombassa, South Africa, Ile St. Paul and Maldive Islands.

\section{Phascolosoma nigrescens Keferstein, 1865}

(Fig. 10, E)

Description: This rather common form usually has uniformly yellow-brown trunks (occasionally with dark leopard spots) ranging in length from $3-45 \mathrm{~mm}$ (commonly $20-40 \mathrm{~mm}$ ). Elsewhere $120 \mathrm{~mm}$ worms have been recorded (Cutler, 1965). The introvert is $75-125 \%$ of the trunk length, carries about $20-40$ rings of distinctive hooks and often has irregular dark bands on its dorsal surface. The vertical clear streak in the hook has a swelling in the middle along its inner side and the basal clear area also exhibits a hump which may (as in specimens from New Caledonia) show a bubble-like outpouching. Edmonds (1980: 59) says... "the hump is enlarged to a tongue-like protrusion" (Fig. 10, E). The internal organs are typically arranged for this genus.

Previous Japanese Records: None.

Material Examined: Tohoku Univ., Sato's coll.-Yap, Palau, and Formosa. Univ. of Tokyo, Ikeda's coll.--Okinawa and Tanegashima Isl.; 6 spec.; (named by us). Horikoshi-13 Stations, Kabira Bay, Ishigakijima; coral reef; 18 spec. Nishikawa-St. 22, off Gobo, Wakayama Pref.; 5 m; 5/78; 2 spec. St. 27, Kushimoto, S end of Kii Peninsula; intertidal; 12/4/75; 1 spec. St. 38, Taketomijima, Okinawa; intertidal; 6/23/75; 2 spec. Cutler-St. 11, 2 km S of Kataura, Kagoshima Pref.; 4/10/79; 3 spec. St. 12, $2 \mathrm{~km}$ E of Koniya, Amami-Oshima; 4/12/79; 3 spec. St. 13, Katetsu, $5 \mathrm{~km}$ E of Koniya, AmamiOshima; 4/13/79; 2 spec. St. 15, 1/2 km E of Koniya, Amami-Oshima; 4/13/79; 1 spec. St. 16, Sokura, $6 \mathrm{~km}$ E of Koniya, Amami-Oshima; 4/14/79; $10 \mathrm{spec}$. St. 20, NNW corner, Sesoko Isl., Okinawa; 4/17/79; 20 spec. St. 31, Hisashi tidal pool, Miyake-jima; 6/15/79; 3 spec. St. 37, east side Ponape, East Caroline Isl.; fringing reef; 7/30/79; 1 spec. Imajima-St. 107, Tanegashima Isl.; coral reef; 6/75; 7 spec. St. 108, Tanegashima Is1.; intertidal; 6/75; 1 spec. St. 115, Sumizaki, Shimnoisaki; intertidal; 1 spec. St. 117, Kabira Bay, Ishigakijima; 7/27/73; 1 spec. St. 148, off Izu-Oshima; dredged $23-65 \mathrm{~m} ; 7 / 77 ; 1$ spec.

Japanese Distribution: Before this study this species was reported by Sato only from Yap and Formosa. However, we found it in the south from Ishigakijima, Okinawa, Amami-Oshima, Tanegashima and then from several localities in Wakayama Pref. and off the Izu Islands. We also named some of Ikeda's unidentified specimens from Okinawa as this species.

Worldwide Distribution: This is a common circumtropical, shallow water species found in all tropical oceans.

\section{Phascolosoma pacificum Keferstein, 1866}

(Fig. 10, B and G; Fig. 11)

Description: This is one of the larger members of this genus; those we examined ranging in trunk length from $15-80 \mathrm{~mm}$ (most less than 50 ). The introvert is 1-2 
times the trunk length with many (up to 100) rings of hooks with a sharp, bent apex (Fig. 10, G). One of the most distinctive features of this species is the large, conical, evenly distributed papillae (Fig. 10, B) which give the worm a coarse look and feel. The arrangement of internal structures is typical except for the nephridia which are $70-100 \%$ of the trunk length (Fig. 11) and fixed to the body wall for most of their length.

One poorly preserved specimen from the Japan Sea (Sado Island) superficially resembles this species but a positive identification is not possible. This record, if it can be confirmed by additional collections is zoogeographically very interesting because of its northern latitude and cooler temperature. It may be a $P$. japonicum with unusually large papillae.

Previous Japanese Records: Ikeda, 1904 -Okinawajima Island and Amami-Oshima.

Material Examined: Tohoku Univ., Sato's coll.-Maki, Yap. Univ. of Tokyo, Ikeda's coll.-Amami-Oshima and Okinawa; 1901; 19 spec. Cutler-St. 12, 2 km E of Koniya, Amami-Oshima; 4/12/ 79; 1 spec. St. 16, Sokaru, $6 \mathrm{~km} \mathrm{E}$ of Koniya, Amami-Oshima; 4/14/79; 1 spec. St. 18, Sesoko M.B.L., Okinawa; 4/17/79; 24 spec. Niigata Univ.-Tassha, Kuroshima, Sado Island; 4/10/64; 1 spec.; dubious.

Japanese Distribution: Found in the south from Okinawa and Amami-Oshima.

Worldwide Distribution: This appears to be a tropical Indo-West Pacific species with two additional records from the Red Sea.

\section{Phascolosoma perlucens Baird, 1868}

(Fig. 10, H)

Description: This tropical species is uncommon in Japanese waters but is easily identified by the large conical, reddish-brown, posteriorly directed papillae on the dorsal surface of the proximal third of the introvert. The trunk is more slender than in most members of this genus, pale with irregular dark patches, and up to $40 \mathrm{~mm}$ long. The 20-25 longitudinal muscle bands can often be seen through the body wall. The slender introvert bears rings of hooks whose distal tip is strongly bent and the central clear area is expanded near its middle. Basally a separate expanded triangular area is present (Fig. 10, H). The arrangement of the internal organs is typical for this genus.

Previous Japanese Records: None.

Material Examined: Horikoshi-6 stations; Kabira Bay, Ishigakijima; coral reef; 6 spec. CutlerSt. 37, east side Ponape, East Caroline Isls.; fringing reef; 7/30/79; 1 spec. St. 38, lagoon; Laura, Majuro, Marshall Isl.; 8/2/79; 2 spec.

Japanese Distribution: Found only at Kabira Bay, Ishigaki Island.

Worldwide Distribution: This is another tropical species found in the Indo-West Pacific, but also from the eastern Pacific, and into the Caribbean Sea at many locations. It appears to be absent from the eastern Atlantic Ocean. 


\section{Phascolosoma scolops (Selenka, DeMan, and Bulow, 1883)}

(Fig. 10, D)

Description: This common and widespread species varies in color from an off-white to light brown with dark reddish brown patches of varying sizes scattered along the dorsal surface of the trunk and introvert. Skin papillae are often conspicuous on the introvert base and posterior end of trunk where they are sometimes up to $22 \mu$ tall, but variable in form. The trunk length ranges from $2-25 \mathrm{~mm}$ (most $10-15 \mathrm{~mm}$ ) and the introvert is from $75-200 \%$ of the trunk length (usually about equal). There are 15-40 rings of hooks around the introvert each hook having a central clear streak and usually a separate basal triangle (Fig. 10, D). The number and size of the hooks varies with age (Cutler and Cutler, 1979; Edmonds, 1980).

The two pairs of retractor muscles originate in the third quarter of the trunk, the ventral pair about $10-20 \%$ of the trunk length posterior to the dorsal. There are some variations on this basic arrangement e.g., from Imajima's St. 106, the dorsal muscle looks very much like a small branch of the ventral; in his St. 110, the two muscles on the same side very quickly fuse into one muscle, and in one from the Univ. of Hong Kong, the left pair was missing leaving only two muscles, the right dorsal and ventral. Variations do exist and in Cutler and Cutler (1981), P. nahaense with its two retractors was reduced to a junior synonym of this species for just this reason. The nephridia open at about the level of the anus, are about $50-75 \%$ of the trunk length and are attached to the body wall for about $50 \%$ of their length. The right nephridium of the specimen from St. 845 has an anterior lobe which is about $20 \%$ of the total nephridium length.

Previous Japanese Records: Ikeda, 1904 -Okinawa to Hokkaido inclusive of Ogasawara Isl. 1924 -Zenibako, Hokkaido. Sato, 1930 -Mutsu Bay. 1937a -Mutsu Bay; Tobi-shima Isl. and Nezugaseki, Yamagata Pref. Okuda, 1946 -Akkeshi Bay, Hokkaido.

\footnotetext{
Material Examined: Horikoshi-6 stations, Kabira Bay, Ishigakijima; coral reef; 6 spec. Univ, of Tokyo, Ikeda's coll.-Naze, Amami-Oshima, Haha and Itoman, Okinawa, Kataura and Akune, Kagoshima Pref. and Chichijima, Ogasawara Isl.; many spec. Univ. of Hong Kong-Hong Kong harbor; 15 spec. Tohoku Univ., Sato's coll.-many bottles. Nishikawa-St. 31; subtidal, off Hikigawa-cho, Wakayama; $12 / 11 / 73 ; 1$ spec. St. 32 ; subtidal, off Hikigawa-cho, Wakayama; 12/19/73; 1 spec. St. 34; Kushimoto, S end of Kii Peninsula; 12/10/73; 4 spec. Cutler-St. 12; 2 km E of Koniya, Amami-Oshima; 4/12/79; 3 spec. St. 13, Katetsu, $5 \mathrm{~km} \mathrm{E} \mathrm{of} \mathrm{Koniya,} \mathrm{Amami-Oshima;} \mathrm{4/13/79;} 4$ spec. St. 18; Sesoko M.B.L., Okinawa; 4/17/79; 1 spec. St. 21; in front of Misaki M.B.L., rock; 4/28/79; $10 \mathrm{spec}$. St. 22 ; in front of Misaki M.B.L.; sandy pockets; 2 spec. St. 23; in front of Misaki M.B.L., sandstone: 24 spec. St. 33; Miyakejima, dead coral; 6/15/79; 2 spec. St. 34; Kurosaki, Miura Peninsula; 6/25/79; 1 spec. Imajima-St. 106; Manazuru, Kanagawa Pref.; 2 m; 1/16/78; 3 spec. St. 108; Tanegashima Isl.; intertidal; 6/75; 5 spec. St. 109; Wamiura, Tsushima Isl.; intertidal; 7/69; 33 spec. St. 110; Wakago H. Nii-jima,; intertidal; 7/77; 2 spec. St. 112; Sumizaki, Shionomisaki; intertidal; 7/20/78; 12 spec. St. 113; Chichijima, Ogasawara Isl.; 6/69; 25 spec. St. 114; Aburattsubo Bay, near Misaki M.B.L., intertidal; 6/71; 1 spec. St. 115; same as St. 112; no date; 4 spec. St. 116; Jayama, Kanagawa Pref.; intertidal; 4/66; 3 spec. Imperial Household——7 (part), Tozaki, Kushimoto; $6 / 3 / 29 ; 1$ spec. 手 832, Kasa-jima, Sagami Bay; shallow; 7/19/63; 1 spec. 光 845, Wareshima, Sagami Bay; 6-7 ftms; 7/26/63; 1 spec. \#948, Mosaki, Kameki-syo; 9 ftms; 7/25/64; 1 spec.
} 
Japanese Distribution: From as far south as Ishigaki Island, along both sides of the main islands up as far as Hokkaido. It is an intertidal species found in coral or soft stone or sometimes in sandy pockets between rocks.

Worldwide Distribution: This species is widely reported from the Indo-Pacific (including Korea and Formosa) and the Red Sea. There are a few scattered Atlantic Ocean and Caribbean Sea records.

\section{Phascolosoma species}

(Fig. 10, I)

Description: This single worm is a distinctive organism. The extended introvert is about equal in length to the 8-mm, papillated, brownish trunk. There are 18 tentacles in a crescent dorsal to the mouth. The unique introvert hooks are arranged in about 50 rings, the first six being unpigmented, then becoming dark and close together. The form (Fig. 10, I) is unlike that shown for any other Phascolosoma.

Internally the longitudinal muscle bands are highly anastomosed making it impossible to count their number. The pair of ventral retractor muscles have their origin about $75 \%$ of the distance to the posterior end of the trunk, while the thinner dorsal pair originate about $1 \mathrm{~mm}$ anterior to the ventrals. All four remain separate for most of their length. The bilobed nephridia, which open at the level of the anus, are as long as the trunk and are attached to the trunk wall for about twothirds their length. The spindle muscle continues beyond the gut coil to attach to the posterior end of the trunk. The contractile vessel is large, simple, and without villi but it has a bumpy appearance with swellings or bubbles along its length.

Material Examined: Cutler-St. 23; Misaki; tufaceous sandstone; intertidal; 4/28/79; 1 spec.

\section{Genus Apionsoma Sluiter, 1902}

Species small, less than $2 \mathrm{~cm}$ with continuous muscle layer (Fig. 12, A). Two pairs of retractor muscles present and spindle muscle attaches intestinal spiral to posterior end of body; two nephridia single or bilobed (Japanese species are bilobed). The introvert is of variable length and may be more than four times the trunk length. If tentacles are present they arise dorsal to mouth and enclose nuchal organ. Contractile vessel without villi. If hooks are present, often have spinelets at the base. Note: This taxon was reviewed in Gutler (1979) but more recently was elevated to generic status (Cutler and Gibbs, in press).

Key to Apionsoma species known from Japan

1A. Hooks and tentacles absent; introvert 8-14 times trunk length; papillae absent or flattened on posterior end........................... trichocephala

1B. Hooks and tentacles present; introvert 4-10 times trunk length; posterior papillae usually pigmented and raised (Fig. 10, J; Fig. 12, B).....A. misakiana 

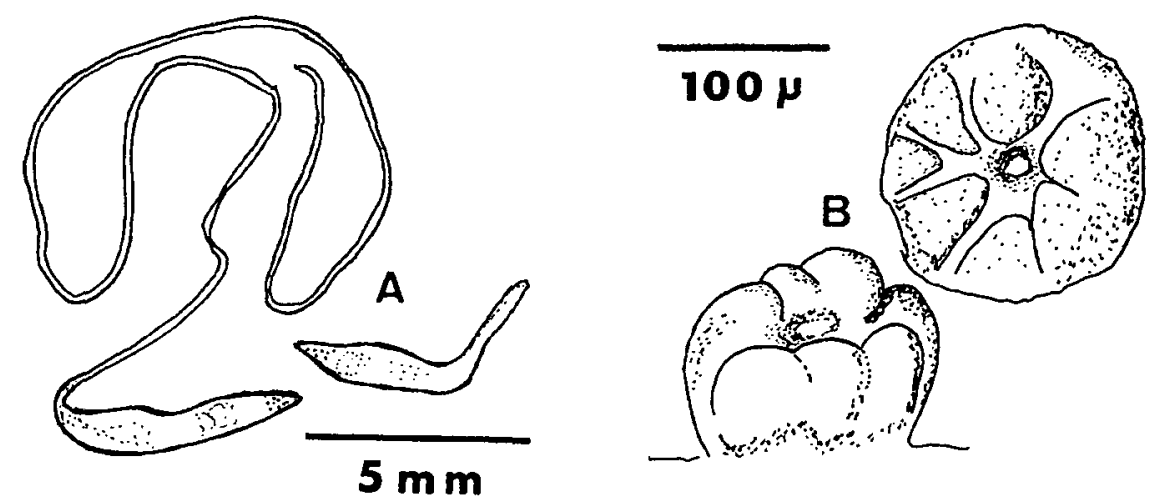

Fig. 12. Genus Apionsoma. A: General form. B: Posterior trunk papillae from A. misakiana.

\section{Apionsoma misakiana (Ikeda, 1904)}

(Fig. 10, J; Fig. 12, B)

Description: This small (2-7 mm trunks), pale, spindle-shaped worm has an introvert which is 4-10 times the trunk length. Rings of very small hooks with 3-6 spinelets at their base (Fig. 10, J) surround the distal end of the introvert which also carries an array of short tentacles dorsal to the mouth. Both hooks and tentacles are very difficult to find if the introvert is not completely extended as the diameter of the introvert is less than $0.5 \mathrm{~mm}$ and the hooks are only $15-25 \mu$ tall. In the contracted state this species closely resembles $A$. trichocephala but the presence of hemispherical papillae especially over the posterior third of the trunk in $A$. miaskiana (which often are darker than the body wall) help to differentiate this species (Fig. 12, B). This problem is discussed in Cutler (1979) and Cutler \& Cutler (1979).

Internally there are two nephridia which begin in juveniles as single lobed structures but eventually develop a pair of large lobes on each side (a few individuals do not; see Cutler and Cutler, 1981). The four equal-sized retractor muscles originate just anterior to the middle of the trunk, both pairs close to and about equal distance from the ventral nerve cord.

At Cutler St. 31, these worms were living in the thin layer of collected sediment made up of diatom skeletons in roots of the green algae Vaucheria sp. and two species of red algae (one in the family Bertholdia) which were growing on the rocks in the tidal pool.

Previous Japanese Recōrds: Ikeda, 1904 -Misaki.

Material Examined: Cutler-St. 31, Hisashi tidal pool, Miyake-jima; 6/15/79; 38 spec. KosakaSt. 48, Uchiura Bay, Yui, Suruga Bay; $160 \mathrm{~m}$; $9 / 29 / 71$; 1 spec. Hayashi-St. W-113, off Wakasa; $125 \mathrm{~m} ; 8 / 27 / 75 ; 1$ spec. Horikoshi-St. $78-11 \mathrm{~K}-2 ; 34^{\circ} 55^{\prime} \mathrm{N}, 138^{\circ} 30^{\prime} \mathrm{E} ; 128 \mathrm{~m} ; 7 / 18 / 78 ; 2$ spec. St. $78-18 \mathrm{OT}^{\circ} ; 34^{\circ} 55^{\prime} \mathrm{N}, 138^{\circ} 45^{\prime} \mathrm{E} ; 153 \mathrm{~m} ; 11 / 20 / 78 ; 1$ spec. Kabira Bay, Ishigaki Island; coral reef; 2 spec. Imajima-St. 107, Tanegashima; coral reef; 6/75; 3 spec. St. 111, Hahajima, Ogasawara Isl.; intertidal; 6/69; 9 spec. St. 113, Miyanohama, Chichijima, Ogawsara Isl.; 6/69; 3 spec. St. 117, Kabira Bay, Ishigaki Isl.; 3 spec. St. 139, Nii-jima; dredge; $60-80 \mathrm{~m} ; 7 / 77 ; 6$ spec. St. 140, Arita Bay, Kushimoto-cho, Wakayama Pref.; 33-35 m; dredge; 2 spec. St. 146, Nii-jima; dredge; 
$74-80 \mathrm{~m} ; 7 / 77 ; 15$ spec. St. 147 , off Izu-Oshima; dredge; $23-65 \mathrm{~m} ; 7 / 77 ; 1$ spec. St. 148, same as $147 ; 12$ spec.

Japanese Distribution: In the Japan Sea, only from Wakasa Bay; on the Pacific side from Suruga Bay, Izu and Ogasawara Islands, then further south from Arita Bay, Tanegashima and Yaeyama Islands.

Worldwide Distribution: In the Pacific it is reported from California, Peru, French Polynesia and Australia; in the Atlantic from Florida, Bahamas, and Brazil; and in the Indian Ocean from Mombassa, Madagascar and Rodriques Island.

\section{Apionsoma trichocephala Sluiter, 1902}

Description: In recent collections this is the second most common member of this phylum. There have been several recent reports in which this species has been discussed (Murina, 1972; Cutler, 1973, 1979; Cutler \& Murina, 1977; Gutler \& Cutler, 1979; Edmonds, 1980).

This is a small (most less than $6 \mathrm{~mm}$ ), slender, spindle-shaped species with a posterior end often tapering to an elongate point and very long (8-14 times the trunk length), slender introvert. Neither hooks nor tentacles are present. However, occasionally a distal "frill" or fringe is observed which may represent reduced tentacles or just a torn introvert. On the posterior and anterior portions of the trunk, low elliptical or round papillae are present. Many worms exhibit transverse grooves, probably caused by irregular contractions of the circular muscle layers.

The two pairs of thin retractor muscles are about equal in size and distance from the ventral nerve cord. The short rectum is attached by a muscle to the body wall anterior to the anus and the location of the anus varies in relationship to the retractor origins (Cutler, 1973) but is never at the anterior of the trunk. This demarcation is poorly defined but we have used the nephridiopore location to mark this point. The nephridia in mature worms generally have two equally long lobes but one does find worms with the second lobe undeveloped or of a reduced size. This is common in 2 or $3 \mathrm{~mm}$ worms and as is the case in A. misakiana and Phascolosoma japonicum kurilense, the production of two lobes is very likely a delayed ontogenetic phenomenon. Gametes were present in those from St. 19, 126, and 143. Previous Japanese Records: None.

Material Examined: Hayashi-8 stations from Tango-kai, Wakasa Bay; 63-116 m; 1978; 41 spec. Imajima-Sto 117, Kabira Bay, Ishigaki Isl.; surface of shell; 7/27/73; 2 spec. St. 126, Arita Bay, Kushimoto-cho, Wakayama Pref.; 7/17/78; 5 spec. St 130, Kushimoto H; $35 \mathrm{~m}$; dredge; 7/78; 52 spec. St. 134, Tosa Bay; $65 \mathrm{~m} ; 2 / 18 / 70 ; 31$ spec. St. 143, Basebo Bay; $10 \mathrm{~m} ; 8 / 72 ; 7$ spec. St. 154, off Kunosan, Suruga Bay; 56-64 m; dredge; 20 spec. St. 156, Okinose, Suruga Bay; 95-100 m; 2/78; 5 spec. St. 161, Tosa Bay; dredge; 7/74; 25 spec. Kosaka-from Suruga Bay: St. 8, Yui-Yaizu, $92 \mathrm{~m} ; 6 / 24 / 71 ; 6$ spec. St. 12, Nishi-Izu, $30 \mathrm{~m} ; 7 / 24 / 73 ; 2$ spec. St. 13, Uchiura Bay, $25 \mathrm{~m} ; 9 / 27 / 71$; 1 spec. St. 17a, Nishi-Izu, $28 \mathrm{~m}$; 7/24/73; 2 spec. St. 17b, Yui-Yaizu, $45 \mathrm{~m}$; 6/25/71; 25 spec. St. 18, Yui-Yaizu; $97 \mathrm{~m} ; 6 / 25 / 71$; 100 spec. St. 28, Yui-Yaizu; $55 \mathrm{~m} ; 6 / 25 / 71 ; 25$ spec. St. 53, Uchiura Bay; $70 \mathrm{~m} ; 9 / 29 / 71 ; 8$ spec. Nishikawa-St. 13, off Gobo, Wakayama; 3/78; 12 spec. Sts. 18, 19, 20, off Kagawa Pref., Seto Inland Sea; 1975; 8 spec. St. 21, off Hyogo Pref., Seto Inland 
Sea; $1975 ; 16$ spec. St. 40, Tanabe Bay; 1/177; 20 spec. Yasuda-Gobo St., off Gobo, Wakayama Pref.; $20 \mathrm{~m} ; 4 / 78$; 11 spec.

Japanese Distribution: Found at depths of 10-100 $\mathrm{m}$ from Wakasa Bay in the Japan Sea and along the Pacific side of Honshu and Shikoku from Suruga Bay to west of Kyushu in Sasebo Bay plus the Inland Sea.

Worldwide Distribution: In the Atlantic this species has been found along the east coast of the U.S. and west coast of Africa; in the Indian Ocean from South Africa and Madagascar; Gulf of Aden and Arabian Sea and in the Pacific from Indonesia to Australia and New Zealand.

\section{Genus Aspidosiphon Diesing, 1851}

A chitinous shield-like structure invariably present at anterior and generally at posterior extremity of trunk; introvert arising from ventral side of anterior shield (Fig. 13, A). Hooks with one or two points present in most cases; longitudinal muscle layers continuous or in separate bands. One pair of introvert retractor muscles, fused to varying degrees; two nephridia.

Discussion: Stephen (1964) divided the genus Aspidosiphon into two genera solely on the basis of their longitudinal body musculature. In Aspidosiphon it forms a continuous sheet, whereas in Paraspidosiphon it is alleged to be divided into numerous bands or bundles. He believed this feature to be constant and unequivocal but
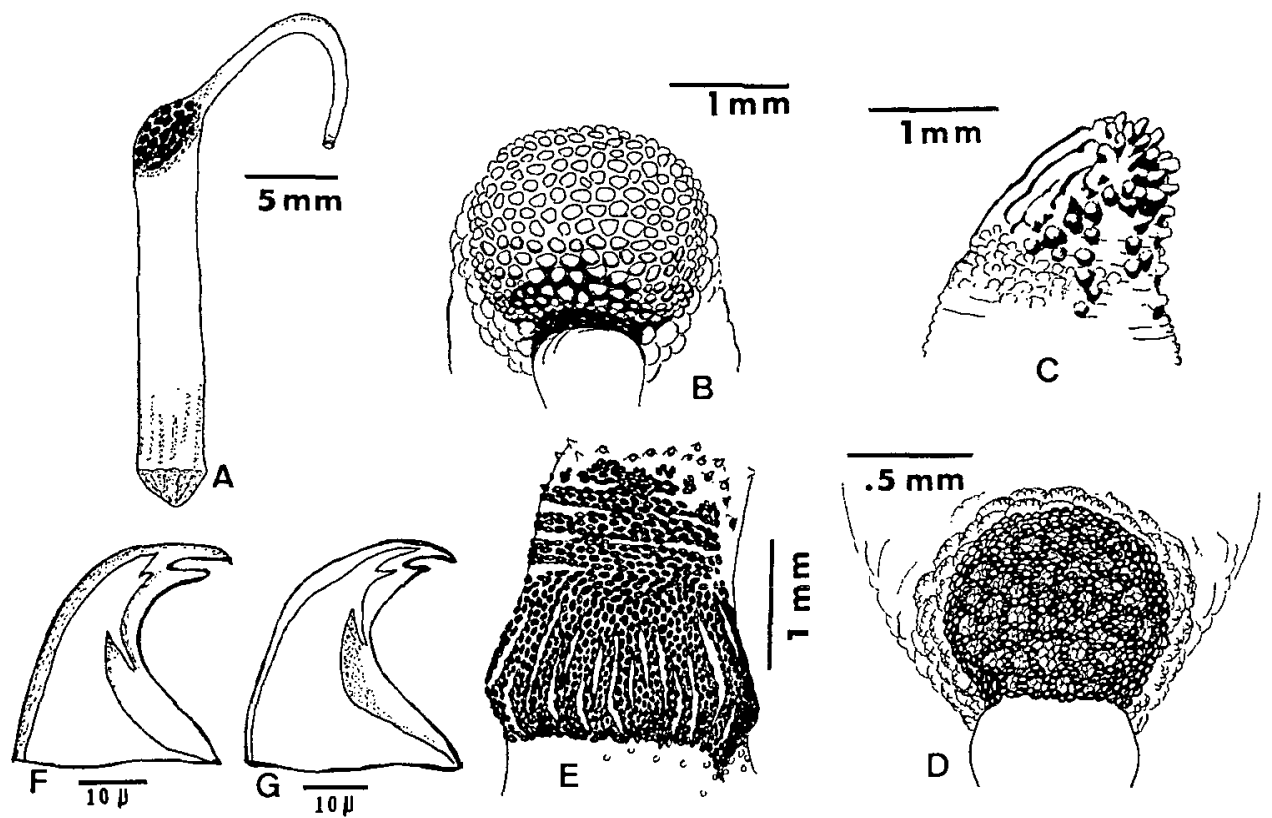

Fig. 13. Genus Aspidosiphon. A: General form. B: Anal shield of $A$. steenstrupii. C: Anal shield of $A$. cf. parvulus. D: Anal shield of $A$. misakiensis. E: Anal shield of $A$. muelleri. F: Hook of $A$. elegans. G: Hook of $A$. steenstrupii. 
our observations (and those of others) do not support this contention i.e., the nature of the body musculature is not clear-cut. Some individuals of Aspidosiphon species show a tendency for the layer to separate into more or less distinct units especially toward the anterior end of the trunk. In some small specimens of Paraspidosiphon species the longitudinal muscle bands are very difficult to distinguish. Stephen believed this single feature was, by itself, a criterion significant enough to warrant generic rank. We remain unconvinced, therefore, we herein continue to treat Paraspidosiphon as a subgenus.

Key to Aspidosiphon species known from Japan

1A. Longitudinal musculature of body wall usually divided into separate bundles....................................... subgenus Paraspidosiphon..... 2

1B. Longitudinal musculature a continuous sheet (sometimes splitting towards anterior end in mature worms) $\ldots . . . . . . . . . .$. subgenus Aspidosiphon s.s...... 5

2A. Introvert hooks have only single points......................... angulatus

2B. Introvert hooks of two types, proximal ones unidentate and distal ones

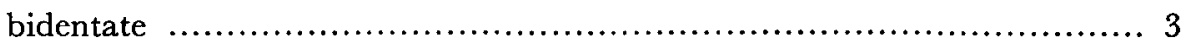

3A. Retractor muscle origins at posterior end of trunk; anal shield with indistinct grooves dorsally.............................................. 4

3B. Retractor muscle origins from $75-90 \%$ of the distance to the posterior end of the trunk; anal shield made up of flat, irregular, polygonal subunits and without grooves (Fig. 13, B) .............................. steenstrupii

4A. Anal shield with conical, spine-like units around ventral margin; component subunits more or less separate, distinct and granular (Fig. 13, G)...

A. parvulus

4B. Anal shield without ventral spines and overall appearance solid with no space between subunits

A. truncatus

5A. Introvert hooks absent; anal shield composed of very fine granules (Pl. II,

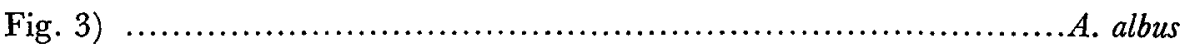

5B. Introvert hooks present; anal shield composed of coarse granules or

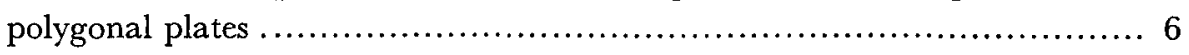

6A. Large brown, spine-like conical papillae present on basal portion of introvert (Pl. II, Fig. 4) .............................................. elegans

6B. Large brown spine-like papillae absent from introvert .................. 7

7A. Introvert hooks all unidentate.................................. exhaustus

7B. Introvert hooks of two types, uni and bidentate, the latter only on distal region ............................................................. 8

8A. Anal shield consists of flat, randomly scattered, granular, polygonal units (Fig. 13, D); intestinal coils irregular and loosely coiled............ misakiensis

8B. Anal shield with longitudinal furrows dorsally and irregular transverse furrows and tall conical units ventrally (Fig. 13, E); gut coil regular and tightly wound A. muelleri 


\section{Aspidosiphon (Aspidosiphon) elegans (Chamisso and Eysenhardt, 1821)}

(Fig. 13, F; Pl. II, Fig. 4)

Description: These animals are smooth, white, or translucent and are 2-57 mm long (most around 10-15 mm). There are bidentate hooks (Fig. 13, F) arranged in rings distally and unidentate, scattered, spine-like hooks behind these. Towards the base of the introvert, there is an area of large, dark, conical spine-like papillae, the larger ones with the apex directed posteriorly (PI. II, Fig. 4). These structures are characteristic for this species and if the introvert is not extended require dissection to discern. Short, stubby tentacles are arranged in a crescent dorsal to the mouth (ibid.). The anal shield is well developed and made up of units which look like mosaic tiles, without grooves or furrows.

The longitudinal muscles form a continuous sheet except for the anterior dorsal region where fragmentation into separate bundles occurs in some worms. The retractor muscles usually originate from $85-90 \%$ of the distance to the posterior end of the trunk. The specimen from St. 31 (Cutler) has only one retractor, the right one is missing. The nephridia are $50-75 \%$ of the trunk length and attached to the body wall for $50-90 \%$ of their length.

A peculiar variation is seen in five of the worms from Cutler St. 18 which were 5 and $6 \mathrm{~mm}$ long. These did not exhibit the large spines on the introvert base and the anal shield was much paler than normal. This may simply be due to their young age and small size. Cutler and Cutler (1981) consider A. spinalis Ikeda, to be a junior synonym. Cutler (1973) used the name $A$. spinalis for what is now considered a new species, A. gosnoldi (Cutler, 1981).

Previous Japanese Records: Ikeda, $1904-A$. spinalis from Amami-Oshima.

Material Examined: Horikishi-many stations; Kabira Bay, Ishigaki-jima; coral reef; 77 spec. Nishikawa-St. 14, near Seto M.B.L., Wakayama Pref.; intertidal; 1/78; 1 spec. St. 31 off Hikigawacho, Wakayama; subtidal; 12/11/73; 5 spec. St. 32 of Hikigawa-cho, Wakayama; subtidal; 12/19/75; 3 spec. Imajima-St. 111, Hahajima, Ogasawara Isls., intertidal; 6/69; 1 spec. St. 112, Sumizaki, Shionomisaki; intertidal; 7/20/78; 1 spec. St. 113, Miyanohama, Chichijima, Ogasawara Isls.; 6/69; 3 spec. St. 123, Arita Bay, Kushimoto-cho, Wakayama Pref.; tidal zone; 7/78; 2 spec. CutlerSt. $12,2 \mathrm{~km}$ east of Koniya, Amami-Oshima; rocks; 4/12/79; 3 spec. St. 13, $5 \mathrm{~km}$ east of Koniya, Amami-Oshima; dead coral; 4/13/79; 2 spec. St. 16, $6 \mathrm{~km}$ east of Koniya, Amami-Oshima; dead coral; 4/14/79; 42 spec. St. 18, Sesoko M.B.L., Okinawa; coral; 4/17/79; 12 spec. St. 20, NNW corner, Sesoko Isl., Okinawa; coral; 4/17/79; 9 spec. St. 31, Hisashi tidal pool, Miyake-jima; 6/15/79; 1 spec. St. 32, Igaya Bay, Miyake-jima; 6/15/79; 1 spec. St. 37, east side Ponape, East Caroline Islands; fringing reef; 7/30/79; 10 spec. St. 38, Laura, Majuro, Marshall Isl., cemented coral sands; lagoon; 8/2/79; 4 spec. St. 39, Laura, Majuro, Marshall Isl., dead coral; ocean side; 8/2/79; 21 spec.

Japanese Distribution: This is a fairly common species found burrowing in coral or soft rock from the Ogasawara Islands, Miyake, and Wakayama, south to Arita Bay, Amami-Oshima, Okinawa, and Ishigaki Island.

Worldwide Distribution: This is a fairly common species found at scattered points in the Indian as well as the South Pacific Oceans. Fairly common in the Caroline and Marshall Islands. It is also reported from the Red Sea. 


\section{Aspidosiphon (Aspidosiphon) exhaustus Sluiter, 1912}

Description: This species has two external characters which facilitate its identification; the presence of only unidentate hooks in rows distally and scattered proximally; and an anal shield which is dark with well-defined borders made up of closely set units giving it a solid appearance with longitudinal grooves in its dorsal 2/3-3/4. These inhabit empty gastropod or occasionally scaphopod shells and are not large (less than $20 \mathrm{~mm}$ ). The retractor muscles originate from the posterior end of the trunk. The nephridia are from $30-50 \%$ of the trunk length and a caecum is present on the rectum.

Previous Japanese Records: None.

Material Examined: Nishikawa-St. 7, $20 \mathrm{~km}$ SE off Koshikijima Isl., W. of Kyushyu; $350-400 \mathrm{~m}$; 10/17/78; 3 spec.; col. T. Imaoka. Imajima-St. 122, Tsukumo Bay, Noto Peninsula; 20 m; 6/66; 2 spec. Horikoshi-St. 79-11, OT04, $34^{\circ} 47^{\prime} \mathrm{N}, 138^{\circ} 42^{\prime} \mathrm{E} ; 450 \mathrm{~m} ; 7 / 19 / 79 ; 8$ spec. St. 76-03 003, $34^{\circ} 56^{\prime} \mathrm{N}, 138^{\circ} 44^{\prime} \mathrm{E} ; 373 \mathrm{~m} ; 2 / 27 / 79 ; 1 \mathrm{spec}$. St. 5, in front of Noto M.B.L.; 1 spec. Hayashi-St. K2, Tango-kai, Wakasa Bay; $68 \mathrm{~m} ; 6 / 7 / 78 ; 1$ spec. St. A-3, Kumihama Bay; $3 \mathrm{~m} ; 4 / 78 ; 8$ spec. St. TA-9-27, Tango-kai, Wakasa Bay; $68 \mathrm{~m}$; 7/26/76; 1 spec. St. TA-19-36, Tango-kai, Wakasa Bay; $75 \mathrm{~m} ; 7 / 26 / 76 ; 1$ spec. Cutler-St. 25, Sagami Bay, near Misaki M.B.L.; $80 \mathrm{~m} ; 5 / 25 / 79 ; 1$ spec. St. 25, Sagami Bay, near Misaki M.B.L.; $10 \mathrm{~m}$; 5/25/79; 1 spec.

Japanese Distribution: This is a deeper water species not previously reported from Japan. We have records from Wakasa Bay and Noto Peninsula, one record west of Kagoshima and others dredged from Suruga and Sagami Bays.

Worldwide Distribution: This is found from several sublittoral locations in the South Pacific, Gulf of Tonkin, South Australia, West Africa, and the type from off Morocco in the Atlantic, plus several recent records from the Western Indian Ocean, being absent from the eastern Pacific Ocean.

\section{Aspidosiphon (Aspidosiphon) misakiensis Ikeda, 1904}

(Fig. 13, D)

Description: This is a small species with trunks usually $5-10 \mathrm{~mm}$ long (largest seen was $18 \mathrm{~mm}$ ) which usually inhabit soft intertidal rock. The introvert is longer than the trunk, up to three times as long in some worms, and carries rings (70 in a $9 \mathrm{~mm}$ worm) of bidentate hooks ( $35 \mu$ tall) distally with scattered unidentate hooks (sometimes referred to as spines) proximally. These are discussed in Cutler and Cutler (1981) with measurements. The anal shield is usually dark brown and made up of granular units of moderate and irregular size (Fig. 13, D). The caudal shield varies from dark to light brown.

The longitudinal body musculature may be a smooth continuous sheet but as noted elsewhere often appears as partially separate longitudinal bands, i.e., this layer seems to split or separate especially along the dorsal anterior region. This is a troublesome trait causing one to initially place it in the wrong subgenus. The nephridia are from $50-100 \%$ of the trunk length and attached to the body wall 
for $50-100 \%$ of their length. The gut coil is uniquely loose and irregular for this genus. The rectum bears a caecum. The retractor muscles originate close (80$90 \%$ ) to the posterior end of the trunk.

Previous Japanese Records: Ikeda, 1904 -near Misaki M.B.L.

Material Examined: Imperial Household- 154, Same-jima, Hayama, Sagami Bay; 10 m; 7/18/53; 1 spec. Univ. of Tokyo, Ikeda's coll.-Nako-zaki, Koajiro, Misaki; Aug. 5; 1 spec. NishikawaSt. 1, near estuary of Sendai River, Tottori Pref.; 6/78; 1 spec. St. 2, same; 12/78; 1 spec. St. 3, same; 10/77; 2 spec. St. 23, off Gobo, Wakayama; $5 \mathrm{~m}$; rocky; 5/78; 6 spec. St. 32, off Hikigawacho, Wakayama; subtidal; 12/11/73; 2 spec. Imajima-St. 109, Wamiura, Tsushima Isl.; intertidal; 7/69; 1 spec. St. 111, Hahajima, Ogasawara Isls.; intertidal; 6/69; 2 spec. St. 112, Sumizaki, Shiononmisaki; intertidal; 7/20/78; 4 spec St. 115, same; 1 spec. St. 125, off Shionomisaki; 50 $\mathrm{m} ; 7 / 78 ; 3$ spec. Cutler-St. 11, $2 \mathrm{~km}$ wets of Kataura, Kagoshima Pref.; mudstone; 4/10/79; 1 spec. St. 22, Misaki M.B.L.; sandy patches in rocks; 4/28/79; 1 spec. St. 28, Kurasaki, Miura Pen.; sandy patches between rocks; 5/25/79; 2 spec. St. 29, Tateyama, Boso Pen.; near Marine Lab.; 6/12/79; 5 spec. St. 31, Hiashi tidal pool, Miyake-jima; 6/15/79; 4 spec. St. 33, dead coral off Miyake-jima; 6/15/79; 3 spec. St. 34, Kurasaki, Miura Pen.; 6/25/79; 2 spec.

Japanese Distribution: From intertidal to $50 \mathrm{~m}$ along the Pacific side of Honshu from Tokyo and Sagami Bays, Wakayama to Kagoshima. In the Japan Sea it has been recorded from Tottori Prefecture and Tsushima Island.

Worldwide Distribution: This species has not been found outside of Japan.

\section{Aspidosiphon (Aspidosiphon) muelleri Diesing, 1851}

(Fig. 13, E)

Description: These 69 specimens have trunks ranging from 2-34 $\mathrm{mm}$ in length but up to $80 \mathrm{~mm}$ lengths have been reported. They usually inhabit empty gastropod shells, and have dark shields at both ends (Fig. 13, E). The anal shield is usually divided into two or three regions: a dorsal zone of longitudinal ridges, a middle zone of polygons sometimes arranged in transverse ridges but sometimes inconspicuous and a ventral portion of warty units which may be conical or spine-like in some individuals. The caudal shield may be less well developed and paler, with radiating furrows.

The introvert, when extended, may be as long as twice the trunk length and carries rings of hooks (up to 100). The distal hooks usually exhibit a secondary point and may be $25 \mu$ tall. The mid-section of the introvert has scattered, blunter, unidentate hooks, sometimes called spines. Between the rings of hooks tubular papillae may be seen. The longitudinal muscle layer sometimes appears split into bands in the area of the anal shield but is generally a continuous sheet. The pair of retractor muscles originate at, or just in front of, the posterior end of the trunk. These may appear as a single muscle with two roots. The nephridia open at the same level as the anus, are $25-80 \%$ of the trunk length and the degree of attachment is variable. There is usually a small caecum on the rectum. The specimens from Imajima's St. 147 and 148 are assigned to this species with some uncertainty due to their small size and damaged condition. 
Remarks: There is a complex of species in this genus which are morphologically very similar: A. inquilinus, A. jukesii, A. kovaleskii and A. muelleri (see Murina, 1964; Gibbs, 1977; Cutler and Gutler, 1979; Edmonds, 1980). The presumed differences lie in the nature of the anal shield, length of introvert, presence or absence of bidentate hooks, and degree of attachment of the nephridia to the body wall. While these may be significant differences, the literature on this is not consistant and there seems to be overlap of characteristics in the various populations. A comparative study is needed. We are only using one name for this population and further study may demonstrate more than a single biological species to be present.

Previous Japanese Records: Ikeda, 1924 -near Misaki M.B.L.

Material Examined: Imperial Household- $\# 244$, Shuraga-ne, Sagami Bay; $40 \mathrm{~m} ; 7 / 14 / 56 ; 1$ spec. \# 391, Amadaiba, Sagami Bay; $61 \mathrm{~m}$; 1/19/59; 2 spec. \#495, Amadaiba, Sagami Bay; 65-75 m; $7 / 26 / 59 ; 1$ spec. \#643, off Jogashima, Sagami Bay; $150-250 \mathrm{~m} ; 6 / 3 / 60 ; 1$ spec. $\$ 779$, W of Jogashima, Sagami Bay; 130-150 m; 2/1/63; 1 spec. $\# 860, W$ of Zyogashima Light House, Sagami Bay; $56-52 \mathrm{~m} ; 2 / 11 / 64 ; 1$ spec. \#865, Shuraga-ne, Sagami Bay; $30-40 \mathrm{~m} ; 2 / 5 / 64 ; 1$ spec. Yokoyama-Kiire, Kagoshima Bay: St. 2, $12 \mathrm{~m}$; 12/14/79; 1 spec. St. 4, 15 m. St. 14, $27 \mathrm{~m} ; 6$ spec. Nishikawa-St. 4, near estuary of Sendai River, Tottori Pref.; 6/78; 2 spec. St. 39, Tanebe Bay; $11 / 77 ; 18$ spec. Imajima-St. 108, Tanegashima; intertidal; 6/75; 1 spec. St. 125, off Shionomisaki; $50 \mathrm{~m}$; 7/78; 3 spec. St. 129, off Nii-jima; $50-75 \mathrm{~m}$; dredge; 15 spec. St. 147, 148, off IzuOshima; 23-65 m; dredge; 7/77; 5 spec. St. 78-11 OT6, Suruga Bay; 1 spec. St. 78-18 OT7, Suruga Bay; 1 spec. Cutler-St. 2, Sagami Bay near Misaki M.B.L.; $30 \mathrm{~m}$; 3/13/79; gastropod shell; 1 spec. St. 10, Island $1 / 2 \mathrm{~km}$ off Katura, Kagoshima Pref.; 4/10/79; 3 spec. St. 24, Sagami Bay near Misaki M.B.L.; $90 \mathrm{~m}$; 5/25/79; solitary coral; 1 spec. Inaba-Oki Island, Japan Sea; 60 m; $5 / 27 / 76 ; 2$ spec.

Japanese Distribution: An intertidal/subtidal distribution from Suruga and Sagami Bays, off Wakayama and Kagoshima Prefectures in the Pacific, plus records from the Japan Sea.

Worldwide Distribution: This is a common deeper water species in the Eastern Atlantic and Mediterranean Sea. In the Pacific it is found only around Japan with one record from the Java Sea.

\section{Aspidosiphon (Aspidosiphon) sp. (cf. albus Murina, 1967)}

(Pl. II, Fig. 3)

Description: This single small $(5 \mathrm{~mm})$ worm has a damaged, incomplete introvert so it's identification is uncertain. Aspidosiphon exiguus (Edmonds, 1974) is very similar, the main difference being that it has hooks while $A$. albus is hookless. This species is usually less than $10 \mathrm{~mm}$ long, slender, white to transparent with an anal shield made up of very fine granular, pale golden units (Pl. II, Fig. 3). The introvert is more than twice the trunk length and carries small tubular papillae. The two retractor muscles originate very near the caudal shield and the longitudinal muscle layer is generally continuous (see Gutler, 1973: 172). Additional undamaged specimens should be located before this name is associated with the Japanese fauna. Previous Japanese Records: None. 
Material Examined: Cutler-St. 24, Sagami Bay near Misaki M.B.L.; 90 m; from gastropod shell; $5 / 25 / 79 ; 1$ spec.

Japanese Distribution: A single specimen dredged from Sagami Bay. Worldwide Distribution: This species is known from Cuba and along the East coast of the U.S. up to $35^{\circ} \mathrm{N}$ at depths between $10-120 \mathrm{~m}$.

\section{Aspidosiphon (Paraspidosiphon) angulatus Ikeda, 1904}

Description: This form is easily identified as it is the only Japanese member of this subgenus without bidentate hooks. The body wall is often translucent so that the muscle bands can be seen through it. The bands are not always well-defined and frequently anastomose. The anal shield has borders which merge into the surrounding epidermis, exhibits longitudinal grooves dorsally and is granular ventrally. The retractor muscles originate in the third quarter of the trunk and the nephridia, which open just behind the anus, are about half the trunk length.

This uncommon species was not found by us even though we collected over 600 members of this genus from Amami-Oshima, Okinawa, Guam and the East Caroline Islands. Also we were unable to locate Ikeda's specimen for verification. Previous Japanese Records: Ikeda, 1904 -Katsuyoki Inlet, Amami-Oshima; intertidal.

Material Examined: None.

Japanese Distribution: Known only from Amami-Oshima.

Worldwide Distribution: There are records from Palau in the West Caroline Islands, French Polynesia, and Madagascar.

\section{Aspidosiphon (Paraspidosiphon) steenstrupii Diesing, 1859}

(Fig. 13, B and G)

Description: This common tropical species is typically about $15 \mathrm{~mm}$ long but our material ranges from $6-40 \mathrm{~mm}$. The animals are pale tan to dark brown with introverts sometimes longer than the trunks, tipped with a cluster of 8-12 tentacles dorsal to the mouth. The introvert has two kinds of hooks: complex bidentate hooks (Fig. 13, G) in rows distally and simpler, small, dark scattered unidentate spine-like hooks over most of the introvert, often exterding all the way back to its base. Superficially, the introvert resembles $A$.(A.) elegans but there is a clear difference when viewed closely.

The distinct anal shield is generally dark, not furrowed, and made up of dense, compact granules giving it a smooth appearance (Fig. 13, B). The skin just behind this shield often has a rough, corky texture. One specimen from Ponape (Cutler, St. 37) is without any pigmentation in its shield.

The infrequently anastomosing longitudinal muscle bands are often visible 
through the body wall. The pair of retractor muscles originate from the body wall $75-90 \%$ of the distance to the posterior end. The nephridia are usually $65-$ $75 \%$ of the trunk length and attached for half or less of their length.

Cutler and Cutler (1981) consider this species to include $A$. makoensis and $A$. formosanus. Edmonds (1980) maintains $A$. formosanus as a separate species based on the differences in the internal clear streak of the hooks. Our observations suggest that a single worm exhibits too much variation in this character for it to be used as species-specific.

Previous Japanese Records: Ikeda, 1904 -Ryukyu Islands and Amami-Oshima. Sato, 1939 -Miyako, Ryukyu Islands.

Material Examined: Univ. of Tokyo, Ikeda's coll.-Nishino-omote, Tanegashima Isl.; 1/1/03; 2 spec. plus 12 spec. in very poor condition with no station data. Nishikawa-St. 29, Kabira Bay, Ishigakijima; intertidal; 6/24/75; 1 spec. St. 30, Oojima, SE Okinawa; intertidal; 7/4/75; 1 spec. Imajima-St. 108, Tanegashima; intertidal; 6/75; 1 spec. Horikoshi-Kabira Bay, Ishigaki-jima; coral reef; 14 spec. Cutler-St. 12, $2 \mathrm{~km}$ E Koniya, Amami-Oshima; rock; 4/12/79; 37 spec. St. 13, 5 km E Koniya, Amami-Oshima; dead coral; 4/13/79; 3 spec. St. 15, $1 \mathrm{~km}$ E Koniya, AmamiOshima; dead coral 4/13/79; 1 spec. St. 16, $6 \mathrm{~km}$ E Koniya, Amami-Oshima; dead coral; 4/14/79; 7 spec. St. 18, Sesoko M.B.L., Okinawa; coral; 4/17/79; $98 \mathrm{spec.} \mathrm{St.} \mathrm{20,} \mathrm{NNW} \mathrm{corner,} \mathrm{Sesoko} \mathrm{Isl.,}$ Okinawa; coral; 4/17/79; 2 spec. St. 36, Pago Bay, Guam; coral rock; 7/27/79; 9 spec. St. 37, Ponape, East Caroline Isl., fringing reef; 7/30/79; 160 spec.

Japanese Distribution: A tropical species found from Tanegashima and south. Worldwide Distribution: A circumtropical species except not found in the eastern Pacific.

\section{Aspidosiphon (Paraspidosiphon) truncatus Keferstein, 1867}

Description: Only a single $12 \mathrm{~mm}$ worm was found by us, but Ikeda said his were up to $50 \mathrm{~mm}$ long (trunk plus introvert). The anal shield is dark and solid with radial furrows clearly set off from the light brown trunk. The small bidentate hooks are in rings followed by an area of unidentate spine-like scattered hooks. The retractor muscles originate from the posterior end and the nephridia are almost as long as the trunk.

Note: There are two apparent errors in Stephen and Edmonds (1972) with respect to this species. The first is the arrangement of the hooks; in the key (p. 239) and the text (p. 258) they are alleged to be scattered. If this were so it would be the only member of this subgenus whose hooks are not in rings. However, in Selenka et. al.'s (1883) redescription and other subsequent authors' works this species is described as having the distal hooks in rings and the proximal ones scattered as in all other Aspidosiphon. The second problem is in its distribution. Keferstein's original material is said to come from Panama but we do not know whether from the Garibbean or Pacific side. Also Fischer's (1914) record from San Salvador is on the Pacific coast of Central America. This misled us in Cutler and Cutler (1979) to mistakenly report its distribution. There are no firm records of this species from any part of the Atlantic Ocean. Additionally, two records from Madagascar are 
omitted in Stephen and Edmonds (Herubel, 1908 and Hammerstein, 1915). Previous Japanese Records: Ikeda, 1904 -Okinawajima, Ryukyu Islands and AmamiOshima.

Material Examined: Cutler-St. 20; in front of Misaki M.B.L.; in rock; 4/28/79; 1 spec.

Japanese Distribution: An apparently rare species found at Misaki M.B.L. and Ryukyu and Amami Islands.

Worldwide Distribution: This is an Indo-Pacific species with two records from the eastern Pacific off Panama and San Salvador.

Aspidosiphon (Paraspidosiphon) sp. (cf. parvulus Gerould, 1913)

(Fig. 13, G)

Description: This single small $(6 \mathrm{~mm})$ worm is not identified with certainty. Gerould's original material of $A$. parvulus was a similar size ( 3 and $4 \mathrm{~mm}$ ) from similar depth $\left(29 \mathrm{~m}\right.$ ) and latitude (about $35^{\circ} \mathrm{N}$ ) but in the western Atlantic. Cutler (1973) moved it into this subgenus and considered it a senior synonym of $A$. spinososcutatus, after a reexamination of the type plus over 1000 recently collected specimens ranging in size from 2-14 mm.

The anal shield has small spines ventrally and ill-defined furrows dorsally (Fig. 13, C). Neither shield is sharply set off from the trunk. The introvert, which is longer than the trunk (but completely retracted in this specimen), has rings of bidentate and unidentate hooks. The frequently anastomosing longitudinal musculature is not well defined suggesting the possibility of a continuous sheet which has fractured. The retractor muscles originate on the caudal shield, the nephridia open just posterior to the anus and are about $50 \%$ of the trunk length.

Material Examined: Nishikawa-St. 25, off Gobo, Wakayama Pref.; 5 m; rocky; 5/78; 1 spec.

Worldwide Distribution: A. paroulus is known from the east coast of the U.S., the Caribbean, and the Gulf of Mexico.

\section{Genus Cloeosiphon Grube, 1868}

Anterior end of trunk with a spheroid to pineapple shaped cap (anal shield) made up of distinct polygonal calcareous units. Introvert protrudes from center of cap and bears rows of bidentate hooks. Two nephridia, one pair of introvert retractor muscles and longitudinal musculature undivided into separate bands. A monotypic genus.

Cloeosiphon aspergillus (Quatrefages, 1865)

(Fig. 14, A; Pl. II, Fig. 5)

Description: This coral inhabiting species is cylindrical in form with trunks measur- 

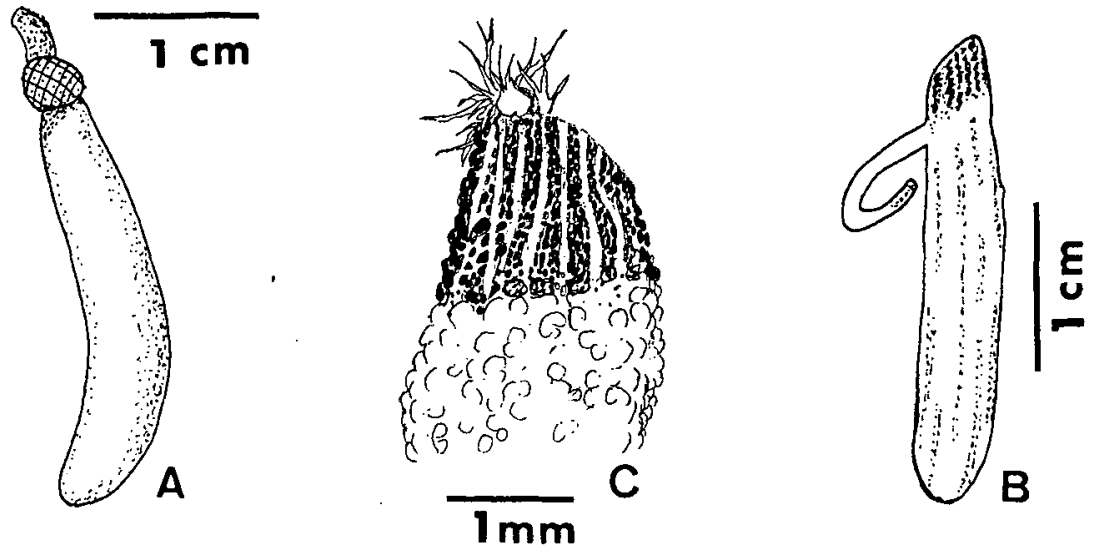

Fig. 14. Genera Cloeosiphon (A) and Lithacrosiphon (B-C). A: General form of $C$. aspergillus. B: General form of Lithacrosiphon sp. C: Anal shield of L. cristatus with epiflora and fauna growing on apex.

ing more than $80 \mathrm{~mm}$ in length (most $10-30 \mathrm{~mm}$ ). The anterior end is covered by a white cap of polygonal calcareous units each with a dark central pore. This cap makes identification easy if the animal is removed from its habitat intact. The shape of this cap and its subunits is quite variable depending on the microhabitat and state of contraction at the time of fixation. This has led to the genesis of several other species names but there is now only this single valid species (see Stephen and Edmonds, 1972: 268).

The posterior end of the trunk is without any shield-like structure. The long slender introvert protrudes from the center of the anterior shield/cap unlike Aspidosiphon and bears rows of sharp, bidentate hooks. The longitudinal musculature is undivided and there is a single pair of retractor muscles. The spindle muscle is posteriorly attached.

Previous Japanese Records: Ikeda, 1904-C. japonicum from Ryukyu and Amami Islands.

Material Examined: Univ. of Tokyo, Ikeda's coll.-2 spec. Horikoshi-Kabira Bay, Ishigakijima, 1977-78; $28 \mathrm{spec}$. Cutler-St. 12, $2 \mathrm{~km}$ E of Koniya, Amami-Oshima; coral; 4/12/79; 8 spec. St. 13, Katetsu, $5 \mathrm{~km}$ E Koniya; coral; 4/13/79; 1 spec. St. 15, $1 \mathrm{~km} \mathrm{E} \mathrm{of} \mathrm{Koniya;} \mathrm{4/13/79;} 3$ spec. St. 18, Sesoko M.B.L., Okinawa; coral; 4/17/79; 16 spec. St. 20, Kunribama, NNW Sesoko M.B.L.; 4/17/79; 1 spec. St. 37, E Ponape Island, East Carolines; reef; 7/30/79; 8 spec.

Japanese Distribution: A tropical species found only in the south from the Ryukyu and Amami Islands.

Worldwide Distribution: This is a widespread species found in shallow, tropical Indo-West Pacific regions.

Gesus Lithacrosiphon Shipley, 1902

Anterior end of trunk with anal shield in form of a hard, calcareous coneshaped cap (sometimes broken and flat or overgrown with epiphytes) (Fig. 14, B). 
Slender introvert from ventral side at base of cap with rows of hooks at distal end. Longitudinal muscles in separate bands and spindle muscle attached posteriorly. One pair of retractor muscles and two nephridia.

Remarks: In Cutler \& Jurczak (1975) this genus was critically reviewed, the conclusion being that there were perhaps three valid species. In Cutler and Cutler (1981) one of these three (L. uniscutatus Ikeda) was reconsidered and at that point was reduced to the status of a junior synonym of $L$. cristatus, leaving only two species, one with a grooved anal cap ( $L$. cristatis) and the other with a granular cap ( $L$. maldivensis). Only the former has been found in Japanese waters.

\section{Lithacrosiphon cristatus Sluiter, 1902}

(Fig. 14, G)

Description: These worms are cylindrical, pale tan, and are commonly 8-15 mm long but a few are up to $25 \mathrm{~mm}$ and one from Guam is $38 \mathrm{~mm}$. The anal shield has $40 \pm 10$ longitudinal grooves (Fig. 14, C) and the introvert bears rows of bidentate hooks around the distal tip while proximally there are scattered unidentate hooks. In some individuals, the bidentate hooks exhibit wear so that the apical point is worn down giving some hooks a blunter, almost unidentate appearance. Care should be taken to examine several hooks from the most distal tip to confirm the true nature of these hooks as mistakes in the past have led to inaccurate descriptions. The pair of retractor muscles originate in the posterior $20 \%$ of the trunk and the longitudinal body musculature is divided into 13-24 (usually 14-18) anastomosing bands. Two long nephridia are present, usually $50-100 \%$ of the trunk length.

Previous Japanese Records: Ikeda, 1904 -Aspidosiphon uniscutatus, Kataura (Kagoshima Pref.).

Material Examined: Horikoshi-Kabira Bay, Ishigaki-jima; 2 spec. Cutler-St. 12, $2 \mathrm{~km} \mathrm{E}$ of Koniya, Amami-Oshima; coral; 4/12/79; 1 spec. St. 18, Sesoko M.B.L., Okinawa; coral; 4/17/79; 2 spec. St. 36, Pago Bay, Guam; coral; 7/27/79; 1 spec. St. 37, E Ponape Island; fringing reef; 7/30/79; 89 spec. St. 39, Laura, Majuro, Marshall Isl.; ocean coral; 8/2/79; 1 spec.

Japanese Distribution: Besides Ikeda's synonomized specimen from Kataura, it is found in Kabira Bay, Okinawa, and Amami-Oshima. We also found it on three Micronesian islands.

Worldwide Distribution: Found in tropical waters of the Pacific Ocean and Caribbean Sea; absent from the Indian and eastern Atlantic Oceans.

\section{Biogeographical Notes}

After consulting the literature on the biogeography of Japanese marine animals e.g., Nomura and Hatai (1936), Miyadi, Kuroda and Habe (1953), Utinomi (1955), 


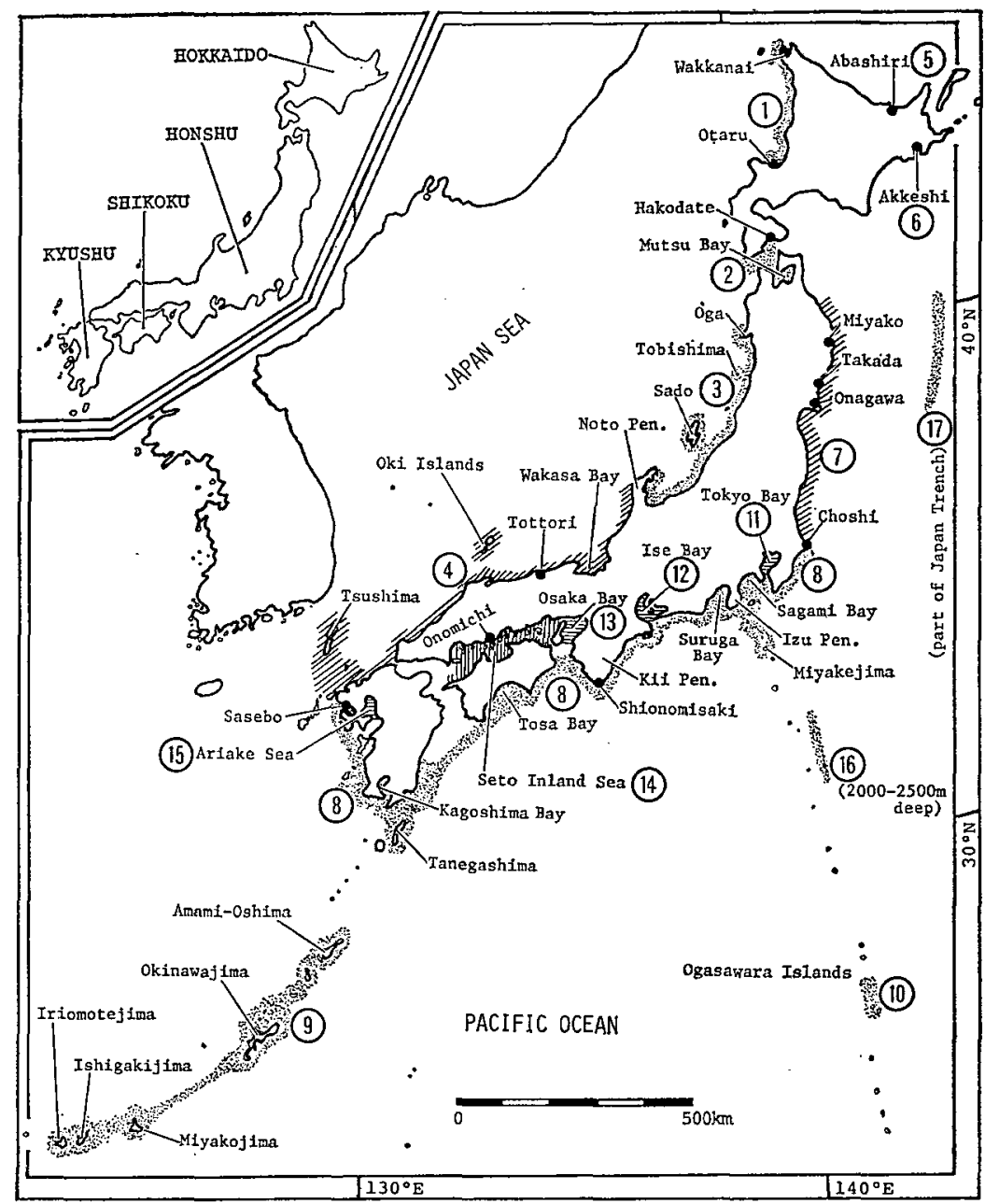

Fig. 15. Map of Japanese Islands showing collection sites divided into 17 districts.

Horikoshi (1962), Okutani and Chinzei (1976) and Nishimura (1965, 1966, 1970, 1981), and comparing the sipunculan fauna of each locality, the localities referred to in the present paper are provisionally divided into 17 districts as shown in Fig. 15. These districts may not represent distinct biogeographical regions. Table 1 shows the occurrence of each species in the above-mentioned districts, as well as the biogeographical elements to which each belongs as defined below:

1) Shallow water species:

IW: Indo-West Pacific element

IWA: Indo-West Pacific \& tropical-warm temperate Atlantic element CT: Circum-tropical element

WTW: World-wide, though not cosmopolitan; tropical to warm-temperate waters 


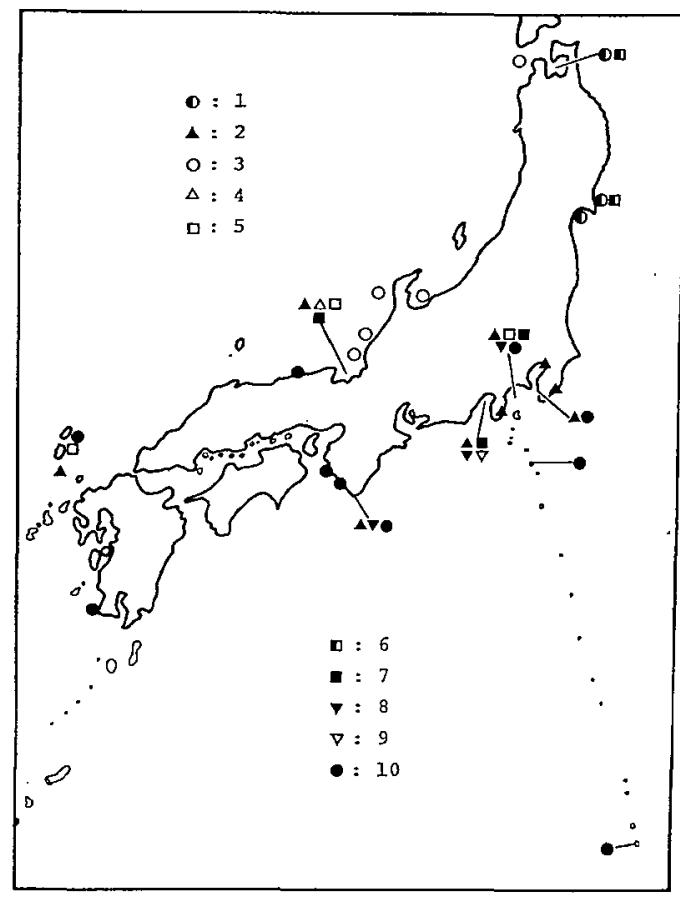

Fig. 16. Distribution of ten species or subspecies endemic to Japanese waters. 1 -Siphonosoma mourense, 2-Golfingia margaritacea ikedai, 3-G. m. soyo, 4-G. signa, 5-Phascolion artificiosum, 6-P. ikedai, 7-P. rectum, 8-Onchnesoma squamatum oliogopapillosum, 9-Themiste elliptica, 10-Aspidosiphon misakiensis.

AP: Amphi-Pacific element

IP: Warm temperate to cooler waters in the Indo-Pacific region

E: Endemic to Japanese waters

2) More or less deeper water (or eurybathic) species:

DE: Endemic to Japanese waters

DW: Not endemic to Japanese waters

Table 2 shows the number of species in each district according to their biogeographical elements and their distribution throughout Japanese waters.

Thirty-eight of these are shallow-water and 21 deeper-water species. The shallow-water fauna consists of $21(55 \%)$ southern (tropical water), seven $(18 \%)$ endemic, four (11\%) more or less cooler-water species (AP+IP), and six (16\%) species of uncertain identity. The deeper-water fauna consists of $17(81 \%)$ species recorded beyond Japanese waters, three (14\%) endemic species, and one $(5 \%)$ species of uncertain identity. The differences in the number of species recorded in the 17 districts as shown in Tables 1 and 2 may be the result of unequal sampling efforts. This may explain the complete lack or rarity of the deep-water species in many districts.

The following observations are offered pending more complete sampling in the future which may require some modification of these conclusions. 
1) The Japanese shallow water sipunculan fauna appears to lack any northern elements such as Okhotsk-Bering and Arctic-North Atlantic. This may be due to very few collections around Hokkaido.

2) The distribution of endemic species is shown in Fig. 16. According to several authors, the shallow bottoms of coastal regions, especially embayments are inhabited by many species endemic to Japanese and adjacent waters (Okutani and Chinzei, 1976; Nishimura, 1981), or categorized as "continental-coast element" (Miyadi, Kuroda and Habe, 1953) or "Japanese element" (Horikoshi, 1962). This pattern may not be applicable to the sipunculans. The ten endemic species (or subspecies) are distributed as follows: Golfingia margaritacea soyo and $G$. signa are limited to the Japan Sea; Siphonosoma mourense (for the possibility that this species may also occur out of Japan see page 201) and Phascolion ikedai to Mutsu Bay and the Pacific side of northeastern Honshu; Onchnesoma squamatum oligopapillosum and Themiste (Lagenopsis) elliptica to the Pacific coasts of Southwestern Japan; while the other four taxa, G. margaritacea ikedai, Phascolion artificiosum, P. rectum and Aspidosiphon misakiensis occur both in the Japan Sea and the Pacific side of Southeastern Japan. A. misakiensis also occurs in the Ogasawara Islands. In contrast, the Ogasawara Islands and the Nansei Archipelago (from Tanegashima southernly to district 9 of Fig. 15) seem to completely lack endemic species of their own. It is interesting that both taxa endemic to the Japan Sea inhabit deeper waters, instead of shallow and more or less warmer waters. This appears to be consistant with the general tendency of endemism in the Japan Sea already pointed out by Nishimura (1966). $O$. squamatum has only been recorded from cooler waters of the North Atlantic and not from the Pacific coasts of North America, so O. squamatum oligopapillosum is probably derived from an ancestral species in the northern element rather than having moved from the western coast of North America (for further discussion see Nishimura, 1981). Consideration of the origination of the other endemic taxa will be postponed until more data is available.

3) The fauna of district 2 (Mutsu Bay and Tsugaru Strait) is similar to that of district 7 (Pacific coast of Northeastern Honshu), while rather different from that of district 3 (Japan Sea side of Northeastern Honshu). This appears to be inconsistent with the prevailing view that the marine fauna of Mutsu Bay is far more similar to that of the Japan Sea than that of the Pacific coast of Northeastern Honshu (for example, Nomura and Hatai, 1936; Utinomi, 1955; Horikoshi, 1962 and Nishimura, 1981). Further collections of sipunculans in these districts are indispensable to draw firm conclusions.

4) The shallow-water fauna of district 7 has a significantly lower percentage of southern elements and a small number of recorded species than district 8 and is quite different from it. The border between districts 7 and 8 (Choshi) has been recognized by others (e.g. Nishimura, 1981) as a boundary between warm-temperate and cooler-temperate waters. On the contrary, the apparent differences in the shallow-water fauna between districts 3 and 4 may be due to inadequate sampling. According to the prevailing view of the biogeographical characteristics of the 
Table 1. Sipunculans recorded from Japanese waters.

\begin{tabular}{|c|c|c|c|c|c|c|c|c|c|c|c|c|c|c|c|c|c|c|c|}
\hline \multirow{2}{*}{ Species } & \multirow{2}{*}{ Depth (m) } & \multicolumn{17}{|c|}{ Districts } & \multirow{2}{*}{ Distribution } \\
\hline & & 1 & 2 & 3 & 4 & 5 & 6 & 7 & 8 & 9 & 10 & 11 & 12 & 13 & 14 & 15 & 16 & 17 & \\
\hline Sipunculus inclusus & $150-365$ & & & & & & & & $\mathrm{x}$ & $\mathrm{x}$ & & & & & & & & & IW \\
\hline S. norvegicus & $20-2470$ & & & & $\mathrm{X}$ & & & & $\mathrm{X}$ & & & & & & & & $\mathrm{X}$ & & DW \\
\hline S. nudus & $0-516$ & & $\mathrm{x}$ & & & & & $\mathrm{x}$ & $\mathbf{x}$ & $\mathbf{x}$ & & & & $\mathbf{x}$ & $\mathrm{x}$ & & & & WTW \\
\hline Siphonosoma cumanense & 0-subtidal & & $\mathrm{x}$ & $\mathbf{x}$ & & & & $\mathrm{X}$ & $\mathrm{x}$ & $\mathrm{x}$ & & $\mathrm{X}$ & $\mathrm{x}$ & $\mathrm{x}$ & $\mathbf{x}$ & & & & IWA \\
\hline S. funafuti & 0-subtida & & & & & & & & $\mathrm{X}$ & $\mathrm{X}$ & & & & & & & & & IW \\
\hline S. mourense & shallow (?) & & $\mathrm{x}$ & & & & & $\mathrm{x}$ & & & & & & & & & & & $E(?)$ \\
\hline S. vastum & 0 & & & & & & & & $\mathrm{x}$ & $\mathrm{x}$ & & & & & & & & & IW \\
\hline Golfingia appendiculata & $205-527$ & & & & $\mathrm{x}$ & & & & $\mathrm{x}$ & & & & & & & & & & DW \\
\hline G. elongata & $75-590$ & & & & $\mathrm{x}$ & & & & $\mathrm{x}$ & & & & & & & & & & DW \\
\hline G. maragritacea ikedai & $0-370$ & & & & $\mathbf{X}$ & & & & $\mathrm{X}$ & & & $\mathbf{X}$ & & & & & & & $\mathbf{E}$ \\
\hline G. m. soyo & $110-552$ & & $\mathbf{x}$ & $\mathrm{x}$ & $\mathrm{x}$ & & & & & & & & & & & & & & $\mathrm{DE}$ \\
\hline G. m. antarctica & 172 & & & & $\mathrm{x}$ & & & & & & & & & & & & & & DW \\
\hline G. signa & $307-658$ & & & & $\mathrm{X}$ & & & & & & & & & & & & & & $\mathrm{DE}$ \\
\hline G. vulgaris & $50-200$ & & $\mathbf{x}$ & & & & & $\mathbf{x}$ & $\mathbf{x}$ & & & & & & $\mathbf{x}$ & & & & DW \\
\hline Nephasoma abyssorum & $116-970$ & & & & $\mathrm{x}$ & & & & $\mathbf{x}$ & & & & & & & & & & DW \\
\hline N. confusa & 1020 & & & & & & & & $\mathrm{x}$ & & & & & & & & & & DW \\
\hline$N$. diaphanes & $75-320$ & & & & $\mathrm{x}$ & & & & $\mathrm{x}$ & & & & & & & & & & DW \\
\hline$N$. cf. pellucida & 0 & & & & & & & & & $\mathrm{x}$ & & & & & & & & & \\
\hline N. subhamata & $435-1690$ & & & & & & & & $\mathrm{x}$ & & & & & & & & & & DW \\
\hline$N$. species & $80-580$ & & & & & & & & $\mathrm{x}$ & & & & & & & & & & \\
\hline Phascolion artificiosum & $13-535$ & & & & $\mathbf{X}$ & & & & $\mathbf{x}$ & & & & & & & & & & $\mathrm{DE}$ \\
\hline P. dentalicolum & $30-260$ & & $\mathrm{x}$ & & & & & $\mathbf{x}$ & $\mathrm{X}$ & & & & & & & & & & DW \\
\hline P. ikedai & $34-$ ca. 60 & & $\mathrm{x}$ & & & & & $\mathrm{X}$ & & & & & & & & & & & $\mathbf{E}$ \\
\hline$P$. indicus & $80-250$ & & & & & & & & $\mathrm{x}$ & & & & & & & & & & DW \\
\hline P. pacificum & $297-6100$ & & & & & & & & $\mathrm{x}$ & & & & & & & & & $\mathbf{x}$ & DW \\
\hline P. rectum & $30-230$ & & & & $\mathrm{x}$ & & & & $\mathrm{x}$ & & & & & & & & & & $\mathbf{E}$ \\
\hline P. strombi & $68-647$ & & & & $\mathbf{X}$ & $\mathbf{x}$ & & & $\mathbf{x}$ & & & & & & & & & & DW \\
\hline
\end{tabular}




\begin{tabular}{|c|c|c|c|c|c|c|c|c|c|c|c|c|c|c|}
\hline P. cf. tuberculosum & $93-112$ & & & & & & & $\mathrm{x}$ & & & & & & \\
\hline $\begin{array}{l}\text { Onchnesoma squamatum } \\
\text { oligopapillosum }\end{array}$ & $14-250$ & & & & & & & $\mathrm{x}$ & & & & & & E \\
\hline O. steenstrupii & 130 & & & & & & & $\mathrm{x}$ & & & & & & DW \\
\hline Themiste (Lagenopsis) elliptica & 51 & & & & & & & $\mathrm{x}$ & & & & & & $\mathbf{E}$ \\
\hline$T .(L$.$) lageniformis$ & 0 (?) & & & & & & & & $\mathrm{x}$ & & & & & IWA \\
\hline T. (L.) minor & 0-shallow & & & $\mathrm{x}$ & & & & $\mathrm{x}$ & & & & $\mathrm{x}$ & & IW \\
\hline T. (Themiste) blanda & $0-5$ & $\mathrm{x}$ & $\mathrm{x}$ & & & & $\mathbf{x}$ & $\mathrm{x}$ & & & & & & AP \\
\hline$T .(T$.$) hexadactyla$ & 0-shallow & & $\mathbf{x}$ & & & $\mathrm{x}$ & $\mathrm{x}$ & & & & & & & AP \\
\hline Thysanocardia nigra & $0-200$ & $\mathrm{x}$ & $\mathrm{x}$ & & & $\mathbf{x}$ & $\mathbf{x}$ & $\mathrm{x}$ & & $\mathbf{x}$ & $\mathrm{x}^{\prime}$ & $\mathrm{x}$ & $\mathrm{x}$ & AP \\
\hline$T$. species & $76-127$ & & & & $\mathbf{x}$ & & & $\mathrm{x}$ & & & & & & \\
\hline Antillesoma antillarum & 0-shallow & & & & & & & $\mathrm{x}$ & $\mathrm{x}$ & & & $\mathrm{x}$ & $\mathrm{x}$ & CT \\
\hline Phascolosoma albolineatum & 0 & & & & & & & & $\mathrm{x}$ & & & & & IW \\
\hline P. japonicum & $0-250$ & $\mathbf{x}$ & $\mathrm{x}$ & $\mathrm{x}$ & $\mathbf{x}$ & & $\mathrm{x}$ & $\mathrm{x}$ & $\mathrm{x}$ & $\mathbf{x}$ & $\mathrm{x}$ & $\mathrm{x}$ & & IP \\
\hline P. nigrescens & $0-65$ & & & & & & & $\mathrm{x}$ & $\mathrm{x}$ & & & & & $\mathrm{CT}$ \\
\hline P. pacificum & $0(?)$ & & & $\mathrm{X}$ ? & & & & & $\mathbf{x}$ & & & & & IW \\
\hline P. perlucens & $0(?)$ & & & & & & & & $\mathrm{x}$ & & & & & $\mathrm{CT}$ \\
\hline P. scolops & $0-18$ & $\mathrm{x}$ & $\mathbf{x}$ & $\mathbf{x}$ & $\mathbf{x}$ & $\mathbf{x}$ & & $\mathrm{x}$ & $\mathrm{x}$ & $\mathrm{x}$ & & & & WTW \\
\hline$P$. species & 0 & & & & & & & $\mathrm{x}$ & & & & & & \\
\hline Apionsoma misakiana & $0-160$ & & & & $\mathrm{x}$ & & & $\mathrm{x}$ & $\mathrm{x}$ & $\mathrm{x}$ & & & & $\mathrm{CT}$ \\
\hline A. trichocephala & $10-116$ & & & & $\mathrm{x}$ & & & $\mathrm{x}$ & $\mathrm{x}$ & & & $\mathrm{x}$ & & WTW \\
\hline Aspidosiphon (Aspidosiphon) elegans & 0 -shallow & & & & & & & $\mathrm{x}$ & $\mathrm{x}$ & $\mathbf{x}$ & & & & IW \\
\hline A. (A.) exhaustus & $3-450$ & & & $\mathrm{x}$ & $\mathrm{x}$ & & & $\mathrm{x}$ & & & & & & DW \\
\hline A. (A.) misakiensis & $0-50$ & & & & $\mathbf{x}$ & & & $\mathrm{x}$ & & $\mathrm{x}$ & & & & $\mathrm{E}$ \\
\hline A. (A.) muelleri & $12-250$ & & & & $\mathbf{x}$ & & & $\mathrm{x}$ & & & & & & DW \\
\hline A. (A.) cf. albus & 90 & & & & & & & $\mathbf{x}$ & & & & & & \\
\hline A. (Paraspidosiphon) angulatus & 0 & & & & & & & & $\mathrm{x}$ & & & & & IW \\
\hline A. $\left(P_{.}\right)$steenstrupii & 0 & & & & & & & $\mathrm{x}$ & $\mathrm{x}$ & & & & & IWA \\
\hline A. (P.) truncatus & 0 & & & & & & & $\mathrm{x}$ & $\mathrm{x}$ & & & & & IW \\
\hline A. (P.) cf. parvulus & 5 & & & & & & & $\mathrm{x}$ & & & & & & \\
\hline Cloeosiphon aspergillus & 0 & & & & & & & & $\mathrm{x}$ & & & & & IW \\
\hline Lithacrosiphon cristatus & 0 & & & & & & & $\mathrm{x}$ & $\mathrm{x}$ & & & & & WTW \\
\hline
\end{tabular}


Table 2. Sipunculans of Japan grouped by districts and biogeographical elements.

\begin{tabular}{|c|c|c|c|c|c|c|c|c|c|c|c|c|c|c|c|c|c|c|}
\hline \multirow{2}{*}{ Biogeographical elements* } & \multicolumn{17}{|c|}{ Districts } & \multirow{2}{*}{$\begin{array}{l}\text { Total in } \\
\text { Japan }\end{array}$} \\
\hline & 1 & 2 & 3 & 4 & 5 & 6 & 7 & 8 & 9 & 10 & 11 & 12 & 13 & 14 & 15 & 16 & 17 & \\
\hline IW & 0 & 0 & 2 & 0 & 0 & 0 & 0 & 6 & 9 & 1 & 0 & 0 & 0 & 1 & 0 & 0 & 0 & 10 \\
\hline IWA & 0 & 1 & 1 & 0 & 0 & 0 & 1 & 2 & 3 & 0 & 1 & 1 & 1 & 1 & 0 & 0 & 0 & 3 \\
\hline GT & 0 & 0 & 0 & 1 & 0 & 0 & 0 & 3 & 4 & 1 & 0 & 0 & 0 & 1 & 1 & 0 & 0 & 4 \\
\hline WTW & 1 & 2 & 1 & 2 & 0 & 1 & 1 & 4 & 4 & 1 & 0 & 0 & 1 & 2 & 0 & 0 & 0 & 4 \\
\hline Total of southern elements** & 1 & 3 & 4 & 3 & 0 & 1 & 2 & 15 & 20 & 3 & 1 & 1 & 2 & 5 & 1 & 0 & 0 & 21 \\
\hline$* * *$ & (25) & (33) & $(80)$ & (38) & $(0)$ & (33) & (25) & (54) & (91) & $(60)$ & (33) & (50) & (67) & $(71)$ & $(50)$ & $(0)$ & $(0)$ & $(55)$ \\
\hline $\mathrm{AP}$ & 2 & 3 & 0 & 0 & 0 & 2 & 3 & 2 & 0 & 0 & 1 & 1 & 0 & 1 & 1 & 0 & 0 & 3 \\
\hline IP & 1 & 1 & 1 & 1 & 0 & 0 & 1 & 1 & 1 & 1 & 0 & 0 & 1 & 1 & 0 & 0 & 0 & 1 \\
\hline $\mathrm{E}$ & 0 & 2 & 0 & 3 & 0 & 0 & 2 & 5 & 0 & 1 & 1 & 0 & 0 & 0 & 0 & 0 & 0 & 7 \\
\hline $\begin{array}{l}\text { Shallow water species of } \\
\text { uncertain identity }\end{array}$ & 0 & 0 & 0 & 1 & 0 & 0 & 0 & 5 & 1 & $\mathbf{0}$ & 0 & 0 & 0 & 0 & 0 & 0 & 0 & 6 \\
\hline DW & 0 & 2 & 1 & 10 & 1 & 0 & 2 & 15 & 0 & 0 & 0 & 0 & 0 & 1 & 0 & 1 & 2 & 17 \\
\hline $\mathrm{DE}$ & 0 & 1 & 1 & 3 & 0 & 0 & 0 & 1 & 0 & 0 & 0 & 0 & 0 & 0 & 0 & 0 & 0 & 3 \\
\hline $\begin{array}{l}\text { Deeper water species of } \\
\text { uncertain identity }\end{array}$ & 0 & 0 & 0 & 0 & 0 & 0 & 0 & 1 & 0 & 0 & 0 & 0 & 0 & 0 & 0 & 0 & 0 & 1 \\
\hline Total in all & 4 & 12 & 7 & 21 & 1 & 3 & 10 & 45 & 22 & 5 & 3 & 2 & 3 & 8 & 2 & 1 & 2 & 59 \\
\hline
\end{tabular}

* see text, p. 313.

** IW+IWA + CT + WTW.

*** percentage of shallow water forms belonging to southern elements. 
Japan Sea, they should be the same. For example, two species belonging to IW and one to IWA occurring in district 3 probably exists in district 4 also. There are undoubtedly fewer sipunculan species on the Japan Sea side of Honshu than the Pacific side and this is not just an artifact of differences in sampling efforts. This paucity of species is due largely to the absence of southern elements (Table 2) as noted by Nishimura (1970).

5) The shallow-water fauna of district 8 differs from that of district 9 in the percentage of southern elements $(54 \%$ in the former, $91 \%$ in the latter). Seven tropical-water species occur only in the latter. These same seven species absent from district 8 are also absent from district 10 (Ogasawara Islands). Further analysis of the fauna of the latter islands may better be put aside until a more intensive survey is made there.

6) The common species in the embayments and inland sea in Japanese waters are Sipunculus nudus, Siphonosoma cumanense, Thysanocardia nigra and Phascolosoma japonicum; the former two belong to the southern elements while the latter two to more or less cooler-water elements. It may be that these sheltered-water species settled in Japanese waters in different ways. Horikoshi (1962) characterized the fauna of the "isolated, more or less sheltered places" around Japan (Seto Inland Sea being a representative) as warm temperate, lacking subtropical species. Our data do not conform to this because we have a high percentage of tropical and subtropical species present (one-half of Inland Sea fauna). The biogeographical peculiarities of Tokyo and Ariake Bays were paid special attention to by Horikoshi (1962) and Miyadi, Kuroda and Habe (1953) respectively. The scarcity of our data in these bays preclude meaningful discussion.

7) Last are some comments about the deeper-water fauna. Golfingia margaritacea ikedai and Phascolion artificiosum, both endemic to Japanese waters seem to occur far deeper in the Japan Sea than in the Pacific. The former occurs from 96-307 $\mathrm{m}$ in the Japan Sea compared to intertidal to shallow water on the Pacific coasts; and the latter $210-535 \mathrm{~m}$, instead of $13 \mathrm{~m}$. This is reminiscent of one of the generalizations made about the deep-water (deeper than 200-300 $\mathrm{m}$ ) fauna of the Japan Sea, i.e., that the fauna may consist of originally sublittoral animals (Nishimura, 1966). The reverse may also be true as shown by the following two deep-water species: Sipunculus norvegicus was found at $20 \mathrm{~m}$ in Wakasa Bay, Japan Sea, while at 2020-2470 $\mathrm{m}$ in the Pacific (district 16). Outside of Japan this species has been recorded from depths of $50-1820 \mathrm{~m}$. Golfingia muricaudata was found at $85 \mathrm{~m}$ in the Tsushima Strait, Japan Sea, while at over $5000 \mathrm{~m}$ in the Japan Trench (district 17). Outside of Japan this species has been recorded from depths of 450$6860 \mathrm{~m}$.

These observations are of a provisional nature with little consideration given to global patterns. Individual patterns are given for each species. Care should be taken when drawing on these data as a few species are represented by few individuals, sometimes of doubtful identity. 


\section{Acknowledgements}

This work was made possible by a grant from the U.S. National Science Foundation (INT 7814554) to E.B.C. It could not have been accomplished without the cooperation of many Japanese biologists who are listed in Cutler and Cutler (1981). We are especially indebted to Drs. M. Imajima, Tokyo, M. Shigei, Misaki, and H. Tsujimura, Tokyo. We thank the South Australian Museum for permission to use selected figures from Edmonds (1980) and Mr. Jan Swartwout for his original drawings.

\section{REFERENCES}

Akesson, B. 1958. A study of the nervous system of the sipunculideae, with some remarks on the development of the two species Phascolion strombi Montagu and Golfingia minuta Keferstein. C.W.K. Gleerup, Lund, Sweden. 249 pp.

Cutler, E.B. 1965. Sipunculids of Madagascar. Cahiers ORSTOM-Océanographie 3 (4): 51-63.

1973. Sipuncula of the Western North Atlantic. Bull. Am. Mus. Nat. Hist. 152: 107-204. 1977. The bathyal and abyssal Sipuncula. Galathea Rep. 14: 135-156.

1979. A reconsideration of the sipunculan taxa Fisherana Stephen, Mitosiphon Fisher and Apionsoma Sluiter. Zool. Jour. Linn. Soc. 65 (4): 367-384.

1981. A new species of Aspidosiphon (Sipuncula) from the Western Atlantic Ocean. Biol. Soc. Wash. 94 (2): 445-449.

1984. Proposed conservation of Siphonosoma cumanense (Keferstein, 1867) over S. edule (Pallas, 1774) (Sipuncula). Bull. Zool. Nom. $41(1): 62-64$.

Cutler, E.B. and N.J. Cutler. 1979. Madagascar and Indian Ocean Sipuncula. Bull. Mus. Natn. d'Hist. Nta. Paris 4: 941-990.

1980. Sipuncula collected by the R/V Vema. Jour. Zool. 190: 193-209.

1981. A reconsideration of Sipuncula named by I. Ikeda and H. Sato. Publ. Seto Mar. Biol. Lab. 26 (1/3): 51-93. 762.

1982. Revision of the genus Siphonosoma (Sipuncula). Proc. Biol. Soc. Wash. 95 (4): 748-

1983. An examination of the Phascolosoma subgenera Antillesoma, Rueppellisoma and Satonus (Sipuncula). Zool. Jour. Linn. Soc. $77:$ 175-187.

Cutler, E.B., N.J. Cutler and T. Nishikawa. 1983. Siphonosoma cumanense and S. edule (Sipuncula): a reevaluation of their separate status. Publ. Seto Mar. Biol. Lab. 27 (4/6): 265-267.

Cutler, E.B. and P.E. Gibbs. (in press). A revision of the sipunculan higher taxa (a cladistic analysis). Zool. Scripta.

Cutler, E.B. and E. Jurczak. 1975. The sipunculan genus Lithacrosiphon Shipley. Zool. Jour. Linn. Soc. 56 : 235-248.

Cutler, E.B. and V.V. Murina. 1977. On the sipunculan genus Golfingia Lankester, 1855. Zool. Jour. Linn. Soc. 60: 173-187.

Edmonds, S.J. 1974. A new species of Sipuncula (Aspidosiphon exigutus n. sp.), belonging to the interstitial fauna of marine beaches collected by Mr. L. Botosaneanu during the second Cuban-Romanian Biospeleological Expedition to Cuba in 1973. Int. Jour. of Speleol. 6: 187-192.

1980. A revision of the systematics of Australian sipunculans (Sipuncula). Rec. S. Aust. Mus. 18 (1): 1-74.

Fischer, W. 1895. Die Gephyreen des Naturhistorischen Museums zu Hamburg. Abh. Geb. Naturw. Hamburg 13: 1-24.

- 1914. Weitere Mitteilungen uber die Gephyreen des Naturhistorischen (Zoologischen) Museums zu Hamburg. Jb. Hamb. Wiss. Anst. 31: 1-28.

Fisher, W.K. 1950. The sipunculid genus Phascolosoma. Ann. Mag. Nat. Hist. 12: 547-552. 
1952. The sipunculid worms of California and Baja California. Proc. U.S. Nat. Mus. 102: $371-450$.

Gerould, J.H. 1907. The development of Phascolosoma. Zool. Jahrb., Abth. Anat. 23 (1): 77-162.

1913. The sipunculids of the eastern coast of North America. Proc. U.S. Nat. Mus. $44: 373-437$.

Gibbs, P.E. 1975. Gametogenesis and spawning in a hermaphroditic population of Golfingia minuta (Sipuncula). J. Mar. Biol. Ass. U.K. 55: 69-82.

1977. British sipunculans. Synopses of the British Fauna (new speries). No. 12, 35 pp. Linnean Soc., London.

Gibbs, P.E., E.B. Culter and N.J. Cutler. 1983. A review of the genus Thysanocardia Fisher (Sipuncula). Zool. Scripta. 12 (4) : 295-304.

Hammerstein, O. 1915. Gephyreen von Madagascar gesammelt von W. Kaudern 1911-1912. Ark. Zool. 9: 1-3.

Herubel, M.A. 1907. Recherches sur les sipunculides. Mem. Soc. Zool. France 20: 107-418.

Horikoshi, M. 1962. Warm temperate region and coastal-water area in the marine biogeography of the shallow water system around the Japanese islands. Quaternary Res. 2 (2-3): 117-124. (In Japanese)

Ikeda, I. 1904. The Gephyrea of Japan. Jour. Coll. Sci., Imp. Univ. Tokyo 20 (4): 1-87. 1924. Further notes on the Gephyrea of Japan, with descriptions of some new species from the Marshall, Caroline, and Palau Islands. Jap. Jour. Zool. 1: 23-44.

Leroy, P. 1936. Les sipunculiens du Museum d'Historie Naturelle de Paris. Bull. Mus. Natn. d'Hist. Nat. Paris, Series 2, 8: 423-426.

Miyadi, D., T. Kuroda and T. Habe. 1953. On the biogeographical provinces in the Japanese and adjacent waters. Seibutsu Kagaku 5 (4): 145-148. (In Japanese)

Murina, V.V. 1957. Abyssal sipunculids (genus Phascolion Theel) of the north-western part of the Pacific collected by Vitjaz expeditions in 1950-1955. Zool. Zhur. 36 (12): 1777-1791.

1964. Report on the sipunculid worms from the coast of South Chinese Sea. Trudy Inst. Ocean. $69: 254-270$.

1967. On the sipunculid fauna of the littoral of Cuba. Zool. Zhur. 46: 35-47.

- 1968. On the distribution of new sipunculid fauna from Cuba and Gulf of Mexico. Revue Roumaine de Biol.-Zool. 13 (6): 421-423.

1972. Contribution of the sipunculdi fauna of the Southern Hemisphere. Zool. Inst. Akad. Nauk USSR 11 (19): 294-314.

1974. New species of the sipunculid genus Phascolion. Zool. Zhur. 53: 282-285. $62-67$.

1976. New and rare species of sipunculids from the East China Sea. Vestnik Zool. 2:

1977. Sipunculans of the Arctic and boreal parts of the Eurasian seas. Zool. Inst., Acad. Sci. USSR, 283 pp.

Nishimura, S. 1965. The zoogeographical aspects of the Japan Sea. Pt. 1. Publ. Seto Mar. Biol. Lab. 13(1): 35-79.

1966. Fauna of the Japan Sea, with reference to its history. In Geologiacl problems of the Japan Sea area: 135-143. (In Japanese)

1970. A view concerning the coastal biota in the Japan Sea. Nankiscibutsu 12 (2): 34 38. (In-Japanese)

1981. Seas and life on the earth: an introduction to marine biogeography. Kaimei-sha, Tokyo. 284 pp. (In Japanese)

Nomura, S. and K. Hatai. 1936. A note on the zoological provinces in the Japanese seas. Bull. Biogeogr. Soc. Japan 6 (21): 207-214.

Okuda, S. 1946. The fauna of Akkeshi Bay XV. Gephyrea. J. Fac. Sci. Hokkaido Univ. ser. zool. $6,9: 221-224$.

Okutani, T. and K. Chinzei. 1976. Seas around Japan and their biota. Kagaku 46 (4): 248-258. (In Japanese)

Ostroumoff, A.A. 1909. Sur les géphyriens du nord de la Mer du Japon. Ezheg. Zool. Muz. 14 : 319-321. 
Sato, H. 1930. Report on the biological survey of Mutsu Bay. 15. Sipunculoidea. Sci. Rep. Tohoku Univ., ser. 4, 5: 1-40.

1934a. Report on the Sipunculoidea, Echiuroidea, and Priapuloidea collected by the SoyoMaru Expedition of 1922-1930. Sci. Rep. Tohoku Univ., Ser. 4, 9: 1-32.

- 1934b. Sipunculiodea and Echuiroidea obtained in Onomichi Bay. Zool. Mag. Tokyo 46: 245-252. (In Japanese)

1935. Sipunculoidea and Echiuroidea of the West Caroline Islands. Sci. Rep. Tohoku Univ., ser. 4, 10: 299-329.

1937a. Echiuroidea, Sipunculoidea, and Priapuloidea obtained in northeast Honshu, Japan. Res. Bull., Saito Ho-on Kai Mus. No. 12: 137-176.

- 1937b. Note on a new sipunculid, Physcosoma kurilense n. sp. found in Shumshir Island. Annotationes Zool. Jap. 16: 117-120.

1939. Studies on the Echiuroidea, Sipunculoidea, and Priapuloidea of Japan. Sci. Rep. Tohoku Univ., ser. 4, 14: 339-459.

Selenka, E., J.G. DeMan, and G. Bulow. 1883. Die Sipunculiden, eine systematische Monographie. Reisen im Archipel Philippinen von Dr. C. Semper, II 4 (1): 1-131.

Sluiter, C.P. 1902. Die Sipunculiden und Echiuriden der "Siboga" Expedition. Rep. Siboga Exped. Monographie 25: 1-53.

Southern, R. 1913. Gephyrea of the coasts of Ireland. Scientific Investigations of the Fisheries branch, Dept. of Agriculture for Ireland 3: 1-46.

Stephen, A.C. 1964. A revision of the classification of the phylum Sipuncula. Ann. Mag. Nat. Hist. 7 (13): 457-462.

—— and S.J. Edmonds. 1972. The Phyla Sipuncula and Echiura. Trustees British Museum (Nat. Hist.) 528 pp.

Utinomi, H. 1955. Studies on the cirripedia of Japan, II. Geographical distribution. Bull. Biogeogr. Soc. Japan 16-19; 113-123. (In Japanese)

Wesenberg-Lund, E. 1963. South African Sipunculids and Echiuroids from coastal waters. Vidensk. Medd. dansk. nat. Foren Kbh. 152: 101-146.

\section{EXPLANATION OF PLATE I}

Fig. 1. Oesophagus of Siphonosoma cumanense showing contractile vessel villi (v).

Fig. 2. Posterior end of Golfingia signa.

Fig. 3. Posterior end of Golfingia appendiculata (A) and G. muricaudata (B).

Fig. 4. Introvert of Phascolion indicus showing displaced anus (a). 
Publ. Seto Mar. Biol. Lab., XXI (4/6), 1984.
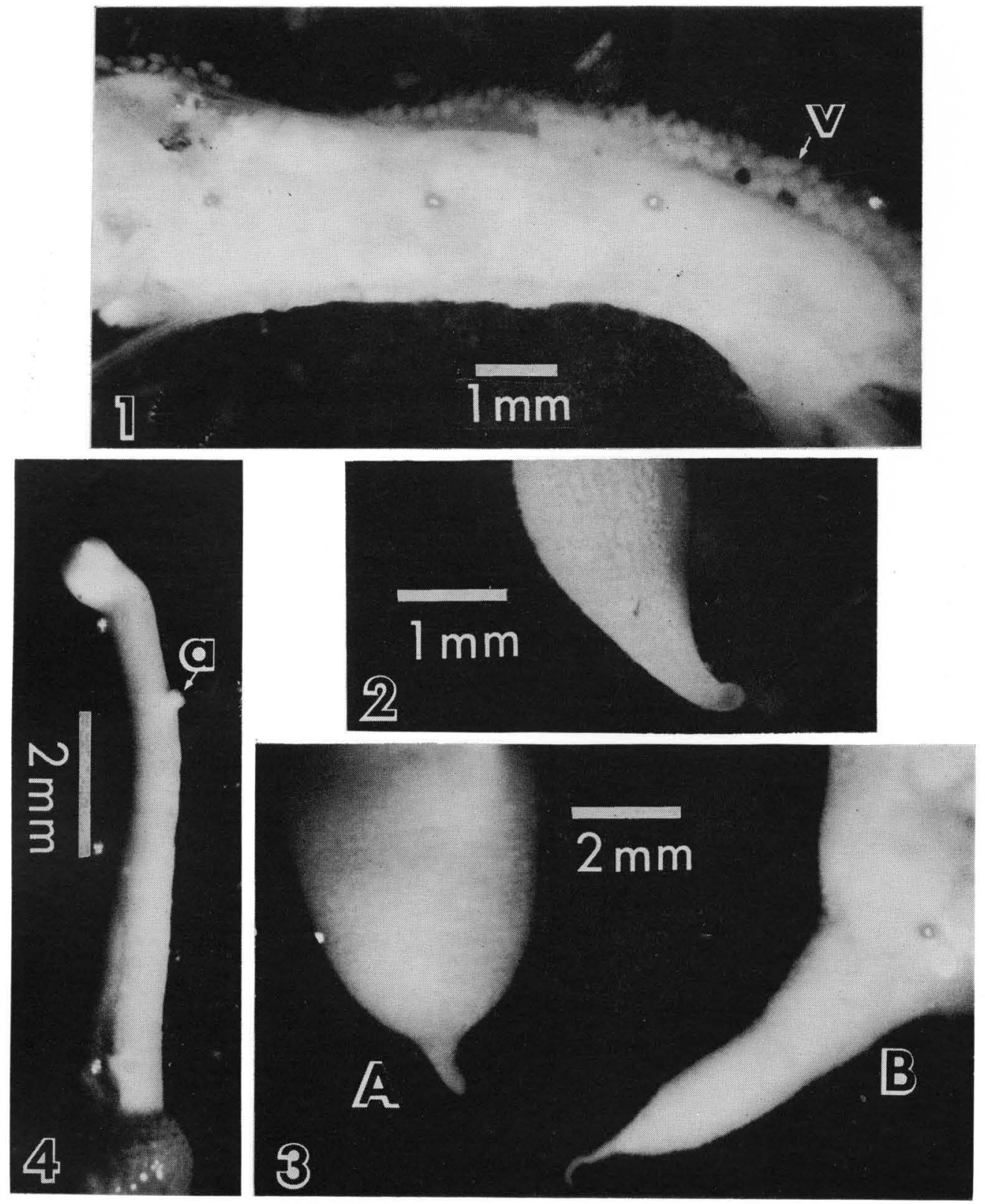

E.B. Gutler, N.J. Cutler \& T. Nishikawa: Sipuncula of Japan 


\section{EXPLANATION OF PLATE II}

Fig. 1. Internal view of Thysanocardia nigra showing contractile vessel villi (v), retractor muscles ( $r$ ), and intestinal coil (i).

Fig. 2. Introvert of Phascolosoma showing rings of hooks (h) and nuchal tentacles (t).

Fig. 3. Anal shield of Aspidosiphon cf. albus.

Fig. 4. Aspidosiphon elegans showing anal shield (sh) and basal introvert spines (s). On right is distal end of introvert with rows of hooks (h), dorsal nuchal tentacles ( $t$ ) and everted oesophagus (o) protruding through mouth.

Fig. 5. Anal shield (cap) of Cloeosiphon aspergillus. 
Publ. Seto Mar. Biol. Lab., XXI (4/6), 1984.

PLATE II

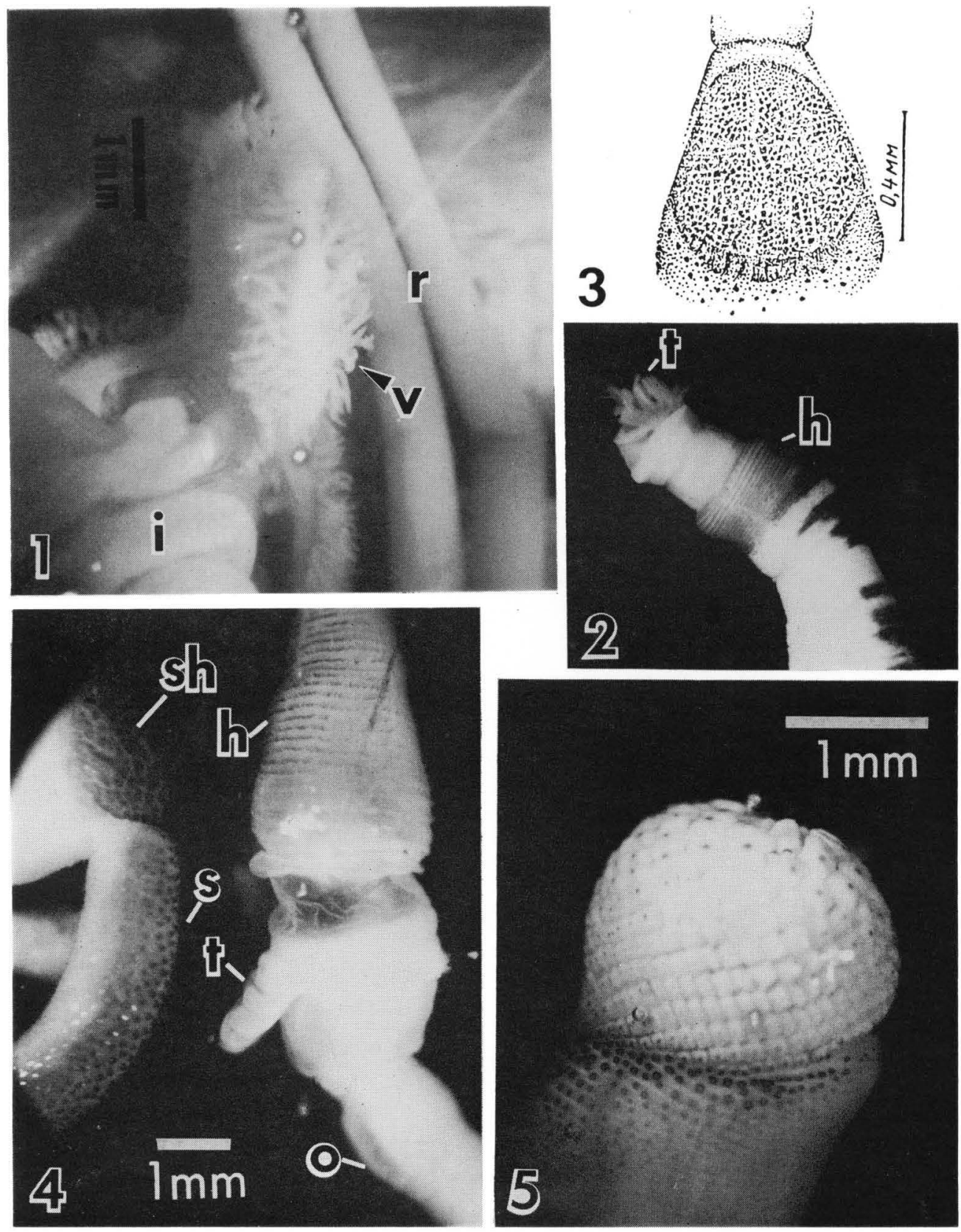

E.B. Cutler, N.J. Cutler \& T. Nishikawa: Sipuncula of Japan 